\title{
Um estudo sobre Teoria dos Grafos e o Teorema das Quatro Cores
}

\author{
Carlos Laércio Gomes de Lima
}



Data de Depósito:

Assinatura:

\title{
Carlos Laércio Gomes de Lima
}

\section{Um estudo sobre Teoria dos Grafos e o Teorema das Quatro Cores}

\author{
Dissertação apresentada ao Instituto de Ciências Ma- \\ temáticas e de Computação - ICMC-USP, como parte \\ dos requisitos para obtenção do título de Mestre em \\ Ciências - Programa de Mestrado Profissional em Ma- \\ temática. VERSÃO REVISADA. \\ Área de Concentração: Matemática \\ Orientadora: Profa. Dra. Marina Andretta
}

\section{USP - São Carlos}

Maio de 2016 
Ficha catalográfica elaborada pela Biblioteca Prof. Achille Bassi e Seção Técnica de Informática, ICMC/USP, com os dados fornecidos pelo(a) autor(a)

Lima, Carlos Laércio Gomes
L732e Um estudo sobre Teoria dos Grafos e o Teorema das Quatro Cores / Carlos Laércio Gomes Lima; orientador Marina Andretta. -- São Carlos, 2016. $106 \mathrm{p}$.

Dissertação (Mestrado - Programa de Pós-Graduação em Mestrado Profissional em Matemática em Rede Nacional) -- Instituto de Ciências Matemáticas e de Computação, Universidade de São Paulo, 2016.

1. Teorema das Quatro Cores. 2. Teorema das Cinco Cores. 3. Teoria dos Grafos. I. Andretta, Marina, orient. II. Título. 


\section{Carlos Laércio Gomes de Lima}

\section{A study on Graph Theory and the Four Color Theorem}

Master dissertation submitted to the Instituto de Ciências Matemáticas e de Computação - ICMC-USP, in partial fulfillment of the requirements for the degree of Mathematics Professional Master's Program. FINAL VERSION.

Concentration Area: Mathematics

Advisor: Profa. Dra. Marina Andretta

\section{USP - São Carlos}

May 2016 

Este trabalho é dedicado a todo aquele que voluntariamente ensina e ajuda o próximo, sem esperar nenhuma recompensa em troca, a não ser o simples prazer de vê-lo vencer. 



\section{Agradecimentos}

Agradeço primeiramente a Deus, criador dos céus e da terra, Senhor de todo o saber, que me deu todas as condições necessárias para o desenvolvimento deste trabalho, além de muitas outras bençãos, pois tudo o que é bom, vem de suas mãos.

À minha família, em especial à minha mãe Maria do Carmo e meu irmão Marcos Laerte por todo o apoio e incentivo, e pelos diversos sacrifícios feitos para que eu tivesse mais tempo hábil para me dedicar a este trabalho.

Um agradecimento especial à minha atenciosa e paciente orientadora Dra. Marina Andretta pelo privilégio de sua formidável orientação, que tornou possível a conclusão deste trabalho. Serei sempre grato por ter me orientado mesmo em condições adversas, se fazendo sempre presente, mesmo estando distante.

Agradeço também os professores do ICMC-USP, especialmente aos professores Hermano de Souza Ribeiro, Luiz Augusto da Costa Ladeira, Miguel Vinícius Santili Frasson e sua orientanda Iris Falqueto Oliveira por todo o empenho que tiveram em nos ensinar através de excelentes aulas, por todos os conselhos, pela paciência e compreensão demonstradas, e por toda a motivação transmitida.

Aos meus colegas de classe, que sempre foram muito unidos e solidários, procurando sempre ajudar uns aos outros em todos os aspectos.

Por fim, agradeço à Coordenação de Aperfeiçoamento de Pessoal de Nível Superior (CAPES) pela concessão da bolsa de estudos. 

"Confia no Senhor de todo o teu coração e não te estribes no teu próprio entendimento".

(Provérbios 3:5) 



\section{Resumo}

LIMA, C. L. G.. Um estudo sobre Teoria dos Grafos e o Teorema das Quatro Cores. 2016. 106 f. Dissertação (Mestrado - Programa de Mestrado Profissional em Matemática.) - Instituto de Ciências Matemáticas e de Computação (ICMC/USP), São Carlos - SP.

Neste trabalho estudamos um pouco de Teoria dos Grafos, abordando diversas definições e teoremas interessantes. Apresentamos o Teorema das Quatro Cores, desde o surgimento do problema com Francis Guthrie. Analisamos a demonstração do teorema realizada por Alfred Bray Kempe e sua refutação através do contraexemplo de Percy John Heawood. Analisamos também a demonstração do Teorema das Cinco Cores de Percy John Heawood. Por fim, apresentamos a primeira demonstração válida do Teorema das Quatro Cores, como sua particularidade de ter sido feita com o auxílio de um computador. O trabalho é concluído com uma análise sobre os benefícios que o conhecimento de Teoria dos Grafos pode render aos alunos do Ensino Básico, e como professor o pode trabalhar este assunto em sala de aula, inclusive abordando o problema de coloração de mapas.

Palavras-chave: Teorema das Quatro Cores, Teorema das Cinco Cores, Teoria dos Grafos. 



\section{Abstract}

LIMA, C. L. G.. A study on Graph Theory and the Four Color Theorem. 2016. 106 f. Dissertation (Master - Professional Masters Program in Mathematics.) - Instituto de Ciências Matemáticas e de Computação (ICMC/USP), São Carlos - SP.

In this paper we study Graph Theory, addressing various definitions and interesting theorems. We present the Four Color Theorem, since the origin of the problem with Francis Guthrie. We analyze the proof of the theorem presented by Alfred Bray Kempe, and its refutation by Percy John Heawood counter-example. We also analyze the Percy John Heawood demonstration of the Five Color Theorem. Finally, we present the first valid proof of the Four Colors Theorem, with its peculiarity of having been done with the aid of a computer. We conclude with an analysis of the beneficial that the knowledge of Graph Theory can render students of Basic Education, and how a teacher can work this topic in the classroom, including addressing the problem of map coloring.

Key-words: Four Colors Theorem, Five Colors Theorem, Graph Theory. 



\section{Sumário}

\begin{tabular}{llr}
\hline 1 & Introdução & 19
\end{tabular}

\begin{tabular}{|lll}
2 & Um pouco de Teoria dos Grafos & 21
\end{tabular}

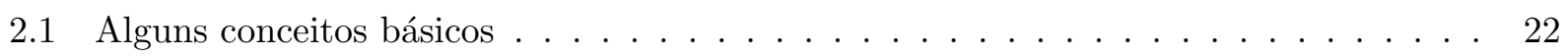

2.2 Conjuntos estáveis e cliques $\ldots \ldots \ldots \ldots \ldots \ldots$

2.3 Coloração de vértices $\ldots \ldots \ldots \ldots \ldots \ldots \ldots$

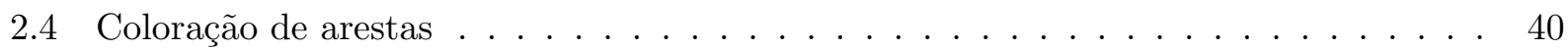

\begin{tabular}{|lll}
\hline 3 & O Problema das Quatro Cores & 43 \\
\hline
\end{tabular}

3.1 Um pouco de história $\ldots \ldots \ldots \ldots \ldots$. . . . . . . . . . . . . . . 43

3.2 A demonstração de Kempe $\ldots \ldots \ldots \ldots$. . . . . . . . . . . . . . . 46

$3.3 \quad$ Análise da demonstração de Kempe . . . . . . . . . . . . . . . . . . . . . . . . . 48

$3.4 \quad \mathrm{O}$ contraexemplo de Percy John Heawood $\ldots \ldots \ldots$. . . . . . . . . . . . . 68

3.5 Avanços nos estudos do Problema das Quatro Cores . . . . . . . . . . . . . . 77

3.6 A resolução do Problema das Quatro Cores $\ldots \ldots \ldots$. . . . . . . . . . . . . . 85

\begin{tabular}{|lrr}
\hline 4 & Aplicações em sala de aula & 89
\end{tabular}

4.1 A Teoria dos Grafos no Ensino Básico . . . . . . . . . . . . . . . . . . . . . . . 89

4.2 Apresentando a Teoria dos Grafos $\ldots \ldots \ldots$. . . . . . . . . . . . . . 90

4.3 Resolvendo problemas do cotidiano com o auxílio dos Grafos $\ldots \ldots$. . . . . . . . 90

4.4 Grafos e formas de demonstração $\ldots \ldots$. . . . . . . . . . . . . . . . . . . 102

\begin{tabular}{|lr}
5 Considerações finais & 103
\end{tabular} 



\section{Capítulo 1}

\section{Introdução}

No século XVIII surgiu um novo ramo da matemática, conhecido hoje como Teoria dos Grafos. Desde o seu surgimento, a Teoria dos Grafos tem sido muito útil na resolução de problemas do cotidiano, como no Problema das Pontes de Königsberg e no Problema das Quatro Cores. Uma das maiores vantagens de se trabalhar com grafos é por eles serem facilmente representados graficamente, o que facilita a análise de problemas, tornando-os mais acessíveis às pessoas com menor grau de conhecimento científico, como, por exemplo, aos alunos que ainda cursam a Educação Básica.

O Problema das Quatro Cores é um dos mais conhecidos problemas já estudados e solucionados com o auxílio da Teoria dos Grafos. A história de sua origem e das várias tentativas de solucioná-lo é muito interessante. Entre os seus pontos mais interessantes, temos a demonstração desenvolvida por Alfred Bray Kempe, que foi bem aceita pela comunidade matemática, mas que, incrivelmente, continha uma falha, encontrada somente onze anos depois por Percy John Heawood. A descoberta só não foi tão trágica por Heawood ter salvo parte da demonstração de Kempe e demonstrado o Teorema das Cinco Cores.

Tendo em vista a atual necessidade que o sistema educacional traz de encontrar maneiras de envolver os alunos com a matemática, de forma que essa lhes faça sentido, ou seja, de modo que eles vejam uma real aplicação do conhecimento adquirido, este trabalho apresenta um estudo sobre Teoria dos Grafos e o Teorema das Quatro Cores, funcionando como apoio aos professores para o uso da Teoria dos Grafos como forma de representar e resolver problemas do cotidiano.

Após iniciarmos o trabalho, no Capítulo 2, com um estudo sobre Teoria dos Grafos, apresentamos, no Capítulo 3, o estudo do Problema das Quatro Cores como exemplo principal de modelagem e resolução de problemas do cotidiano através de grafos. Este estudo rendeu, por meio de Percy 
John Heawood, o primeiro fruto: o Teorema das Cinco Cores. Além da promissora estratégia usada por Alfred Bray Kempe em sua demonstração sutilmente falha do Teorema das Quatro Cores.

Após analisarmos a demonstração de Alfred Bray Kempe e o contraexemplo apresentando por Percy John Heawood, apresentamos a demonstração do Teorema das Cinco Cores que Heawood "garimpou" da demonstração falha de Kempe. A demonstração do Teorema das Cinco Cores de Heawood envolveu prova por indução finita e por contradição.

Ainda no Capítulo 3, apresentamos algumas estratégias que foram usadas para tentar solucionar o Problema das Quatro Cores, como a coloração de arestas de grafos, e o Jogo Icosiano, que envolve os chamados circuitos hamiltonianos. Chegamos também a comentar a complexidade da primeira demonstração válida do Teorema das Quatro Cores, e o inovador uso de computadores em sua demonstração, possibilitando, assim, uma reflexão e discussão sobre o uso e importância dos computadores na matemática, e as mudanças na forma de se ver e estudar matemática que esse processo inovador nos traz.

Finalizamos este trabalho, no Capítulo 4, fazendo algumas aplicações (sugeridas para a sala de aula) da Teoria dos Grafos na modelagem e resolução de problemas do cotidiano, como forma de motivar os educadores a optarem por trabalhar este rico conteúdo com seus alunos.

Esperamos que o presente trabalho seja útil para professores, alunos de licenciatura, alunos do Ensino Básico, e demais leitores, como fonte de conhecimento sobre Teoria dos Grafos e o Teorema das Quatro Cores, além de incentivo à utilização dos grafos como ferramenta para a resolução de problemas. 


\section{Capítulo 2}

\section{Um pouco de Teoria dos Grafos}

A Teoria dos Grafos é uma das áreas da matemática de origem contemporânea. Sua origem se deu com a ilustração que Leonhard Euler (1707-1783) usou para representar e estudar o Problema das Pontes de Königsberg] e o seu desenvolvimento e consolidação se deve, dentre outro motivos, ao estudo que diversos matemáticos fizeram sobre o Problema das Quatro Cores.

O problema conhecido como Problema das Pontes de Königsberg foi criado pelos moradores da cidade. Parte da cidade de Königsberg consistia em duas ilhas cercadas pelas águas do rio Pregel. Para permitir chegar até elas havia sete pontes conforme ilustrado na Figura 2.1.

Figura 2.1: Pontes de Königsberg
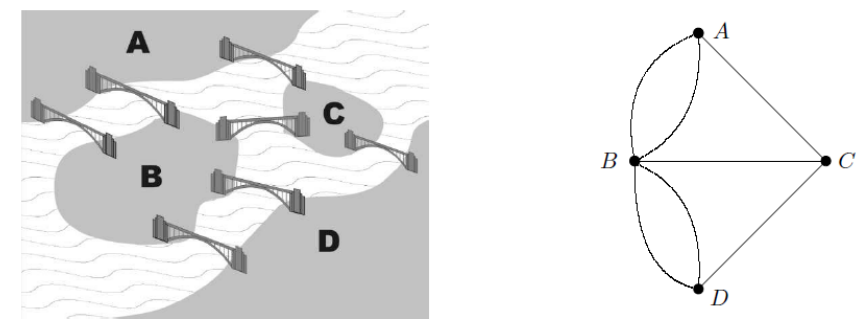

Fonte: (CARDOSO, 2005)

Os moradores de Königsberg queriam encontrar um trajeto em que eles passassem por todas as pontes uma única vez, terminando no ponto de partida. Para resolver o problema, Leonhard Euler representou o mesmo através de uma figura que hoje chamamos de grafo, conforme ilustrado na Figura 2.1.

Leonhard Euler chegou até o grafo mostrado na Figura 2.1 ao eliminar os detalhes do mapa de

\footnotetext{
${ }^{1}$ Pequena cidade hoje chamada de Kaliningrado, localizada no norte da Europa.
} 
Königsberg que eram irrelevantes para encontrar a solução do problema, como as dimensões das pontes e as dimensões das ilhas. O grafo encontrado por Euler tinha quatro vértices (representados pelos pontos), dois deles representando, cada qual, uma das duas margens do rio Pregel, e os outros dois, representando, cada qual, uma das ilhas. O grafo tinha também sete arestas (representadas pelas linhas), que representavam as pontes interligando as regiões da cidade.

Analisando o problema através da ilustração por grafo, Leonhard Euler concluiu que era impossível encontrar uma solução para o Problema das Pontes de Königsberg, visto que, para atravessar cada vértice $v$ seriam necessárias duas arestas incidindo (com ponta) em $v$, uma para entrar e outra para sair dele, ou seja, para que cada aresta (ponte) fosse percorrida uma única vez, cada vértice deveria possuir um número par de arestas incidindo sobre ele, o que não acontece, como podemos ver com o vértice $C$ da Figura 2.1. Logo, sabemos que é impossível encontrar uma solução para este problema.

Desta forma, se deu o princípio do que chamamos hoje de Teoria dos Grafos, tendo início com Leonhard Euler, como citamos acima, e evoluindo ao ser usado como ferramenta no estudo do Problema das Quatro Cores sobre o qual falaremos no Capítulo 3.

\subsection{Alguns conceitos básicos}

Apresentaremos agora algumas definições sobre grafos, alguns de seus tipos e propriedades, e alguns exemplos e ilustrações.

\subsubsection{O que são grafos?}

Um grafo é um par $(V, A)$, em que $V$ é um conjunto qualquer, e $A$ é um subconjunto de $V^{(2)}$, ou seja, dos pares não ordenados de elementos distintos de $V$. Chamamos os elementos do conjunto $V$, de vértices, e os elementos do conjunto $A$, de arestas.

Sendo $v$ e $w$ dois vértices distintos de um grafo, representaremos a aresta formada por esse par de vértices como $\{v, w\}$ ou $v w$, ou ainda por $w v$.

Sendo $v w$ uma aresta, diremos que esta aresta incide em $v$ e $w$, ou que $v$ e $w$ são pontas desta aresta. Além disso, diremos que os vértices $v$ e $w$ são vizinhos ou adjacentes. 


\subsubsection{Algumas notações}

Dado um grafo qualquer $G$, representamos o conjunto de vértices deste grafo por $V(G)$ e o conjunto de arestas por $A(G)$. Representamos o número de vértices de um grafo qualquer $G$ por $n(G)$ e o número de arestas por $m(G)$, ou seja, $n(G)=|V(G)|$ e $m(G)=|A(G)|$.

Sendo $G$ um grafo correspondente ao par $(V, A)$, chamamos de complemento de $G$ e representamos por $\bar{G}$ o conjunto $\left(V, V^{(2)} \backslash A\right)$.

Chamamos um grafo $G$ de completo quando $A(G)=V(G)^{(2)}$, e chamamos de vazio quando $A(G)=\emptyset$. Um exemplo é apresentando na Figura 2.2 .

Figura 2.2: Exemplo de grafo completo e de grafo vazio

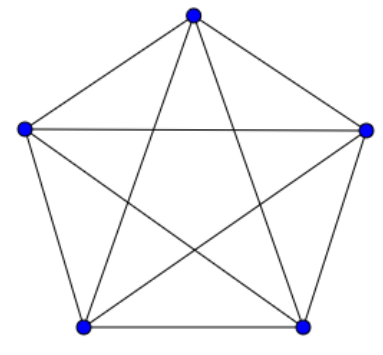

Grafo completo
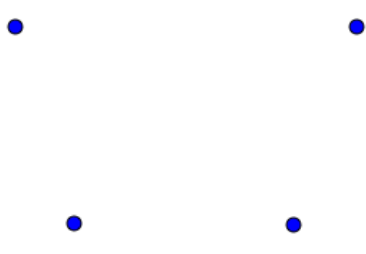

Grafo vazio

Chamamos de $K_{n}$ os grafos completos que possuem $n$ vértices. Semelhantemente, chamamos de $\overline{K_{n}}$ os grafos vazios com $n$ vértices.

\subsubsection{Alguns tipos de grafos}

Vejamos agora alguns tipos especiais de grafos.

\section{Grafo planar}

Um grafo $G$ é chamado de planar se é possível desenhá-lo em um plano, sem que suas arestas se cruzem, ou seja, sem que haja intersecão entre suas arestas. 
Podemos ver na Figura 2.3 um exemplo de grafo planar e de grafo não-planar.

Figura 2.3: Exemplo de grafo planar e de grafo não-planar

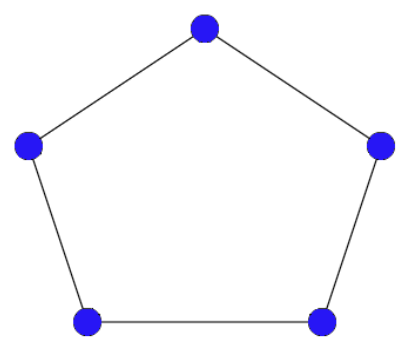

Grafo Planar

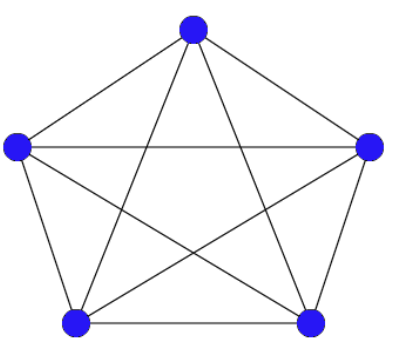

Grafo não-planar

Se $G$ é um grafo planar, então uma representação gráfica de $G$ no plano divide o mesmo em regiões chamadas faces. Cada face de um grafo é caracterizada pelas arestas que a contornam, ou pela região infinita do plano que não é contornada por arestas. A Figura 2.4 destaca as faces de alguns grafos.

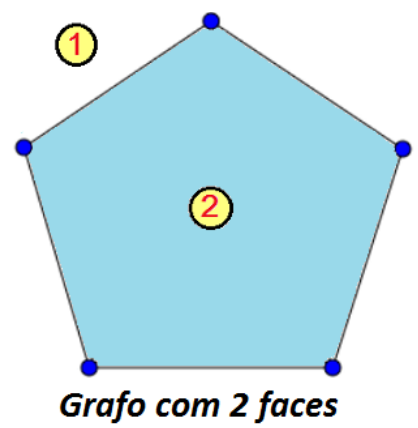

Grafo com 2 faces

Figura 2.4: Faces de alguns grafos

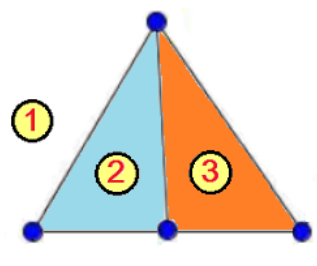

Grafo com 3 faces

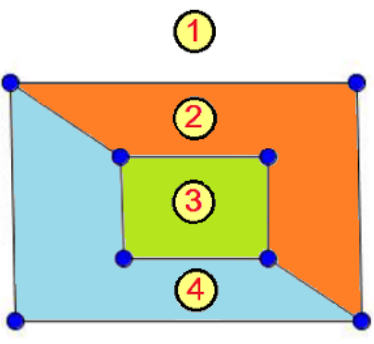

Grafo com 4 faces

\section{Grafo das arestas}

Dizemos que duas arestas de um grafo $G$ são adjacentes ou vizinhas, quando elas possuem uma ponta em comum. Desta definição resulta o que chamamos de grafo das arestas de $G$.

Seja $G^{\prime}$ o grafo das arestas de $G$. Temos que o conjunto de vértices $V\left(G^{\prime}\right)$ é $A(G)$, e o conjunto de arestas $A\left(G^{\prime}\right)$ é formado pelos pares de arestas adjacentes de $G$. 
As Figuras 2.5 e 2.6 são dois exemplos de grafo das arestas.

Figura 2.5: Grafo das arestas do $K_{3}$
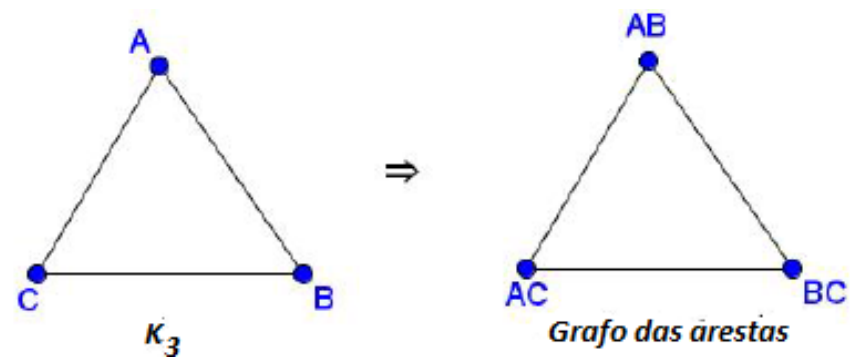

Figura 2.6: Grafo das arestas do $K_{4}$
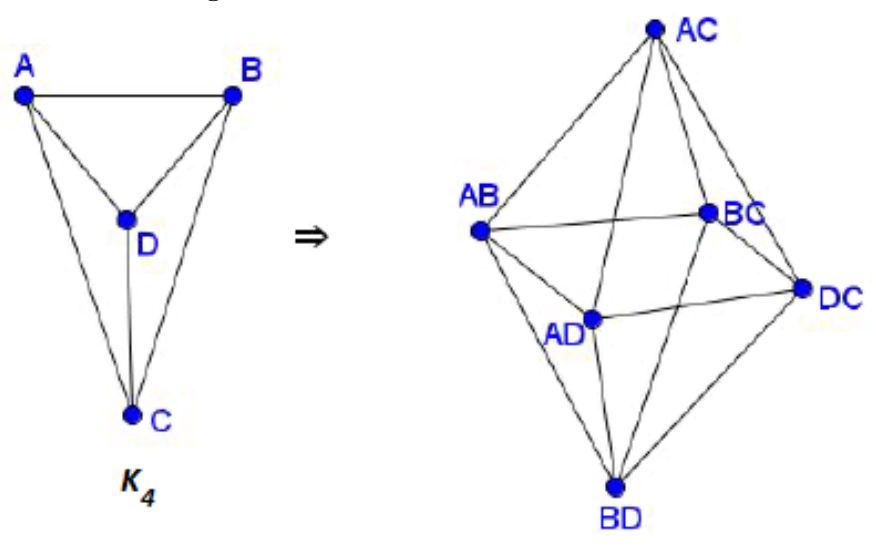

Grafo das arestas

\subsubsection{Isomorfismo}

Existe isomorfismo entre dois grafos $G$ e $H$ caso haja uma função bijetora $f(V(G)) \rightarrow V(H)$ de forma que dois vértices $v$ e $w$ são adjacentes em $G$ se e somente se $f(v)$ e $f(w)$ são adjacentes em $H$. Dados dois grafos $G$ e $H$, dizemos que eles são isomorfos caso exista um isormofismo entre eles.

Quando existe um isomorfismo entre dois grafos, é possível alterar os nomes dos vértices de um deles de forma que os dois grafos se tornem exatamente iguais. 
A Figura 2.7 apresenta exemplos de grafos que, embora estejam desenhados de forma diferentes, são isomorfos.

Figura 2.7: Exemplo de grafos isomorfos
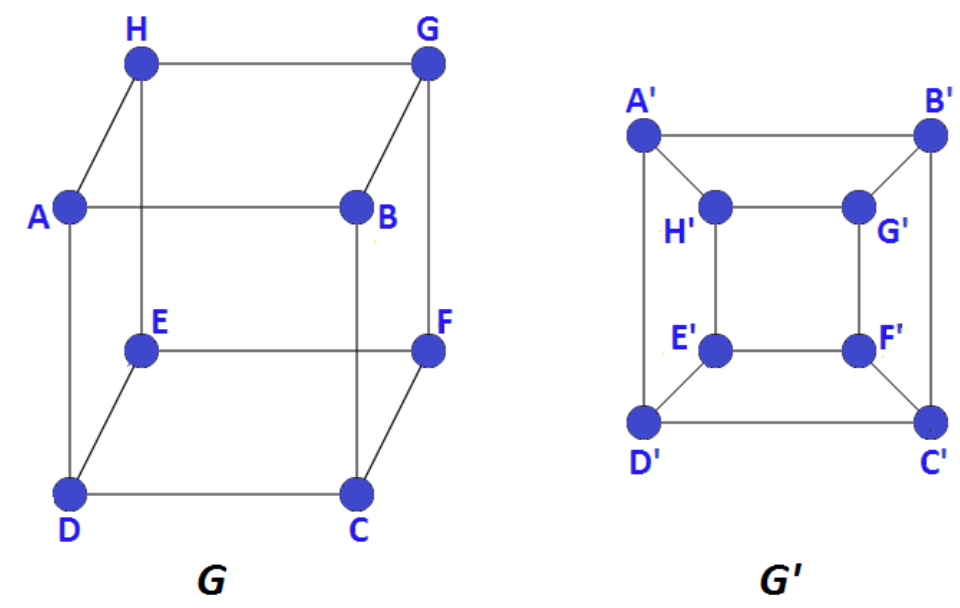

$\boldsymbol{G}^{\prime}$

No exemplo da Figura 2.7 temos que $V(G)=\{A, B, C, D, E, F, G, H\}$ e $V\left(G^{\prime}\right)=\left\{A^{\prime}, B^{\prime}, C^{\prime}, D^{\prime}, E^{\prime}, F^{\prime}, G^{\prime}, H^{\prime}\right\}$. Nossa função bijetora de $f(V(G)) \rightarrow V\left(G^{\prime}\right)$ é:

$f(A) \rightarrow A^{\prime}$

$f(B) \rightarrow B^{\prime}$

$f(C) \rightarrow C^{\prime}$

$f(D) \rightarrow D^{\prime}$

$f(E) \rightarrow A^{\prime}$

$f(F) \rightarrow F^{\prime}$

$f(G) \rightarrow G^{\prime}$

$f(H) \rightarrow H^{\prime}$.

\subsubsection{Vizinhança}

Sendo $X$ um conjunto de vértices de um grafo $G$, chamamos de vizinhança de $X$ o conjunto de todos os vértices pertencentes a $V(G) \backslash X$ que são vizinhos de algum vértice de $X$, e representamos este conjunto por $\Gamma(X)$.

Definimos também a vizinhança de um único vértice $v$ pertencente a $V(G)$ como sendo o conjunto de todos os vértices pertencentes a $V(G) \backslash\{v\}$ que são vizinhos de $v$, e representamos este conjunto por $\Gamma(v)$. 
Vejamos um exemplo ilustrado na Figura 2.8.

Figura 2.8: Vizinhança

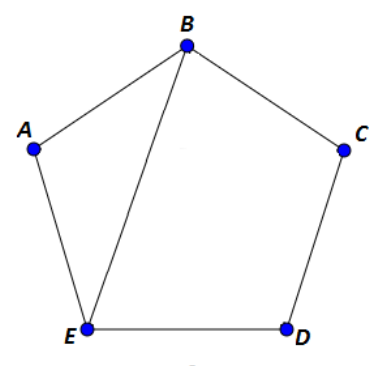

Grafo $G$

Tomemos o conjunto $X=\{A, B\}$ de vértices pertencentes ao grafo $G$ (representado na Figura 2.8, temos que a vizinhaça de $X$ é $\Gamma(X)=\{C, E\}$. Já a vizinhança do vértice $E$ é $\Gamma(E)=\{A, B, D\}$.

\subsubsection{Corte}

Sendo $G$ um grafo qualquer, e $X$ um conjunto de vértices pertencentes a $V(G)$, chamamos o conjunto das arestas que têm uma de suas pontas pertecentes ao conjunto $X$ e a outra pertencente ao conjunto $V(G) \backslash X$ de corte associado ao conjunto $X$. Representamos este tipo de conjunto por $\nabla_{G}(X)$.

Podemos também ter um corte associado a um único vértice $v$ pertecente a um grafo $G$, que é o conjunto de arestas de $G$ que incidem no vértice $v$ e em outro vértice pertencente ao conjunto $V(G) \backslash\{v\}$. Representamos este tipo de conjunto por $\nabla_{G}(v)$.

Tomemos como exemplo o grafo ilustrado na Figura 2.9.

Figura 2.9: Corte

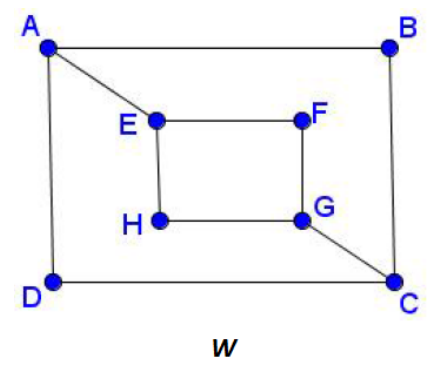

Tomando o conjunto $X=\{A, B, C, D\}$ de vértices pertencentes ao grafo $W$ (representado na Figura 2.9), temos que o corte em $W$ associado ao conjunto $X$ é o conjunto $\nabla_{W}(X)=\{(A, E),(C, G)\}$, ou seja, é o conjunto que possui arestas com uma ponta em $X$ e a outra em $V(W) \backslash X$. 
Já o corte associado ao vértice $E$ é o conjunto $\nabla_{W}(E)=\{(A, E),(E, F),(E, H)\}$, ou seja, é o conjunto das três arestas que incidem no vértice $E$ e em outro vértice pertencente ao conjunto $V(W) \backslash\{E\}$.

\subsubsection{Graus}

Sendo $v$ um vértice de um grafo qualquer, chamamos de grau de $v$ o número de arestas que incidem sobre ele. Representamos este número por $g(v)$.

Observemos que $g(v)$ é igual à cardinalidade de $\Gamma(v)$, e também igual à cardinalidade de $\nabla_{G}(v)$, ou seja, $g(v)=|\Gamma(v)|=|\nabla(v)|$.

Dado um grafo $G$, chamamos de grau máximo de $G$ o maior grau entre todos os vértices de $G$, e o representamos por $\Delta(G)$, ou seja, $\Delta(G)=\max \{g(v) \mid v \in V(G)\}$.

De maneira análoga, definimos o grau mínimo de um grafo qualquer $G$ como sendo o menor grau entre todos os vértices de $G$, e o representamos por $\delta(G)$, ou seja, $\delta(G)=\min \{g(v) \mid v \in V(G)\}$.

Caso todos os vértices de um grafo tenham o mesmo grau, dizemos que este grafo é regular. Se o grau de todos os vértices for $k$, também dizemos que este grafo é $k$-regular.

Vejamos alguns teoremas relativamente simples, porém muito úteis no estudo de grafos.

Teorema 2.1.7.1 A soma dos graus de todos os vértices de um grafo qualquer é igual ao dobro do número de arestas.

Demonstração: Dado um grafo $G$ qualquer, cada aresta de $G$ incide em dois vértices, logo, cada aresta contribui em duas unidades na soma dos graus de todos os vértices, ou seja

$$
\sum_{v \in V} g(v)=2|A(G)|
$$

Teorema 2.1.7.2 Todo grafo tem um número par de vértices de grau ímpar.

Demonstração: Podemos calcular a soma dos graus de todos vértices de um grafo como:

$$
n=n_{p}+n_{i}
$$


em que $n_{p}$ é a soma dos graus dos vértices de grau par, e $n_{i}$ é a soma dos graus dos vértices de grau ímpar.

Como, para todo grafo $(\mathrm{V}, \mathrm{A})$, a soma dos graus dos vértices é igual ao dobro do número de arestas, a somatória dos graus dos vértices $(n)$ é par.

Sabemos que $n_{p}$ é par, pois é uma soma de números pares.

Já $n_{i}$ é uma soma de números ímpares que resulta em:

$$
\left\{\begin{array}{l}
\text { par } \Leftrightarrow \text { total de vértices somados for par; } \\
\text { ímpar } \Leftrightarrow \text { total de vértices somados for ímpar. }
\end{array}\right.
$$

Como $n$ e $n_{p}$ são pares, e $n=n_{p}+n_{i}$, temos que $n_{i}$ é par. Portanto, o total de vértices de grau ímpar é um número par, como se queria demonstrar.

Teorema 2.1.7.3 Todo grafo que possui dois ou mais vértices tem pelo menos dois vértices de mesmo grau.

Demonstração: Supondo $G$ um grafo em que todos os $n$ vértices possuem graus diferentes, como o maior grau que um vértice pode ter é $n-1$, os graus dos $n$ vértices são: $0,1,2, \ldots,(n-1)$.

Porém, sabe-se que em um mesmo grafo não é possível existir um vértice de grau $(n-1)$ e outro vértice de grau 0 , pois um vértice de grau $(n-1)$ é adjacente a todos os outros vértices, o que impossibilita a existência do vértice de grau 0.

Portanto, por contradição, conclui-se que em todo grafo $G$ pelo menos 2 vértices possuem mesmo grau.

Teorema 2.1.7.4 Para todo grafo $G$, temos que $\Delta(\bar{G})=n(G)-\delta(G)-1$ e $\delta(\bar{G})=n(G)-\Delta(G)-1$.

Demonstração: Seja $G$ um grafo qualquer, e $v$ um vértices de $G$, denotemos por $\bar{v}$ o mesmo vértice $v$ visto em $\bar{G}$. Como $n(G)=n(\bar{G})$, temos que $n(G)-1$ é o valor máximo para $g(v)$ e para $g(\bar{v})$. Logo, $g(v)+g(\bar{v})=n(G)-1$, ou seja, $g(v)+g(\bar{v})$ é constante. Desta forma, $g(\bar{v})$ será máximo quando $g(v)$ for mínimo, ou seja, $g(\bar{v})=\Delta(\bar{G})$ quando $g(v)=\delta(G)$. Portanto,

$$
\Delta(\bar{G})=n(G)-\delta(G)-1
$$


Analogamente, $g(\bar{v})$ será mínimo quando $g(v)$ for máximo, ou seja, $g(\bar{v})=\delta(G)$ quando $g(v)=\Delta(G)$. Portanto,

$$
\delta(\bar{G})=n(G)-\Delta(G)-1
$$

\subsubsection{Passeios, caminhos, circuitos, árvores e florestas}

Chamamos de passeio em um grafo $G$ uma sequência alternada de vértices $v_{o}, v_{1}, v_{2}, \ldots, v_{p}$ e arestas $a_{1}, a_{2}, \ldots a_{p}$, começando e terminando em vértices, como em $P=v_{0} a_{1} v_{1} a_{2} v_{2} \ldots a_{p} v_{p}$, em que $v_{i}$ e $v_{i-1}$ são as pontas da aresta $a_{i}$, e $v_{o}$ e $v_{p}$ são respectivamente a origem e fim (extremos) do passeio $P$. Um passeio é dito fechado se $v_{0}=v_{p}$ e dito aberto, caso contráro.

Se todos os vértices de um passeio em um grafo $G$ são distintos, ele é chamado de caminho, e no caso de todas as arestas serem distintas, ele é chamado de trilha (ou trajeto). Porém, se todos os vértices de um passeio são distintos, então todas as arestas também são, logo, todo caminho em $G$ é também uma trilha em $G$. Para representar um caminho, podemos escrever os vértices e arestas $C=v_{0} a_{1} v_{1} a_{2} v_{2} \ldots a_{p} v_{p}$, como também somente os vértices $C=v_{0} v_{1} v_{2} \ldots v_{p}$. Como um caminho é também um grafo, uma outra forma de representá-lo é $C=\left(\left\{v_{1}, v_{2}, \ldots, v_{p}\right\},\left\{v_{i} v_{i+1} \mid 1 \leq i<n\right\}\right)$.

Chamamos de circuito os passeios fechados, em que todos os vértices, com exceção dos extremos, são distintos. E chamamos de tamanho (ou comprimento) de um passeio (caminho ou circuito) o número arestas que ele possui. Notemos que um caminho de tamanho $k$ possui $k+1$ vértices, já um circuito de tamanho $k$ possui $k$ vértices. Se o tamanho de um passeio for zero, significa que o grafo consiste de apenas um vértice. Dizemos que um passeio (caminho ou circuito) é par se tem tamanho par e ímpar se tem tamanho ímpar.

A Figura 2.10 apresenta um exemplo de caminho, circuito e trilha.

Figura 2.10: Exemplo de caminho, circuito e trilha

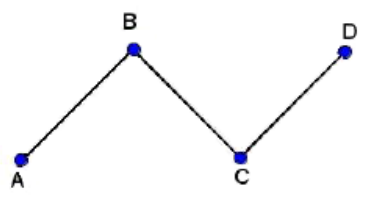

Caminho

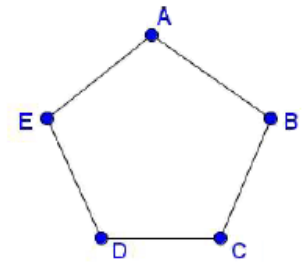

Circuito

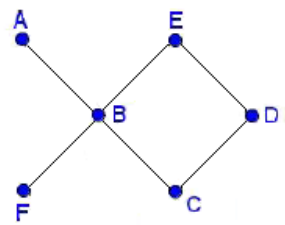

Trilha 
É comum que circuitos de tamanho três, quatro, cinco, seis,..., sejam respectivamente chamados de triângulo, quadrado, pentágono, hexágono, e assim por diante.

Dado um grafo $G$, se $G$ não possui nenhum circuito, dizemos que este grafo é uma floresta. Se, além disso, para todo par $u, v$ de vértices de $G$ há um caminho de $u$ a $v$, dizemos que $G$ é uma árvore.

A Figura 2.11 apresenta um exemplo de floresta e árvore.

Figura 2.11: Exemplo de floresta e árvore
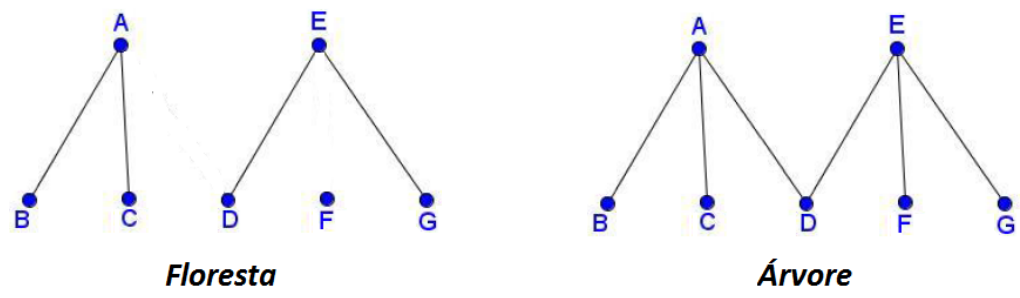

Vejamos um teorema relacionado a circuitos.

Teorema 2.1.8.1 Todo corte de um circuito tem cardinalidade par, ou seja, para qualquer conjunto $X$ de vértices de um circuito $O$, o corte $\nabla_{O}(X)$ tem cardinalidade par.

Demonstração: (Prova por Indução Finita) Sejam $O$ um circuito e $X$ um conjunto de vértices de $O$, tomemos como base da indução um conjunto $X$ de cardinalidade 1 . Neste caso, o corte $\nabla_{O}(X)$ tem cardinalidade par $=2$, pois cada vértice em um circuito tem grau 2 e, sendo assim, as duas arestas que incidem em $X$ tem sua outra ponta em $V(G) \backslash X$. Logo, o enunciado é verdadeiro para um conjunto $X$ de cardinalidade 1 .

Agora, supondo que a cardinalidade de $X$ é $n \geq 1$, em que o corte $\nabla_{O}(X)$ tem cardinalidade par, provemos que um conjunto $X^{\prime}$ de $n+1$ elementos também tem corte de cardinalidade par.

Supondo que a cardinalidade de $X$ é $n$, em que o corte $\nabla_{O}(X)$ tem cardinalidade par, se acrescentarmos um vértice $y \in V(G) \backslash X$ ao conjunto $X$, obtemos um novo conjunto $X^{\prime}=X \cup\{y\}$ de $n+1$ elementos. Desta forma, temos três casos possíveis:

Caso 1: $y$ é adjacente a dois vértices $\{a, b\} \in X$. Neste caso, a cardinalidade de $\nabla_{O}\left(X^{\prime}\right)$ é $\left|\nabla_{O}(X)\right|-2$, pois as duas arestas ya e $y b$ que pertencem a $\nabla_{O}(X)$ ambas não pertencem a $\nabla_{O}\left(X^{\prime}\right)$ (pois possuem ambas as pontas em $X^{\prime}$ ). Sendo assim, como a cardinalidade de $\nabla_{O}(X)$ é par, a cardinalidade $\nabla_{O}\left(X^{\prime}\right)$ também é par. 
Caso 2: $y$ é adjacente a dois vértices $\{u, v\} \in V(G) \backslash X$. Neste caso, a cardinalidade de $\nabla_{O}\left(X^{\prime}\right)$ é $\left|\nabla_{O}(X)\right|+2$, pois as duas arestas yu e yv que não pertencem a $\nabla_{O}(X)$, ambas pertencem a $\nabla_{O}\left(X^{\prime}\right)$ (pois uma de suas pontas $y$ pertence a $X^{\prime}$ e outra $\{u, v\}$ pertence a $V(G) \backslash X^{\prime}$ ). Desta maneira, a cardinalidade de $\nabla_{O}\left(X^{\prime}\right)$ também é par.

Caso 3: $y$ é adjacente a um vértice $c \in X$, e a um vértice $z \in V(G) \backslash X$. Neste caso, $\left|\nabla_{O}\left(X^{\prime}\right)\right|=\left|\nabla_{O}(X)\right|-1+1=\left|\nabla_{O}(X)\right|$, visto que a aresta $y c$ que pertence a $\nabla_{O}(X)$ não pertence a $\nabla_{O}\left(X^{\prime}\right)$ (pois possui ambas as pontas em $X^{\prime}$ ), porém a aresta $y z$ que não pertence a $\nabla_{O}(X)$ pertence a $\nabla_{O}\left(X^{\prime}\right)$ (pois uma de suas pontas $y$ pertence a $X^{\prime}$ e a outra ponta $z$ pertence a $V(G) \backslash X^{\prime}$ ), e desta maneira, a cardinalidade de $\nabla_{O}\left(X^{\prime}\right)$ também é par.

Logo, por indução, provamos que todo corte de um circuito tem cardinalidade par.

\subsubsection{Subgrafos}

Chamamos de subgrafo de $G$ qualquer grafo $H$, em que $V(H) \subseteq V(G)$ e $A(H) \subseteq A(G)$. Caso $V(H) \neq V(G)$ ou $A(H) \neq A(G)$, dizemos que o subgrafo $H$ é próprio.

Dado um grafo $G$ e um conjunto $X$ tal que $X \subseteq V(G)$, chamamos de subgrafo de $G$ induzido por $X$ ao grafo $(X, B)$, em que $B \subseteq A(G)$ é o conjunto de todas as arestas cujas duas pontas pertencem ao conjunto $X$. Representamos este tipo de grafo por $G[X]$.

Caso um caminho $C$ seja um subgrafo de um grafo $G$, dizemos que $C$ é um caminho em $G$, ou que o grafo $G$ contém o caminho $C$. A mesma nomenclatura também se aplica para os circuitos que são subgrafos de $G$.

Teorema 2.1.9.1 Um grafo $G$ é uma floresta se e somente se cada uma de suas arestas é um corte, ou seja, para cada aresta a existe um subconjunto $X$ de $V(G)$ tal que $\nabla(X)=\{\boldsymbol{a}\}$.

Demonstração: Vamos provar primeiramente que, se $G$ é uma floresta, então cada uma de suas arestas é um corte.

Sendo $m$ uma aresta qualquer de $G$ com pontas $a$ e $b$, chamemos de $X$ o conjunto união de todos os vértices dos caminhos de extremo $a$ (incluindo $a$ ), que não contenham o vértice $b$. Vamos provar que $m$ é um corte associado ao conjunto $X$. 
Supondo existir um vértice $v$ pertencente a $X$, e adjacente a um outro vértice $v^{\prime}$ pertencente a $V(G) \backslash X$, temos que $v^{\prime}$ pertence ao conjunto de vértices de algum caminho de extremo $b$ (caso contrário $v^{\prime}$ pertenceria a $\left.X\right)$, logo, como $a$ é adjacente a $b, v$ é adjacente a $v^{\prime}$ e existe caminho entre $a$ e $v$, e também entre $v^{\prime}$ e $b$, então existe um circuito (cujo conjunto de vértices contém $a, b, v$ e $\left.v^{\prime}\right)$, o que é um absurdo, visto que, por hipótese $G$ é uma árvore. Portanto, por absurdo concluímos que $m$ é a única aresta com uma ponta em $X$ e a outra em $G \backslash X$, ou seja, $m$ é um corte. Portanto, como $m$ é uma aresta qualquer de $G$, concluímos que, se $G$ é uma floresta, então cada uma de suas arestas é um corte.

Provemos agora que, se toda aresta de $G$ é um corte, então $G$ é uma floresta.

Se toda aresta $m$ de $G$, cujas pontas podemos chamar de $a$ e $b$, é um corte $\nabla(X)$ associado a um conjunto $X$ de vértices, em que $a$ pertecence ao conjunto $X$, e $b$ ao conjunto $V(G) \backslash X$ (como exemplificado na Figura 2.12, não existe nenhuma outra aresta com uma ponta em $X$ e outra em $V(G) \backslash X$ além de $m$. Consequentemente, não existe nenhum outro caminho de extremidade $a$ e $b$ além da aresta $m$, ou seja, $m$ não pertence a nenhum circuito. Portanto, se toda aresta de $G$ é um corte, $G$ não possui circuitos (é um floresta).

Figura 2.12

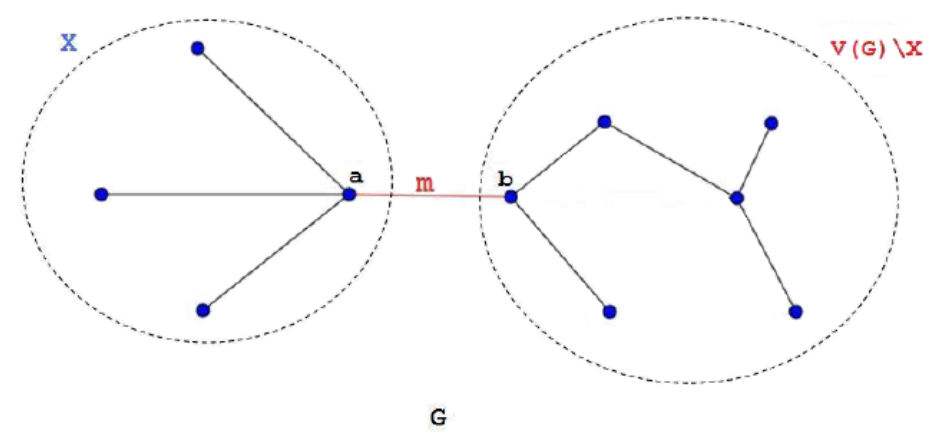

\subsubsection{Grafos conexos e componentes}

Dizemos que um grafo $G$ é conexo quando, para quaisquer dois vértices $u$ e $v$, existe um caminho de origem $u$ e fim $v$.

Dado um subgrafo conexo $H$ de um grafo $G$, se não existe nenhum outro subgrafo conexo $H^{\prime}$ de $G$ tal que $H \subset H^{\prime}$, ou seja, $H$ é subgrafo próprio de $H^{\prime}$, então dizemos que $H$ é maximal. 
Chamamos de componente (ou componente conexo) de um grafo $G$ a qualquer subgrafo conexo maximal de $G$.

Vejamos agora alguns teoremas relacionados a grafos conexos.

Teorema 2.1.10.1 Seja $G$ um grafo tal que $\Delta(G) \leq 2$, então cada componente de $G$ é um caminho ou um circuito.

Demonstração: Se $C$ é um componente do grafo $G$, no qual $\Delta(G) \leq 2$, temos que todo vértice de $C$ possui grau 0,1 ou 2 .

Consideremos três situações possíveis:

Caso 1: $C$ possui vértice de grau 0.

Se $C$ possui um vértice $v$ de grau 0 , então $v$ é um vértice isolado, e sendo assim, $C$ é um caminho.

Caso 2: $C$ possui vértice de grau 1.

Se $C$ possui um vértice $w$ de grau 1, pelo Teorema 2.1.7.3, $C$ possui um número par de vértices de grau ímpar. Sendo assim, $C$ necessariamente possui outro vértice $x$ igualmente de grau 1 , e não havendo nenhum outro vértice em $C$, então $C=w x$ é um caminho. Porém, caso $C$ possua algum outro vértice $y$, como $C$ é conexo, existe um caminho entre $w$ e $y$ e entre $x$ e $y$, ou seja, $y$ pertence ao caminho de pontas $w$ e $x$, portanto $C$ é um caminho.

Caso 3: $C$ não possui vértice de grau 0 e 1.

Se $C$ não possui vértice de grau 0 e 1 , logo todos os vértices de $C$ são de grau 2 , portanto $C$ é um circuito.

Desta forma concluímos que, se $G$ é tal que $\Delta(G) \leq 2$, então cada componente de $G$ é um caminho ou um circuito.

Teorema 2.1.10.2 Todo grafo $G$ satisfaz a desigualdade $m(G) \geq n(G)-c(G)$, em que $c(G)$ é o número de componentes de $G$.

Demonstração: (Prova por Indução Finita) Tomemos como base da indução um grafo $G$, em que $n(G)=1$. Neste caso, temos que $m(G)=0$ e $c(G)=1$. Logo, substituindo na desigualdade

$$
\begin{array}{r}
m(G) \geq n(G)-C(G) \\
\Rightarrow 0 \geq 1-1 \\
\Rightarrow 0 \geq 0 .
\end{array}
$$


Verificamos assim que a desigualdade é verdadeira.

Agora, supondo que $m\left(G^{\prime}\right) \geq n\left(G^{\prime}\right)-c\left(G^{\prime}\right)$ é válido para um grafo $G^{\prime}$ qualquer com $n\left(G^{\prime}\right)=x$, provemos que para um grafo $G \operatorname{com} n(G)=x+1$ a desigualdade também é válida.

Tomando um grafo $G$ com $n(G)=x+1$ e retirando um de seus vértices $v$, obtemos um novo grafo $G^{\prime} \operatorname{com} n\left(G^{\prime}\right)=x$, portanto, por hipótese, temos que $m\left(G^{\prime}\right) \geq n\left(G^{\prime}\right)-c\left(G^{\prime}\right)$.

Restituindo o vértice $v$ ao grafo $G^{\prime}$, obtemos novamente o grafo $G$, e temos as seguintes possibilidades:

Caso 1: O vértice $v$ possui grau zero, desta forma é também um componente maximal. Neste caso, temos que $m(G)=m\left(G^{\prime}\right), n(G)=n\left(G^{\prime}\right)+1$ e $c(G)=c\left(G^{\prime}\right)+1$. Logo, substituindo na desigualdade

$$
\begin{array}{r}
m\left(G^{\prime}\right) \geq n\left(G^{\prime}\right)-c\left(G^{\prime}\right) \\
\Rightarrow m(G) \geq n(G)-1-(c(G)-1) \\
\Rightarrow m(G) \geq n(G)-1-c(G)+1 \\
\Rightarrow m(G) \geq n(G)-c(G) .
\end{array}
$$

Portanto, a desigualdade $m(G) \geq n(G)-c(G)$ é verdadeira.

Caso 2: O vértice $v$ possui grau $k+y$, e é adjacente a $k$ componentes diferentes (fazendo com que $k$ componentes se tornem um único componente). Neste caso, temos que $m(G)=m\left(G^{\prime}\right)+k+y$, $n(G)=n\left(G^{\prime}\right)+1$ e $c(G)=c\left(G^{\prime}\right)-(k-1)$. Logo, substituindo na desigualdade

$$
\begin{array}{r}
m\left(G^{\prime}\right) \geq n\left(G^{\prime}\right)-c\left(G^{\prime}\right) \\
\Rightarrow m(G)-k-y \geq n(G)-1-(c(G)+(k-1)) \\
\Rightarrow m(G)-k-y \geq n(G)-1-c(G)-k+1 \\
\Rightarrow m(G)-y \geq n(G)-c(G) .
\end{array}
$$

Como $y$ é maior ou igual a zero, então $m(G) \geq m(G)-y \geq n(G)-c(G)$. Portanto a desigualdade $m(G) \geq n(G)-c(G)$ é verdadeira.

Dos casos 1 e 2 concluímos que se a desigualdade é válida para $G^{\prime} \operatorname{com} n\left(G^{\prime}\right)=x$, então a desigualdade também vale para $G$, em que $n(G)=x+1$. Logo, por indução, provamos que todo grafo $G$ satisfaz a desigualdade $m(G) \geq n(G)-c(G)$. 
Teorema 2.1.10.3 Um grafo conexo $G$ é uma floresta se e somente se, para cada aresta a de $G$, o grafo $G-a$ não é conexo.

Demonstração: Vamos provar primeiramente que, se um grafo conexo $G$ é uma floresta, então para cada aresta $a$ o grafo $G-a$ não é conexo.

Tomando uma aresta a qualquer de $G$ cujas pontas são $u_{1}$ e $u_{n}$ e, supondo, por absurdo, que $G-a$ é conexo, temos que existe um caminho $u_{1} u_{2} \ldots u_{n}$ entre $u_{1}$ e $u_{n}$. Logo, $u_{1} u_{2} \ldots u_{n} \cup u_{1} u_{n}$ é um circuito em $G$, mas, por hipótese, $G$ é uma floresta. Portanto, concluímos que $G-a$ (em que $a$ é uma aresta qualquer) não é conexo.

Provemos agora que, se para cada aresta $a$ de um grafo conexo $G$, o grafo $G-a$ não é conexo, então $G$ é uma floresta.

Tomando um grafo $G$ em que, para toda aresta $a, G-a$ não é conexo, e supondo, por absurdo, que $G$ possui um circuito $v_{1} v_{2} \ldots v_{n} v_{1}$, então, ao retirar de $G$ uma aresta $a$ cujas pontas são $v_{n}$ e $v_{1}$, ainda existe um caminho $\left(v_{1} v_{2} \ldots v_{n}\right)$ entre $v_{1}$ e $v_{n}$, ou seja, se $G$ é conexo, então $G-a$ também é conexo. Mas, por hipótese, $G-a$ não é conexo. Portanto, concluímos que $G$ não possui circuito $(G$ é uma floresta).

Desta forma, podemos concluir que, um grafo conexo $G$ é uma floresta $\Leftrightarrow$ para cada aresta $a$, o grafo $G-a$ não é conexo.

\subsection{Conjuntos estáveis e cliques}

Dependendo de algumas características, podemos classificar os conjuntos de vértices de um grafo como conjuntos estáveis ou como cliques, como veremos abaixo.

\subsubsection{Conjuntos estáveis}

Dizemos que um conjunto de vértices $X$ de um grafo $G$ é estável (ou independente) se todos os seus elementos são dois a dois não adjacentes, ou seja, nenhuma aresta tem como pontas dois vértices de $X$. 
A Figura 2.13 apresenta alguns exemplos de grafos mostrando conjuntos estáveis de vértices (vermelhos).

Figura 2.13: Exemplos de conjuntos estáveis
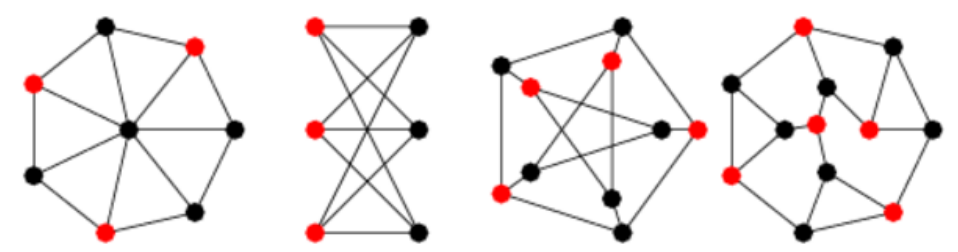

Fonte: http://mathworld.wolfram.com/IndePendentVertexSet.html. Acesso em: 21 nov. 2015.

Quando um conjunto $X$ de vértices de um grafo $G$ é estável e, para todo conjunto estável $Y$ de vértices de $G$, a cardinalidade de $X$ é maior ou igual a cardinalidade de $Y$, ou seja, $|X| \geq|Y|$, dizemos que o conjunto estável $X$ é máximo.

Chamamos a cardinalidade de um conjunto estável máximo de vértices de um grafo $G$ de índice de estabilidade de $G$, e o representamos por $\alpha(G)$.

\subsubsection{Cliques}

Dizemos que um conjunto $C$ de vértices de um grafo $G$ é um clique se todos os seus elementos são dois a dois adjacentes, ou seja, para todo par de vértices $u$ e $v$ pertencentes a $C$ existe uma aresta com pontas $u$ e $v$.

Quando um conjunto $C$ de vértices de um grafo $G$ é um clique e, para todo conjunto clique $C^{\prime}$ de vértices de $G$, a cardinalidade de $C$ é maior ou igual a cardinalidade de $C^{\prime}$, ou seja, $|C| \geq\left|C^{\prime}\right|$, dizemos que o conjunto clique $C$ é máximo.

Chamamos a cardinalidade de um conjunto clique máximo de vértices de um grafo $G$ de número clique de $G$, e o representamos por $\omega(G)$.

Existe uma forte relação entre conjuntos estáveis e cliques: um conjunto $X$ de vértices de um grafo $G$ é estável se e somente se $X$ é um clique no grafo complementar $\bar{G}$.

\subsection{Coloração de vértices}

Chamamos de coloração de vértices de um grafo $G$ a atribuição de cores aos vértices de $G$ de tal forma que vértices adjacentes tenham cores distintas. Podemos entender a coloração de vértices 
de $G$ como uma função: $f: V(G) \rightarrow\{1, ., k\}$, tal que para vértices adjacentes sejam atribuídos números distintos, em que cada número representa um cor diferente, e $k$ é a quantidade total de cores.

A Figura 2.14 traz alguns exemplos de grafos apresentando uma coloração adequada de vértices:

Figura 2.14: Exemplos de coloração de vértices
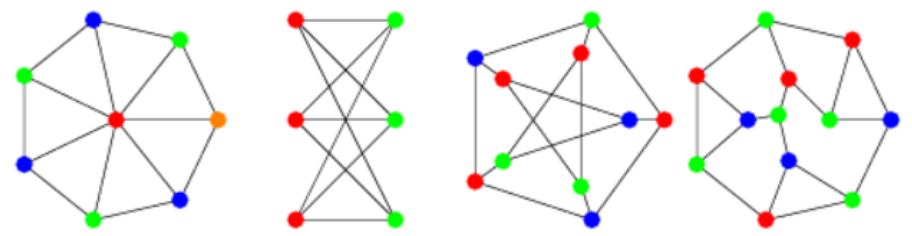

Fonte: httP://mathworld.wolfram.com/VertexColoring.html. Acesso em: 21 nov. 2015.

\subsubsection{Colorações mínimas}

Não há grandes dificuldades para realizar uma coloração de vértices quando não há uma restrição quanto ao número de cores a ser usado. Porém, a tarefa de encontrar uma coloração utilizando o menor número possível de cores é onde se encontra o desafio.

Chamamos a coloração dos vértices de um grafo $G$ de mínima quando a quantidade de cores diferentes usadas é a menor possível. A esse número mínimo de cores nós chamamos de número cromático. O número cromático de um grafo $G$ é representado por $\chi(G)$.

A Figura 2.15 traz alguns exemplos de número cromático para alguns grafos:

Figura 2.15: Exemplos de número cromático

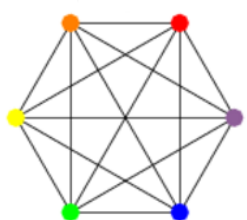

$\chi\left(K_{6}\right)=6$

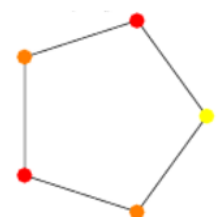

$\chi\left(C_{5}\right)=3$

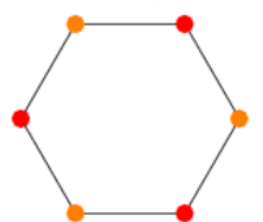

$\chi\left(C_{6}\right)=2$

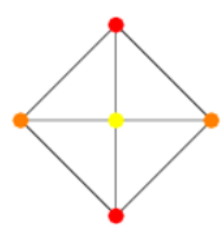

$\chi\left(W_{5}\right)=3$

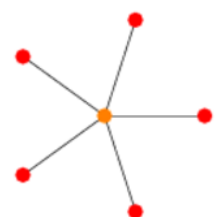

$\chi\left(S_{6}\right)=2$

Fonte: http://mathworld.wolfram.com/ChromaticNumber.html. Acesso em: 21 nov. 2015.

Dizemos que um grafo $G$ é colorível com $k$ cores ou que $G$ é $k$-colorível quando $\chi(G) \leq k$. 


\subsubsection{Delimitação superior do número cromático}

Podemos obter um delimitador superior para o número cromático, conforme Teorema 2.3.2.1.

Teorema 2.3.2.1 Para todo grafo $G$, temos que $\chi(G) \leq \Delta(G)+1$.

Demonstração: Considere um grafo $G$, cujo conjunto de vértices representamos por $V(G)=\left\{v_{1}, \ldots, v_{n}\right\}$, e o conjunto de suas possíveis cores pelo conjunto dos números naturais $\mathbb{N}$, em que cada número $x \in \mathbb{N}$ representa uma cor diferente. Realizamos a coloração dos vértices de $G$ colorindo cada um de seus vértices $v_{i}$ com a cor representada pelo menor número de $\mathbb{N}$ que ainda não foi usada para colorir algum dos seus vizinhos.

Como cada vértice $v_{i}$ de $G$ possui grau menor ou igual a $\Delta(G)$, ou seja, cada vértice $v_{i}$ possui no máximo $\Delta(G)$ vizinhos, temos que sempre haverá uma cor representada por um número menor ou igual a $\Delta(G)+1$ disponível para colorir cada vértice de $G$. Desta forma, este processo cria uma coloração adequada para qualquer grafo $G$, de forma que $\chi(G) \leq \Delta(G)+1$, como queríamos demonstrar.

\subsubsection{Delimitação inferior do número cromático}

Também podemos obter um delimitador inferior para o número cromático, conforme o teorema 2.3.3.1.

Teorema 2.3.3.1 Para todo grafo $G$, temos que $\chi(G) \geq \frac{n(G)}{\alpha(G)}$.

Demonstração: Denotamos por classe de cor o conjunto de todos os vértices de uma mesma cor. Sendo $G$ um grafo adequadamente colorido com $\chi(G)$ cores, temos que cada uma de suas classes de cor $V_{1}, V_{2}, \ldots, V_{\chi(G)}$ é um conjunto estável. Então, a cardinalidade de cada classe de cor em $G$ é no máximo $\alpha(G)$. Logo,

$$
\begin{array}{r}
n(G)=\sum_{i=1}^{\chi(G)}\left|V_{i}\right| \leq \chi(G) \cdot \alpha(G) . \\
\Rightarrow \chi(G) \geq \frac{n(G)}{\alpha(G)} .
\end{array}
$$

Desta forma, concluímos a demonstração do teorema.

Há também um outro delimitador inferior para o número cromático, apresentado pelo Teorema 2.3.3.2. 
Teorema 2.3.3.2 Para todo grafo $G$, temos que $\chi(G) \geq \omega(G)$.

Demonstração: Sendo $f: V(G) \rightarrow\{1, . ., k\}$ uma coloração dos vértices de um grafo $G$ qualquer, em que cada número representa uma cor diferente, e $k$ representa a quantidade total de cores, se $C$ é um conjunto clique de vértices de $G$, sabemos que $k \geq|C|$.

Supondo que o grafo $G$ possua coloração mínima de seus vértices, e $C$ é clique máximo, ou seja $k=\chi(G)$ e $|C|=\omega(G)$, então, pela desigualdade acima, temos que $\chi(G) \geq \omega(G)$, como queríamos demonstrar.

\subsection{Coloração de arestas}

Chamamos de coloração de arestas de um grafo $G$ a atribuição de cores às arestas de $G$ de tal forma que arestas adjacentes tenham cores distintas. Podemos entender a coloração de arestas de $G$ como uma função: $f: A(G) \rightarrow\{1, . ., k\}$, tal que para arestas adjacentes sejam atribuídos números distintos, em que cada número representa um cor diferente, e $k$ é a quantidade total de cores.

A Figura 2.16 traz alguns exemplos de grafos apresentando uma coloração adequada de arestas:

Figura 2.16: Exemplos de coloração de arestas
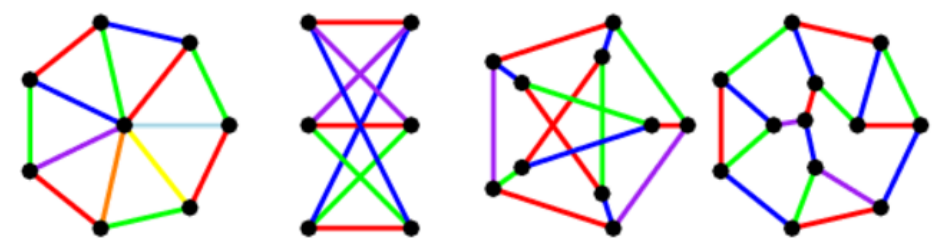

Fonte: http://mathworld.Wolfram.com/EdgeColoring.html. Acesso em: 21 nov. 2015.

\subsubsection{Colorações mínimas}

Semelhante à coloração de vértices, não há grandes dificuldades para realizar uma coloração de arestas quando não há uma restrição quanto ao número de cores a ser usado. O desafio se encontra em conseguir uma coloração utilizando o menor número possível de cores.

Chamamos a coloração das arestas de um grafo $G$ de mínima quando a quantidade de cores diferentes usadas é a menor possível. A esse número mínimo de cores nós chamamos de índice cromático. O índice cromático de um grafo $G$ é representado por $\chi^{\prime}(G)$. 
Existe uma relação entre coloração de arestas com coloração de vértices, visto que a coloração de arestas de um grafo $G$ qualquer é equivalente à coloração dos vértices do grafo das arestas de $G$. Logo, se $G^{\prime}$ é o grafo das arestas de $G$, temos que $\chi^{\prime}(G)=\chi\left(G^{\prime}\right)$.

\subsubsection{Delimitação inferior do índice cromático}

Podemos obter um delimitador inferior para o índice cromático, conforme Teorema 2.4.2.1.

Teorema 2.4.2.1 Para todo grafo $G$, temos que $\chi^{\prime}(G) \geq \Delta(G)$.

Demonstração: Sendo $G$ um grafo qualquer, cuja coloração das arestas possui $k$ cores, temos que, para qualquer vértice $v \in V(G)$, o número $k$ é maior ou igual ao grau de $v$, ou seja, $k \geq g(v)$.

Supondo que o grafo $G$ possua coloração mínima de suas arestas, e o vértice $v$ seja de grau máximo, ou seja $k=\chi^{\prime}(G)$ e $g(v)=\Delta(G)$, então, pela desigualdade acima, temos que $\chi^{\prime}(G) \geq$ $\Delta(G)$, como queríamos demonstrar.

\subsubsection{Delimitação superior do índice cromático}

Também podemos obter um delimitador superior para o índice cromático, como indicado pelo Teorema 2.4.3.1) de Vizing.

Teorema (de Vizing) 2.4.3.1 Para todo grafo $G$, temos que $\chi^{\prime}(G) \leq \Delta(G)+1$.

Um demonstração deste importante teorema pode ser encontrada em

(FEOFILOFF \& KOHAYAKAWA \& WAKABAYASHI, 2011).

É interessate observarmos que, conciliando o Teorema 2.4.3.1 com o Teorema 2.4.2.1, encontramos:

$$
\Delta(G) \leq \chi^{\prime}(G) \leq \Delta(G)+1
$$

Com este resultado, concluímos que o indíce cromático de qualquer grafo é $\Delta(G)$ ou $\Delta(G)+1$, ou seja, ele pode variar em apenas uma unidade em relação a $\Delta(G)$.

Vimos até aqui algumas delimitações que valem para grafos quaisquer. Porém, é importante destacarmos que para grafos específicos, podemos ter delimitadores ainda melhores. Por exemplo, para grafos planares, como veremos mais adiante, o número cromático é menor ou igual a quatro. 


\section{Capítulo 3}

\section{O Problema das Quatro Cores}

\subsection{Um pouco de história}

A história da matemática, em especial a do Problema das Quatro Cores, é muito interessante, pois através dela podemos compreender melhor como surgiram curiosos problemas da matemática, as diferentes estratégias usadas pelos matemáticos em busca de solucioná-los, e os sucessos e "fracassos" que alcançaram no decorrer dos tempos. Nas seções 3.1.1 e 3.1.2 é apresentado um pouco da curiosa história do Problema das Quatro Cores.

\subsubsection{Surge o problema}

No ano de 1852, um matemático inglês chamado Francis Guthrie (1831-1899), recém-formado na University College, em Londres, estava pintando um mapa dos condados ${ }^{1}$ da Inglaterra, utilizando o critério de pintar condados vizinhos com cores diferentes.

Ao realizar esta pintura, Francis Guthrie notou que era possível colorir aquele mapa (respeitando o critério estabelecido) utilizando apenas quatro cores. Em seguida, Francis Guthrie tentou o mesmo procedimento com outros mapas diferentes, e conseguiu pintar cada um deles com apenas quatro cores.

Desta forma, surgiu o conhecido Problema das Quatro Cores: "Todo mapa (plano ou sobre uma superfície esférica) pode ser pintado com apenas quatro cores?"

Francis Guthrie, como era matemático, tentou provar que a resposta ao Problema das Qua-

\footnotetext{
${ }^{1}$ Divisão territorial existente na Inglaterra e nos E.U.A..
} 
Figura 3.1: Mapa dos Condados da Inglaterra

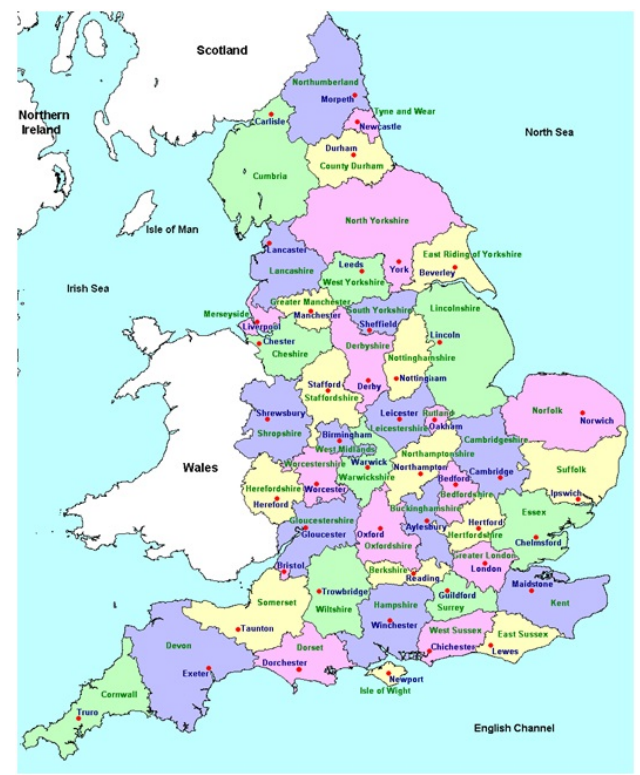

Fonte: <HtTps://WwW.Pinterest.com/DldeEda/maps/>. Acesso em: 21 nov. 2015.

tro Cores era "sim", porém não conseguiu elaborar nenhuma demonstração matemática para tal. Francis Guthrie, então, passou o problema para seu irmão Frederick Guthrie (1883-1866), que nesta época era estudante de matemática. Frederick Guthrie também não conseguiu demonstrar que a conjectura era de fato verdadeira, então passou o problema para seu professor Augustus De Morgan (1806-1871), que se interessou pelo problema e por isso se empenhou por encontrar uma resposta.

Com Augustus De Morgan, o Problema das Quatro Cores começou a evoluir rumo a uma resposta. Ele observou que em alguns mapas existem quatro "países" e que cada um deles faz fronteira com os outros três, e que nestes casos não é possível pintá-lo com somente três cores, respeitando o critério de variação de cores entre "países" vizinhos 2 A Figura 3.2 é um exemplo de mapa com estas características.

Figura 3.2: Exemplo de mapa que não pode ser pintado com menos de quatro cores

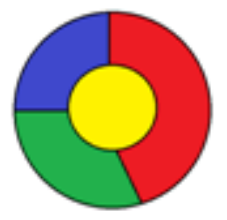

\footnotetext{
${ }^{2}$ Aqui e até o final do texto consideraremos que um mapa é possível de ser colorido caso seja possível colori-lo respeitando o critério de que "países" vizinhos não possuam a mesma cor.
} 
Um exemplo real de mapa que não pode ser pintado com menos do que quatro cores (dito mapa tetracromático) é o mapa da América do Sul, no qual os quatro países Brasil, Paraguai, Argentina e Bolívia tem a propriedade de que cada um deles faz fronteira com os outros três, como podemos observar na Figura 3.3 .

Figura 3.3: Exemplo de mapa tetracromático

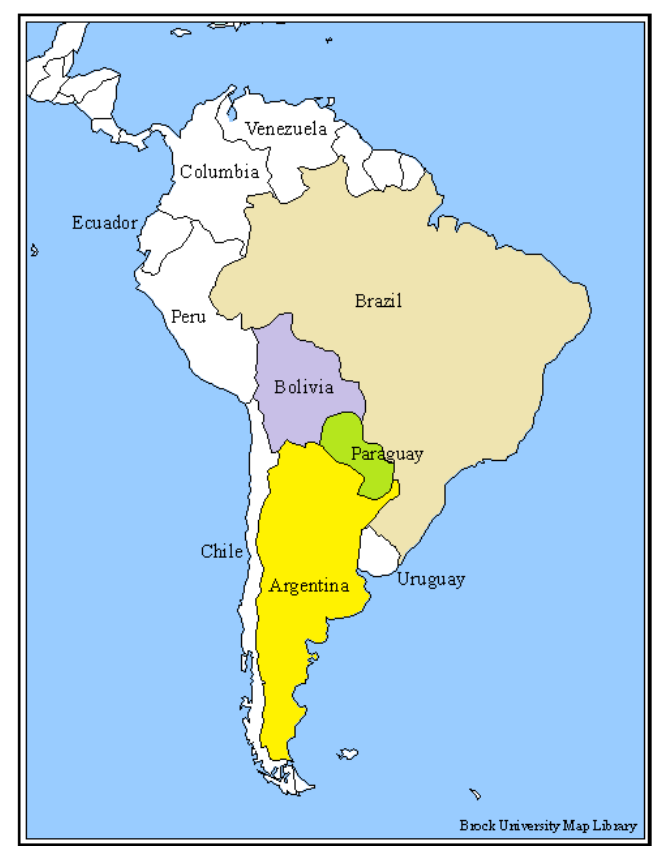

Fonte: Adaptação de HTTP://WWW.DOMINIOPUBLICO.GOV.BR/DOWNLOAD/IMAGEM/BU000007.GIF. Acesso em: 21 nov. 2015.

Seguindo a mesma linha de raciocínio mencionado acima, Augustus De Morgan conjecturou: tomando cinco "países" quaisquer de um mapa, pelo menos dois deles não são vizinhos entre si. Ou seja, Augustus De Morgan supunha que a conjectura de Francis Guthrie era verdadeira, pois caso exista algum mapa contendo um conjunto de cinco países, em que cada um deles faz fronteira com os outros quatro, então é necessário pelo menos cinco cores para colori-lo, sendo desta forma um contraexemplo para afirmação de que todo o mapa pode ser colorido com quatro cores. Veremos mais adiante que a conjectura de Augustus De Morgan é verdadeira.

\subsubsection{O problema se torna conhecido}

Talvez a maior contribuição de Augustus de Morgan para a resolução do Problema das Quatro Cores tenha sido a divulgação do problema (repassou-o para outros matemáticos e também para seus alunos). Tanto é que ele foi considerado por muitos como o autor original do problema. 
O problema se tornou mais amplamente conhecido 26 anos depois de ter sido formulado por Francis Guthrie, quando em 1878 um artigo chamado the solution of a problem which recently achieved some renown, que dizia respeito ao problema, foi publicado no periódico Nature pela London Mathematical Society por meio de seu presidente Arthur Cayley (1821-1895). A divulgação do problema trouxe frutos rapidamente, tanto que, no ano seguinte ao da divulgação (1879), um advogado ligado à London Mathematical Society, chamado Alfred Bray Kempe (1849-1922), publicou uma demonstração de que quatro cores eram suficientes para colorir qualquer mapa. Embora advogado, o inglês Alfred Bray Kempe havia estudado matemática na Cambridge University, e por isso manteve seu interesse por ela.

A demonstração de Alfred Bray Kempe foi analisada por diversos matemáticos, que anuíram a ela, pondo fim às investigações sobre o Problema das Quatro Cores. Porém, a curiosidade e desejo de encontrar uma resposta ao Problema das Quatro Cores recomeçou novamente após onze anos (1890) da calmaria trazida pela demonstração de Alfred Bray Kempe, quando um homem chamado Percy John Heawood (1861-1955), que foi membro do corpo docente, administrador e vice-reitor do Durham College na Inglaterra, encontrou um erro na demonstração de Alfred Bray Kempe, um erro que não podia ser corrigido.

Percy John Heawood havia conhecido o problema quando ainda era estudante na Oxford University, em 1880, onde um de seus professores expunha frequentemente o problema.

\subsection{A demonstração de Kempe}

A demonstração de Alfred Bray Kempe consistia basicamente na demonstração das seguintes afirmações:

1. Se existe um mapa pentacromático, ou seja, um mapa que não pode ser pintado com menos de cinco cores, então também existe um mapa pentacromático normal, ou seja, um mapa que não contém nenhum "país" totalmente envolvido por outro, e no qual cada ponto de interseção de fronteira é sempre compartilhado por exatamente três "países".

A Figura 3.4 apresenta exemplos de mapas que não são normais. O primeiro mapa não é normal, pois o "país" circular A está envolvido totalmente pelo "país" B. Já o segundo mapa não é normal por possuir um ponto de interseção de fronteira compartilhado por mais de três "países". 
Figura 3.4: Exemplos de mapas não-normais
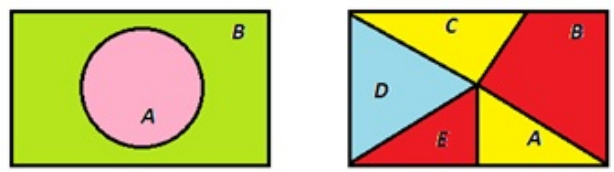

Fonte: Adaptação de (SOUSA, 2001)

2. Se existe um mapa pentacromático normal, então existe um mapa pentacromático normal mínimo, ou seja, um mapa pentacromático que possui número de "países" menor ou igual a todos os outros mapas pentacromáticos.

3. Qualquer mapa normal contém pelo menos um "país" com no máximo cinco vizinhos.

Esta afirmação indica que em todo mapa normal ocorre pelo menos uma das quatro configurações ("país" com 2, 3, 4 ou 5 vizinhos) ilustradas na Figura 3.5 .

Figura 3.5: Configuracoes inevitáveis apresentadas por Kempe
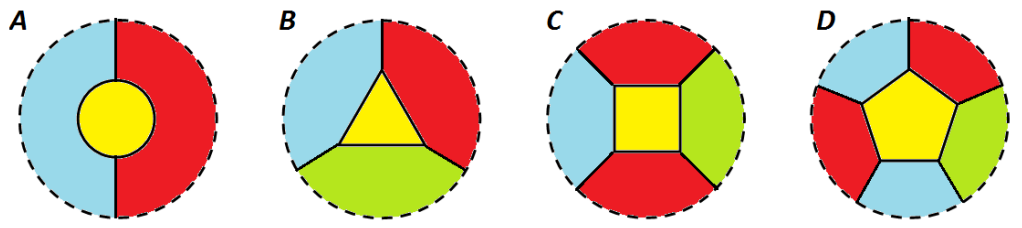

Fonte: Adaptação de (SECCO, 2013)

4. Um mapa pentacromático normal mínimo não pode conter um "país" com menos do que seis vizinhos.

Alfred Bray Kempe tentou demonstrar o Teorema das Quatro Cores por contradição. Caso conseguisse demonstrar todas as quatro afirmações, encontraria uma contradição entre as duas últimas, invalidando imediatamente a hipótese da existência de um mapa pentacromático normal mínimo, que por sua vez invalidaria a hipótese inicial: a existência de um mapa pentacromático, provando desta forma o Teorema das Quatro Cores.

Kempe demonstrou corretamente as afirmações 1, 2 e 3, porém cometeu um erro na tentativa de demonstrar a afirmação 4. A estratégia que Kempe utilizou para demonstrar esta afirmação foi provar que em um mapa pentacromático qualquer, as quatro configurações inevitáveis da afirmação 3 ("país" com dois, três, quatro ou cinco vizinhos) são redutíveis? 3 , ou seja, Kempe tentou mostrar

\footnotetext{
${ }^{3}$ Não podem fazer parte de um mapa pentacromático normal mínimo.
} 
que se existe um mapa pentacromático com alguma das quatro configurações inevitáveis, então existe um mapa pentacromático "menor", ou seja, um mapa que possui menor número de "países", o qual não possui a configuração ocorrida no mapa original. Em poucas palavras, se existe um mapa pentacromático, então existe outro mapa também pentacromático menor do que ele, o que implica na inexistência de um mapa pentacromático normal mínimo. O erro na demonstração de Kempe ocorreu quando tentou demonstrar que um mapa pentacromático que possui um "país" com cinco vizinhos é redutível.

\subsection{Análise da demonstração de Kempe}

Antes de começarmos a analisar a demonstração de Alfred Bray Kempe, faremos algumas considerações sobre o uso de grafos para o estudo do Problema das Quatro Cores. Em seguida, analisaremos cada uma das afirmações da prova de Kempe, enunciadas na Seção 3.2 .

\subsubsection{Tratando mapas como grafos}

Para facilitar os estudos relacionados ao Problema das Quatro Cores, muitas vezes os mapas foram tratados como grafos. Qualquer mapa normal $M$ pode ser representado por um grafo plano, representando os pontos de interseção de fronteiras através dos vértices, e as fronteiras que ligam estes pontos através das arestas. Um exemplo de grafo representando um mapa pode ser visto na Figura 3.6 .

Figura 3.6: Representação de um mapa através de um grafo
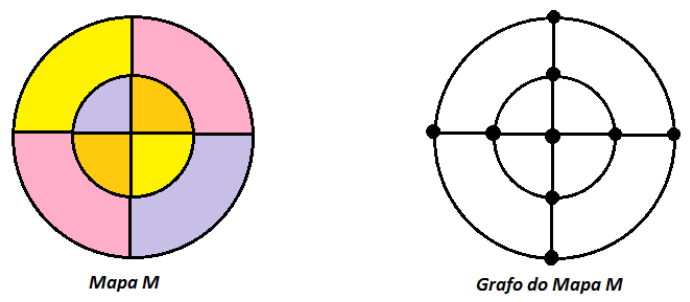

Há também outra forma de representação de mapas através de grafos, na qual os "países" do mapa são representadas pelos vértices do grafo, e uma aresta do grafo incide em dois vértices se e somente se existe uma fronteira entre os dois "países" que os vértices representam. Esse tipo de grafo é chamado grafo dual do mapa. A Figura 3.7 apresenta um exemplo de grafo dual de um mapa. 
Figura 3.7: Representação de um mapa através de um grafo dual
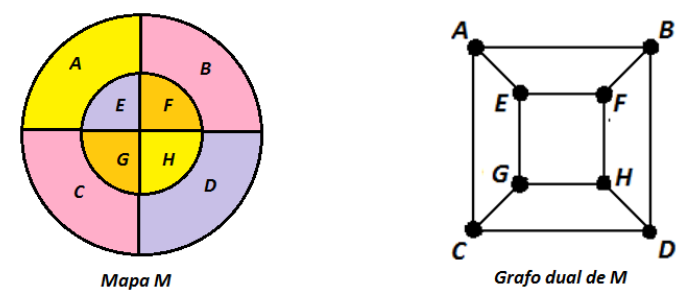

\subsubsection{Mapas normais}

Já vimos que existem mapas que necessitam de quatro cores para serem coloridos e, a partir deste conhecimento, temos a certeza de que quatro é o número mínimo de cores que permite colorir qualquer mapa. E como também já observamos, uma das formas (a usada por Kempe e a principal usada por diversos outros matemáticos) de provar o Teorema das Quatro Cores é provando a inexistência de mapas pentacromáticos.

Como existe uma grande variedade (de configurações) de mapas, para desenvolver a sua demonstração, Alfred Bray Kempe reduziu seu campo de análise, mostrando que seria suficiente provar o Teorema das Quatro Cores para os considerados mapas normais. São considerados mapas normais aqueles que:

I) não contêm nenhuma face totalmente envolvida por outra,

II) tem cada um de seus vértices de fronteira compartilhado por exatamente três faces.

A Figura 3.4 apresenta exemplos de mapas não-normais.

Vamos demonstrar que é suficiente provar o Teorema das Quatro Cores para os mapas normais. Para isto basta provarmos que:

(i) se existe um mapa pentacromático $M$ que possui uma de suas faces totalmente envolvida por outra, então também existe um mapa pentacromático normal, ou seja, um mapa que não possui nenhuma de suas faces totalmente envolvida por outra.

(ii) se existe um mapa pentacromático $M$ que possui um de seus vértices de fronteira compartilhado por mais de três faces, então também existe um mapa pentacromático normal, ou seja, um mapa que não possui nenhum de seus vértices de fronteira compartilhado por mais de três faces.

Demonstração de (i): Sendo $M$ um mapa não-normal do tipo I, em que uma face $B$ é totalmente envolvida por uma face $A$, pode-se obter um mapa normal $M^{\prime}$ a partir de $M$ excluindo 
a face $B$, como mostrado na Figura 3.8 .

Figura 3.8: Transformando um mapa não-normal em normal

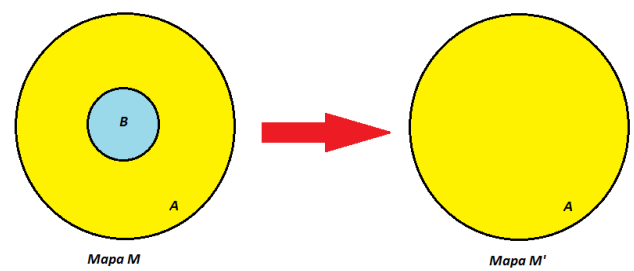

Fonte: Adaptação de (SOUSA, 2001)

Neste caso, facilmente se percebe que caso o mapa $M$ seja pentacromático, o mapa $M^{\prime}$ também o é.

Demonstração de (ii): Sendo $M$ um mapa não-normal do tipo II, no qual existe um vértice $v$ de fronteira compartilhado por mais de três faces (como ilustrado na Figura 3.9), pode-se obter um mapa normal $M^{\prime}$ a partir de $M$, incluindo uma nova face no lugar do vértice $v$.

Figura 3.9: Transformando um mapa não-normal em normal
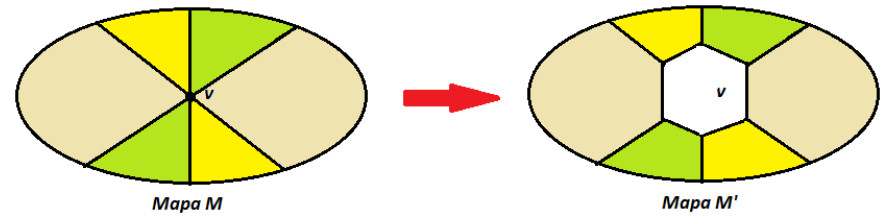

Cada face do novo mapa $M^{\prime}$ possui os mesmos vizinhos que o mapa $M$, e ainda pode ter um vizinho adicional, que é a nova face que substituiu o vértice $v$. Se $M$ é pentacromático, $M^{\prime}$ também o é.

\subsubsection{Mapa pentacromático normal mínimo}

Depois de restringir o campo de análise dos mapas para somente os mapas normais, visto que existe uma infinidade de mapas normais, Kempe sabiamente restringiu ainda mais o foco de sua análise, observando que se existe algum(ns) mapa(s) pentacromático(s), obviamente também existe pelo menos um mapa pentacromático normal mínimo, que é um mapa pentacromático que possui número de faces menor ou igual a todos os outros mapas pentacromáticos existentes. 


\subsubsection{Configurações inevitáveis}

Como já dissemos anteriormente, Kempe tentou demonstrar o Teorema das Quatro Cores por contradição e, para alcançá-la, tentou demonstrar que não existe um mapa pentacromático normal mínimo, o que por sua vez invalidaria a hipótese inicial: a existência de um mapa pentacromático, provando desta forma o Teorema das Quatro Cores. Para alcançar seu objetivo, ele encontrou uma característica existente em todo mapa normal: qualquer mapa normal possui pelo menos uma face com no máximo cinco vizinhos. Para realizarmos esta prova, faremos uso da Fórmula de Euler.

\section{A fórmula de Euler}

O Teorema de Euler, que em sua origem trata de vértices, faces e arestas de poliedros convexos, também se aplica a grafos planos conexos.

Teorema 3.1 (Teorema de Euler) Se um grafo plano e conexo tem v vértices, a arestas e $f$ faces, tal que $v \geq 1$, então:

$$
v+f-a=2
$$

Demonstração: (Prova por Indução Finita) Seja $G$ um grafo plano e conexo, com v vértices, $a$ arestas e $f$ faces, tal que $v \geq 1$. Tomemos como base de indução um grafo $G$ que possui $a$ arestas, em que $a \leq 1$, ou seja, $a=0$ ou $a=1$.

Sendo $a=0$, temos que o grafo $G$ possui um único vértice $(v=1)$, e, consequentemente, possui uma única face $(f=1)$, portanto:

$$
v+f-a=1+1-0=2 .
$$

Sendo $a=1$, como por hipótese nosso grafo é conexo e, por nossa definição de grafo, não pode haver uma aresta com pontas coincidentes (laços), temos que $G$ possui exatamente dois vértices $(v=2)$, que são as pontas da aresta. Tendo $G$ uma única aresta, consequentemente este grafo apresenta uma única face $(f=1)$, portanto:

$$
v+f-a=2+1-1=2 .
$$

Verificamos assim que a afirmação é válida para $a \leq 1$. 
Suponhamos agora que a afirmação seja válida para qualquer grafo conexo que possui número de arestas menor do que $a$, em que $a \geq 1$. Se $G$ possui $a$ arestas, temos duas situações possíveis: $G$ é uma árvore ou não.

Se o grafo $G$ é uma árvore, então $G$ possui algum vértice $v$ de grau 1 , conforme ilustrado na Figura 3.10 .

Figura 3.10: Exemplo de árvore

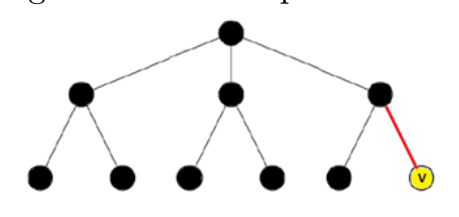

Logo, o grafo $G-v$ possui $v-1$ vértices, $a-1$ arestas e $f$ faces. Como $G-v$ possui menos do que $a$ arestas, por hipótese

$$
\begin{array}{r}
(v-1)+f-(a-1)=2 \\
\Rightarrow v+f-a=2 .
\end{array}
$$

Se o grafo $G$ não é uma árvore, então $G$ possui alguma aresta $e$ pertencente a algum circuito de $G$, conforme ilustrado na Figura 3.11

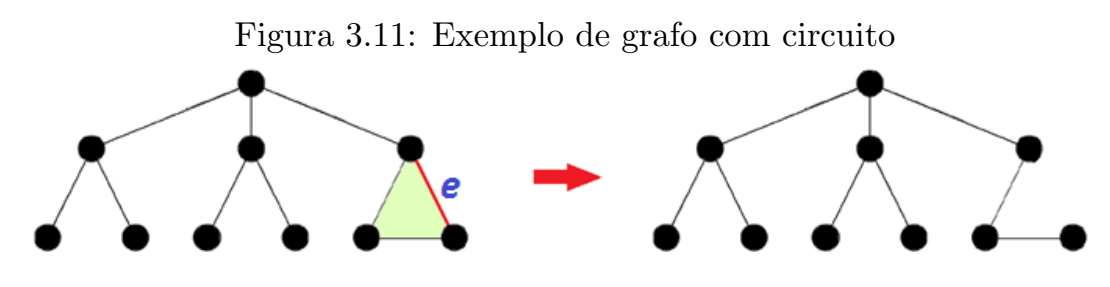

Neste caso, o grafo $G-e$ possui $v$ vértices, $a-1$ arestas e $f-1$ faces. Como $G-e$ possui menos do que $a$ arestas, por hipótese:

$$
\begin{array}{r}
v+(f-1)-(a-1)=2 \\
\Rightarrow v+f-a=2 .
\end{array}
$$

Concluímos assim que, para os dois casos possíveis ( $G$ é uma árvore, ou não é), a tese é verdadeira. Logo, por indução, provamos que para todo grafo $G$ plano e conexo, com $v$ vértices, $a$ arestas e $f$ faces, é verdade que $v+f-a=2$.

Desta forma, concluímos que a Fórmula de Euler, originalmente descoberta válida para poliedros convexos, também é válida para grafos planos, o que se torna extremamente útil para o estudo e análise do Problema das Quatro Cores. 


\section{Todo mapa tem um país com no máximo cinco vizinhos}

Voltemos agora para a análise da demonstração de Alfred Bray Kempe. Como já dissemos, Kempe buscou uma característica existente em todo o mapa, para, através dela, provar que não existe nenhum mapa pentacromático por nenhum deles possuir a característica que faz parte de todo o mapa normal. A característica existente em todo o grafo que Kempe estudou é a que é enunciada no Teorema 3.1, que relaciona um mapa com seu grafo (conforme exemplificado na Figura 3.6).

Teorema 3.1 Todo mapa tem pelo menos uma face com no máximo cinco arestas, ou seja, todo mapa tem pelo menos uma face com no máximo cinco vizinhos.

Faremos uma demonstração deste teorema utilizando como base a demonstração de (SAMPAIO, 2004, p. 10), a qual utiliza o Teorema de Euler aplicado a grafos e o fato de que em um grafo que representa um mapa (onde os pontos de intersecção de fronteiras são representados pelos vértices, e as fronteiras que ligam estes pontos são representadas pelas arestas), cada vértice tem grau maior ou igual a três, e cada aresta tem dois vértices distintos como extremidade.

Demonstração: Suponhamos um mapa com vértices $\left(w_{1}, w_{2}, \ldots, w_{v}\right), f$ faces e $a$ arestas, no qual cada vértice tem grau maior ou igual a três, e no qual cada aresta tem dois vértices distintos como extremidades, ou seja, um mapa comum, como ilustrado na Figura 3.12.

Figura 3.12

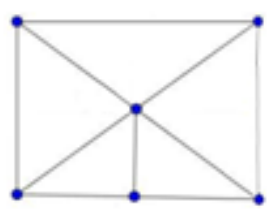

Como a soma dos graus de todos os vértices é igual ao dobro do número de arestas, então

$$
\sum_{i=1}^{v} g\left(w_{i}\right)=2 a .
$$

E como, em nosso caso, cada vértice tem grau maior ou igual a três, temos que

$$
\sum_{i=1}^{v} g\left(w_{i}\right) \geq 3 v
$$


Das equações 3.1 e 3.2 , concluímos que

$$
3 v \leq 2 a
$$

Além disso, pelo Teorema de Euler, temos que

$$
\begin{aligned}
v+f-a & =2 \\
\Rightarrow 3 v+3 f-3 a & =6 .
\end{aligned}
$$

Como $3 v \leq 2 a$, então, se trocarmos o $3 v$ por $2 a$ na última linha das equações 3.3 , teremos que

$$
\begin{array}{r}
2 a+3 f-3 a \geq 6 \\
\Rightarrow 3 f-a \geq 6 \\
\Rightarrow a \leq 3 f-6 .
\end{array}
$$

Agora, multiplicando ambos os lados da desigualdade por 2, teremos

$$
\Rightarrow 2 a \leq 6 f-12 \text {. }
$$

Sabemos que $f>0$, pois todo mapa possui pelo menos uma face. Então, dividimos ambos os lados da inequação por $f$.

$$
\Rightarrow \frac{2 a}{f} \leq 6-\frac{12}{f}
$$

Como o número de faces $f$ é sempre positivo, temos que

$$
\begin{aligned}
\frac{2 a}{f} \leq & 6-\frac{12}{f}<6 \\
& \Rightarrow \frac{2 a}{f}<6 .
\end{aligned}
$$

Considere que a face $f_{1}$ possui $a_{1}$ arestas, $f_{2}$ possui $a_{2}$ arestas, $f_{3}$ possui $a_{3}$ arestas, ...., $f_{f}$ possui $a_{f}$ arestas. Podemos calcular a média de arestas por face

$$
\frac{\left(a_{1}+a_{2}+a_{3}+\ldots+a_{f}\right)}{f} .
$$


Notemos que quando somamos as arestas de todas as faces de um mapa, acabamos somando duas vezes cada aresta, visto que cada aresta é compartilhada por exatamente duas faces. Logo

$$
a_{1}+a_{2}+a_{3}+\ldots+a_{f}=2 a .
$$

Agora, substituindo o resultado da equação (3.6) na equação (3.5), encontramos que a média de arestas por face pode ser dada por

$$
\frac{2 a}{f}
$$

Comparando a média de arestas por face dada por (3.7) com o lado esquerdo da desigualdade (3.4), vemos que é exatamente o mesmo valor. Ou seja, em um mapa qualquer, a média de arestas por face é sempre menor do que 6. Portanto, podemos concluir que pelo menos uma face de um mapa qualquer possui no máximo 5 vizinhos, ou seja, alguma face possui a configuração representada pela Figura 3.5 .

\subsubsection{Mapa pentacromático normal mínimo versus configurações inevitáveis}

A parte final da tentativa de prova de Kempe consistia em provar que não existe um mapa pentacromático normal mínimo com alguma face com no máximo cinco vizinhos (alguma face apresentando alguma das configurações ilustradas na Figura 3.5. Foi na parte final deste raciocínio que Kempe cometeu um erro, como iremos analisar mais adiante.

Lema 3.1 Um mapa pentacromático normal mínimo não pode conter uma face com dois vizinhos.

Demonstração: Supondo que exista um mapa $M$, sendo $M$ um mapa pentacromático normal mínimo, contendo uma face com dois vizinhos, como ilustrado na Figura 3.13. Podemos remover a face que possui dois vizinhos, retirando sua fronteira com uma das faces vizinhas, tornandoas uma única face, obtendo assim um novo mapa $M^{*}$, que possui uma face a menos do que $M$. Obviamente sendo, $M$ um mapa normal, o novo mapa $M^{*}$ continua sendo normal. Porém, como $M$ é pentacromático normal mínimo, então $M^{*}$ pode ser colorido com quatro cores (pois possui menos face do que o mapa pentacromático normal mínimo $M$ ). 
Figura 3.13: Configuração de 2 vizinhos é redutível

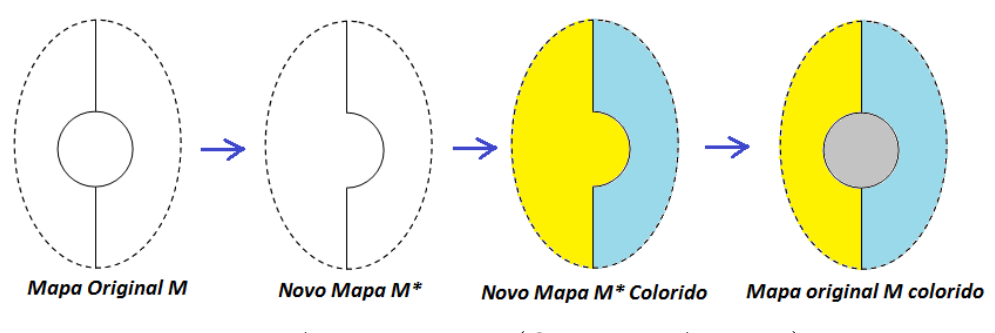

Fonte: Adaptação de (OLIVEIRA, 2010)

Sendo assim, pintamos o novo mapa $M^{*}$ com quatro cores, e em seguida devolvemos a face retirada, como ilustrado na Figura 3.13. Agora podemos escolher uma das cores restantes (diferente das cores dos vizinhos) para colorir a face restituída. Ou seja, se o mapa $M^{*}$ pode ser colorido com quatro cores, o mapa $M$ também o pode. Mas, por hipótese, $M$ é pentacromático, logo, por contradição, concluímos que um mapa pentacromático normal mínimo não pode conter uma face com dois vizinhos.

Lema 3.2 Um mapa pentacromático normal mínimo não pode conter uma face com três vizinhos.

Demonstração: Supondo que exista um mapa $M$, sendo $M$ um mapa pentacromático normal mínimo, contendo uma face com três vizinhos, podemos demonstrar que $M$ é redutível utilizando a mesma estratégia usada na demonstração feita para o caso anterior (mapa pentacromático normal mínimo contendo uma face com dois vizinhos). Primeiramente, removemos a face que possui três vizinhos, retirando a fronteira com um deles, tornando-os uma única face, como ilustrado na Figura 3.14. Desta forma, encontramos um novo mapa $M^{*}$, que possui uma face a menos do que o mapa pentacromático normal mínimo $M$. Logo, $M^{*}$ pode ser colorido com quatro cores (pois ele não pode ser pentacromático por possuir uma face a menos do que um mapa pentacromático normal mínimo).

Figura 3.14: Configuração de 3 vizinhos é redutível

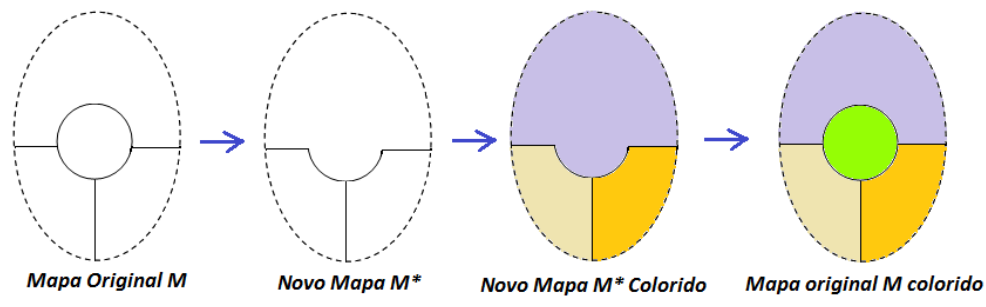

Fonte: Adaptação de (OLIVEIRA, 2010) 
Após colorir $M^{*}$ com quatro cores, podemos devolver a face retirada; em seguida verificamos que também esta pode ser colorida com alguma das quatro cores restante do mapa, pois como a face devolvida possui apenas três vizinhos, ao menos uma cor resta para poder colori-la (uma cor diferente que as dos seus três vizinhos). Logo, se $M^{*}$ pode ser colorido com quatro cores, $M$ também pode, o que representa uma contradição com a hipótese inicial de que $M$ é pentacromático. Portanto, por contradição, concluímos que um mapa pentacromático normal mínimo não pode conter uma face com três vizinhos.

Lema 3.3 Um mapa pentacromático normal mínimo não pode conter uma face com quatro vizinhos.

No caso em que um mapa pentacromático normal mínimo contém uma face com quatro (ou cinco) vizinhos, já não nos é útil a mesma estratégia de demonstração usada para as configurações anteriores (face com dois ou três vizinhos). Vejamos o porquê.

Supondo que exista um mapa pentacromático normal mínimo $M$ contendo uma face com quatro vizinhos, removemos esta face retirando a fronteira dela com uma de suas faces vizinhas, tornandoas uma única face, como ilustrado na Figura 3.15. Desta forma encontramos um novo mapa $M^{*}$ que possui uma face a menos que o mapa pentacromático normal mínimo $M, \operatorname{logo} M^{*}$ pode ser colorido com quatro cores (pois ele não pode ser pentacromático por possuir uma face a menos do que um mapa pentacromático normal mínimo).

Figura 3.15: Configuração de 4 vizinhos é redutível

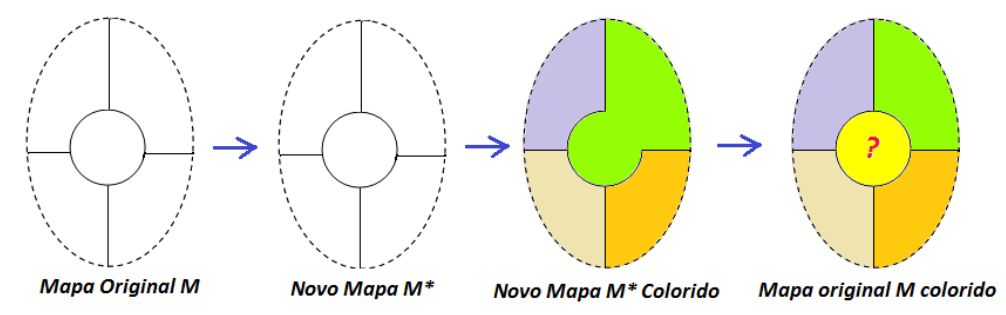

Fonte: Adaptação de (OLIVEIRA, 2010)

Após colorir $M^{*}$ com quatro cores, podemos devolver a face retirada, porém, desta vez, não temos certeza se podemos colori-la com alguma das quatro cores, porque a face devolvida possui quatro vizinhos, e cada um deles pode ter sido colorido com uma cor diferente, obrigando a face devolvida ser colorida com uma quinta cor. Desta forma, não conseguimos provar a impossibilidade de existência de um mapa pentacromático normal mínimo contendo uma face com quatro vizinhos utilizando esta estratégia. 
Para lidar com essa situação, vamos utilizar o método desenvolvido por Kempe, chamado de Cadeias de Kempe (Kempe Chains) e o seguinte Teorema 3.3.5.1 (que foi conjecturado por August De Morgan):

Teorema 3.3.5.1 Tomando-se cinco faces quaisquer de um mapa, pelo menos duas delas não são vizinhas.

Demonstração: Supondo que exista um mapa contendo um conjunto de cinco faces, em que cada uma delas faz fronteira com as demais quatro, consideremos o grafo dual deste mapa (ilustrado na Figura 3.16.

Figura 3.16: Grafo dual de um mapa com cinco faces, em que cada uma delas faz fronteira com as demais

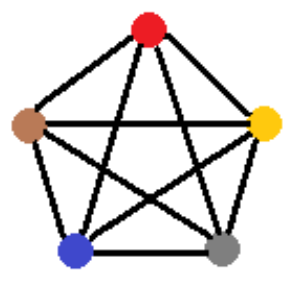

Vemos que o grafo dual é um $K_{5}$, o qual não é planar. Porém, pode-se provar que o grafo dual de um mapa é sempre planar. Logo, concluímos por absurdo que a conjectura de De Mogan estava correta: em todo mapa, tomando cinco faces, pelo menos duas delas não são vizinhas.

Definição: Chamamos de Cadeia de Kempe uma sequência de faces adjacentes coloridas adequadamente, em que cada uma delas possui uma cor, dentro de um conjunto de apenas duas cores. Em outras palavras, olhando para o grafo dual do mapa, uma Cadeia de Kempe é um caminho, em que cada vértice é colorido com uma dentre duas cores.

Tomando um grafo dual de um mapa $M$, caso exista um caminho contendo somente vértices de uma Cadeia de Kempe, e cujos extremos são os vértices representantes das faces não adjacentes verde e roxa, vizinhas de $S$, então dizemos que as referidas faces verde e roxa são conectadas através de uma Cadeia de Kempe, como ilustrado na Figura 3.17. 
Figura 3.17: Exemplo de Cadeia de Kempe

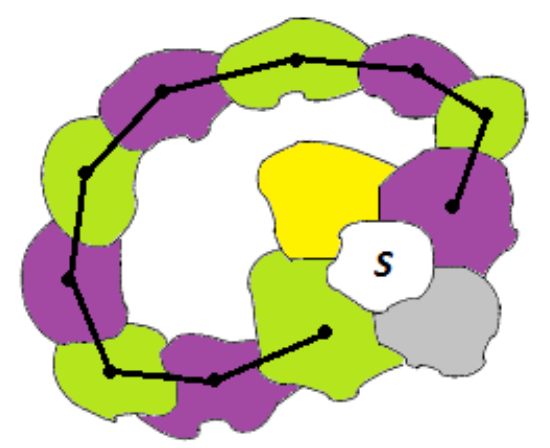

Fonte: Adaptação de (ZHANG \& CHARTRAND \& LESNIAK, 2011)

Demonstração (Lema 3.3): Após realizarmos o processo de redução do número de faces (através da eliminação da face $S$ que possui quatro vizinhos), seguido da coloração do mapa com quatro cores, e finalizando com a restituição da face retirada, como descrito anteriormente, teremos duas possibilidades com relação à face $S$ (que possui quatro vizinhos) recém-restituída:

Caso 1: A face $S$ possui duas faces vizinhas com a mesma cor.

Neste caso, foram usadas no máximo três cores distintas na coloração das faces vizinhas de $S$, restando ao menos uma das quatro cores usadas na coloração das faces de $M^{*}$, a qual pode ser utilizada na coloração da face $S$ (como ilustrado na Figura 3.18).

Figura 3.18: Configuração de 4 vizinhos é redutível

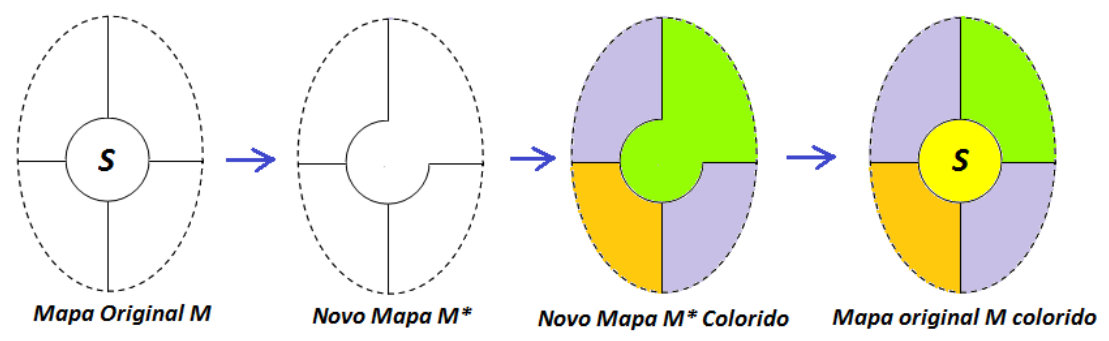

Fonte: Adaptação de (OLIVEIRA, 2010)

Logo, se $M^{*}$ pode ser colorido com quatro cores, $M$ também pode, o que representa uma contradição com a hipótese inicial de que $M$ é pentacromático. Portanto, por contradição, concluímos que um mapa pentacromático normal mínimo não pode conter uma face com quatro vizinhos, em que dois deles possuem a mesma cor. 
Caso 2: Cada uma das quatro faces vizinhas de $S$ possui cor diferente das demais.

Neste caso iremos aplicar o método das Cadeias de Kempe. Sendo $S$ a face que possui quatro vizinhos, sabemos, pelo teorema 3.3.5.1, que pelo menos dois vizinhos de $S$ não tem fronteira em comum. Escolhamos duas destas faces vizinhas de $S$ que não possuem fronteira comum entre si, e vamos supor que uma dessas faces possui cor verde $(v)$ e a outra cor roxa $(r)$.

A partir desta hipótese teremos duas situações possíveis: ou as duas faces vizinhas de $S$ não adjacentes (verde e roxa) são conectadas através de uma Cadeia de Kempe, ou não são, como exemplificado na Figura 3.19 .

Figura 3.19: Casos possiveis de Cadeia de Kempe

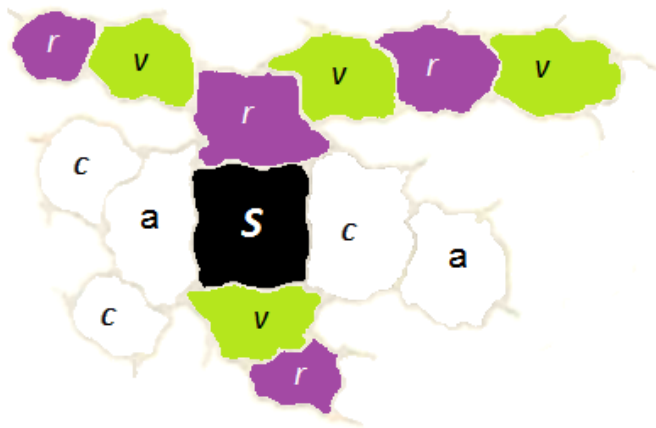

Caso 1

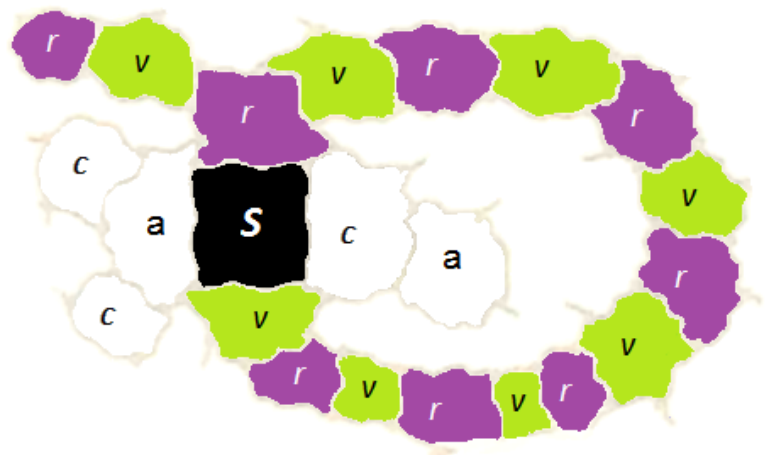

Caso 2

Fonte: Adaptação de (LEWARD, 2014)

Caso 2.1: Supondo que as duas faces não adjacentes (verde e roxa) vizinhas $S$ não são conectadas por uma Cadeia de Kempe, então podemos utilizar a seguinte estratégia para reduzir a quantidade de cores diferentes na vizinhança de $S$ : escolhemos uma das cadeias (a que se inicia com o vizinho roxo de $S$ ou a que se inicia com o vizinho verde de $S$ ), e então permutamos as cores desta cadeia (trocando as cor das faces verdes por roxo, e a cor das faces roxas por verde), como ilustrado na Figura 3.20 . 
Figura 3.20: Cadeia de Kempe (caso 2.1) - Invertendo as cores
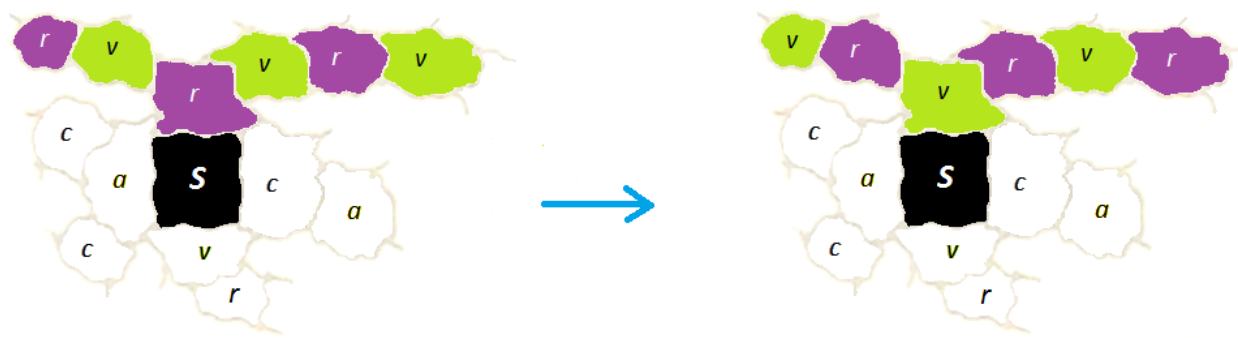

Caso 2.1

Fonte: Adaptação de (LEWARD, 2014)

Sabemos que podemos fazer esta permutação nas duas cores das faces de uma cadeia, visto que todos os vizinhos de suas faces possuem cores diferente destas duas cores. Caso contrário, estes vizinhos também fariam parte da cadeia.

Através do processo de permutação de cores das faces de uma das cadeias, como, por exemplo, da cadeia iniciada pelo vizinho verde de $S$, a face $S$ passou a ter vizinhos de apenas três cores distintas, visto que agora $S$ tem dois vizinhos com a mesma cor (verde, no nosso exemplo). Sendo assim, ainda resta uma quarta cor, com a qual podemos colorir a face $S$.

Caso 2.2: Supondo que as duas faces não adjacentes (verde e roxa) vizinhas de $S$ são conectadas por uma Cadeia de Kempe, então, neste caso, permutar as cores de todas as faces não seria útil na redução de cores distintas na vizinhança da face $S$, visto que o que aconteceria seria apenas a troca de posição das cores, pois a face vizinha verde de $S$ passaria a ser roxa, e a face vizinha roxa passaria a ser verde.

Porém, notemos que, se as duas faces não adjacentes de $S$ são conectadas por uma Cadeia de Kempe, então não pode existir outra Cadeia de Kempe entre as outras duas faces vizinhas de $S$ (observe a Figura 3.19), as quais consideraremos sendo uma delas amarela $(a)$ e a outra cinza $(c)$.

A impossibilidade das outras duas faces (amarela e cinza) vizinhas de $S$ serem conectadas por uma Cadeia de Kempe se deve ao fato de que haveria uma face comum às duas cadeias, caso contrário, uma cadeia corta a outra. Porém, não é possível existir uma face comum as duas cadeias, pois as duas cores das faces de uma das cadeias são distintas das duas cores da outra (hipotética) cadeia. 
Desta forma, podemos escolher uma das duas cadeias iniciadas em uma das duas faces vizinhas de $S$, que não são conectadas por uma cadeia (em nosso exemplo, a cadeia iniciada na face amarela, ou a cadeia iniciada na face cinza), e permutarmos as cores de suas faces, conforme ilustrado na Figura 3.21 .

Figura 3.21: Cadeia de Kempe (caso 2.2) - Invertendo as cores
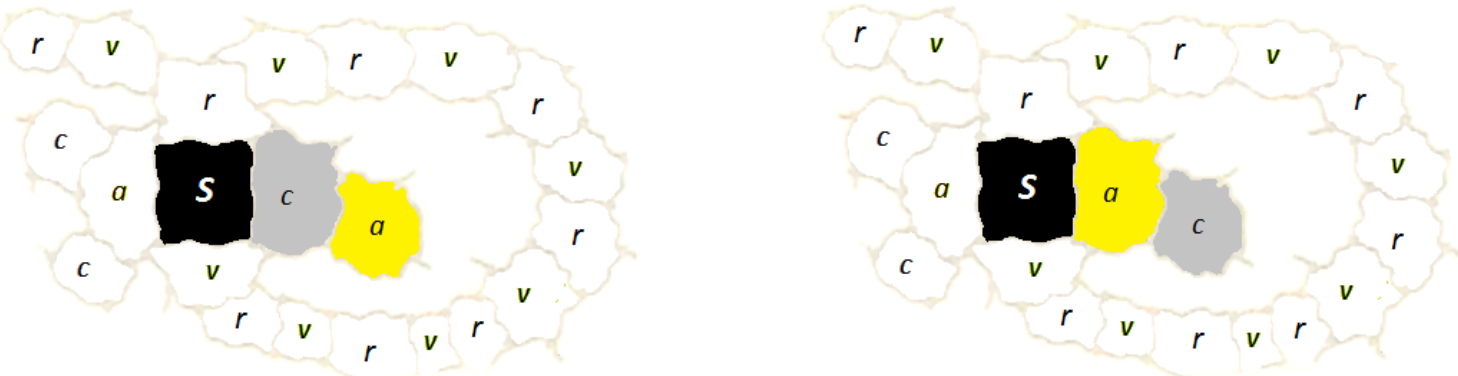

\section{Caso 2.2}

Fonte: Adaptação de (LEWARD, 2014)

No nosso exemplo acima, invertemos as cores da cadeia iniciada na face cinza (c), vizinha de $S$. Desta forma, novamente teremos que $S$ terá apenas vizinhos de três cores distintas, visto que agora $S$ tem duas faces vizinhas com a mesma cor (amarelo no nosso exemplo). Sendo assim, ainda resta uma quarta cor usada na coloração do mapa tetracromático $M^{*}$, a qual pode ser utilizada na coloração da face $S$.

Demonstramos então, com o auxílio do método das Cadeias de Kempe, que se $M^{*}$ pode ser colorido com quatro cores, $M$ também pode, o que representa uma contradição com a hipótese inicial de que $M$ é pentacromático. Portanto, por contradição, concluímos que um mapa pentacromático normal mínimo não pode conter uma face com quatro vizinhos, em que todos eles possuem cores distintas.

Por fim, após demonstrado ser impossível a existência de um mapa pentracromático normal mínimo contendo uma face com quatro vizinhos nos dois casos de coloração possíveis (quando dois vizinhos possuem a mesma cor, e quando todos os quatro vizinhos possuem cores distintas), terminamos a prova por contradição da impossibilidade da existência de um mapa pentacromático normal mínimo contendo uma face com quatro vizinhos.

O caso em que um mapa pentacromático normal mínimo contém uma face com cinco vizinhos é o último a ser analisado na prova de Kempe, e foi justamente nesta parte, quando tentou pro- 
var a impossibilidade da existência desta configuração, que Alfred Bray Kempe cometeu um erro, descoberto por Percy John Heawood, o qual apresentou um contra exemplo, que veremos mais adiante.

Lema 3.4 Um mapa pentacromático normal mínimo não pode conter uma face com cinco vizinhos.

Para demonstrar que um mapa pentacromático normal mínimo contendo uma face com cinco vizinhos não existe, dividiremos a demonstração em duas partes, aplicando a mesma estratégia já usada anteriormente para demonstrar a primeira parte, e aplicando o método das Cadeias de Kempe na demonstração da segunda parte.

Demonstração: Após realizarmos o processo de redução do número de faces (através da eliminação da face $S$ que possui cinco vizinhos), seguido da coloração do mapa com quatro cores, e finalizando com a restituição da face retirada, como descrito acima, teremos duas possibilidades com relação à face $S$ (que possui cinco vizinhos) recém-restituída:

Caso 1: A face $S$ possui dois pares de faces vizinhas com cor igual.

Neste caso, foram usadas no máximo três cores distintas na coloração das faces vizinhas de $S$, restando ao menos uma das quatro cores usadas na coloração das faces de $M^{*}$, a qual pode ser utilizada na coloração da face $S$ (como ilustrado na Figura 3.22).

Figura 3.22: Configuração de 5 vizinhos é redutível

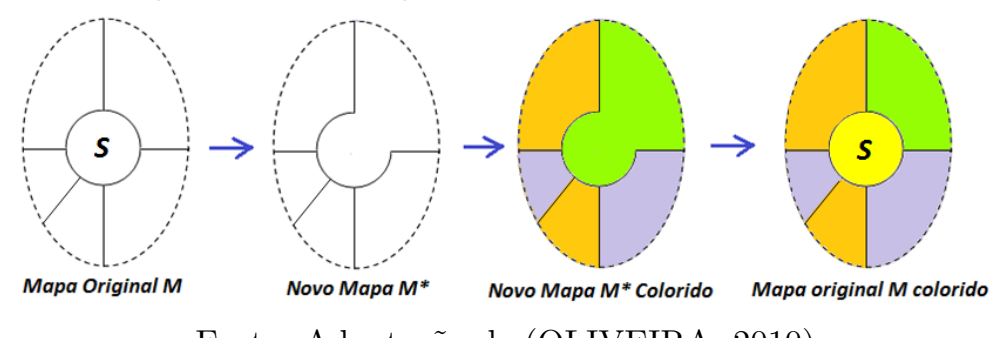

Fonte: Adaptação de (OLIVEIRA, 2010)

Logo, se $M^{*}$ pode ser colorido com quatro cores, $M$ também pode, o que representa uma contradição com a hipótese inicial de que $M$ é pentacromático. Portanto, por contradição, concluímos que um mapa pentacromático normal mínimo não pode conter uma face com cinco vizinhos, em que dois pares deles possuem a mesma cor. 
Caso 2: A face $S$ possui um par de faces vizinhas com cor igual, e outras três faces vizinhas com cores diferentes.

Neste caso iremos aplicar o método das Cadeias de Kempe. Sendo $S$ a face que possui cinco vizinhos, pelo menos dois vizinhos de $S$ possuem uma cor em comum. Vamos supor que essa cor em comum seja cinza, e também iremos supor que a face que está entre as duas faces cinzas possui cor roxa e, por fim, suponhamos que as outras duas faces vizinhas possuem cor amarela e verde. A partir desta hipótese teremos dois casos possíveis.

Caso 2.1: Somente uma (ou nenhuma) das seguintes situações ocorre:

(I) A face roxa e a face verde são conectadas através de uma Cadeia de Kempe.

(II) A face roxa e a face amarela são conectadas através de uma Cadeia de Kempe.

Caso as faces amarela e roxa, vizinhas de $S$, não estejam conectadas por uma Cadeia de Kempe, podemos permutar as cores de uma das Cadeias de Kempe iniciadas em uma dessas faces, por exemplo, a iniciada na face amarela, como ilustrado na Figura 3.23.

Figura 3.23: Configuração de 5 vizinhos é redutível
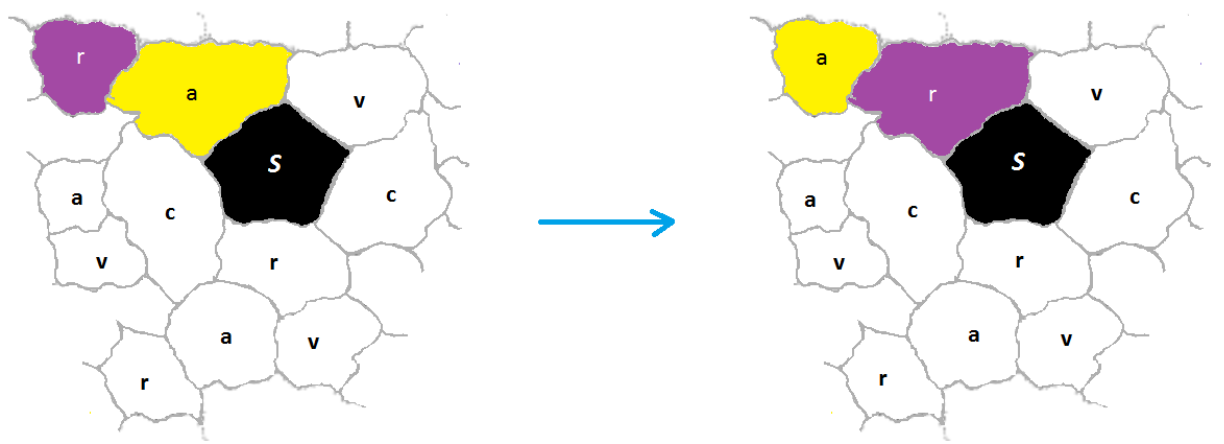

Fonte: Adaptação de (LEWARD, 2014)

Através deste processo, a face $S$ passa a ter faces vizinhas de apenas três cores distintas (roxo, verde e cinza), visto que a face amarela vizinha de $S$ passou a ser roxa. Portanto, resta-nos uma das quatro cores usadas na coloração das faces de $M^{*}$, a qual pode ser utilizada na coloração da face $S$.

Já no caso em que as faces amarela e roxa, vizinhas de $S$, são conectadas por uma Cadeia de Kempe (como ilustrado na Figura 3.24), temos que, por hipótese, as faces verde e roxa, ambas vizinhas de $S$, não são conectadas por outra Cadeia de Kempe, logo podemos permutar as cores das 
faces de uma das duas cadeias: a iniciada na face verde, vizinha de $S$, ou a iniciada na face roxa, também vizinha de $S$.

Figura 3.24: Configuração de 5 vizinhos é redutível

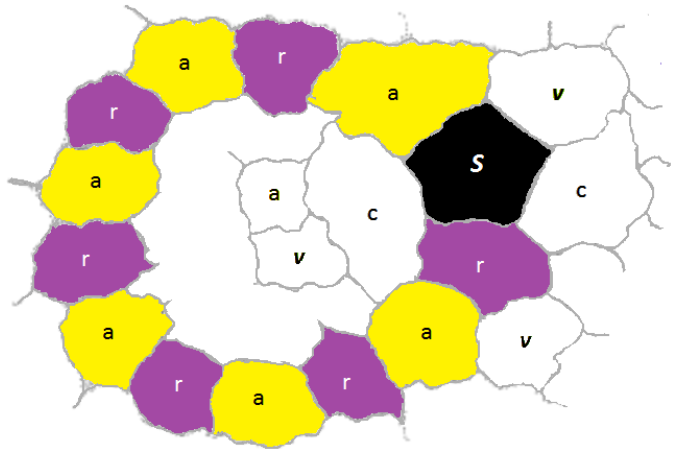

Fonte: Adaptação de (LEWARD, 2014)

Ao permutar as cores de apenas uma das cadeias iniciadas na face verde ou roxa, vizinhas de $S$, a face verde se torna roxa, e vice-versa, desta forma as duas faces vizinhas de $S$ (originalmente verde e roxa) se tornam da mesa cor. Desta forma, a face $S$ passa a ter vizinhos de exatamente três cores distintas (cinza, roxo e amarelo, no nosso exemplo), como ilustrado na Figura 3.25. Portanto, resta ao menos uma das quatro cores usadas na coloração das faces de $M^{*}$, a qual pode ser utilizada na coloração da face $S$ (como ilustrado na Figura 3.25).

Figura 3.25: Configuração de 5 vizinhos é redutível
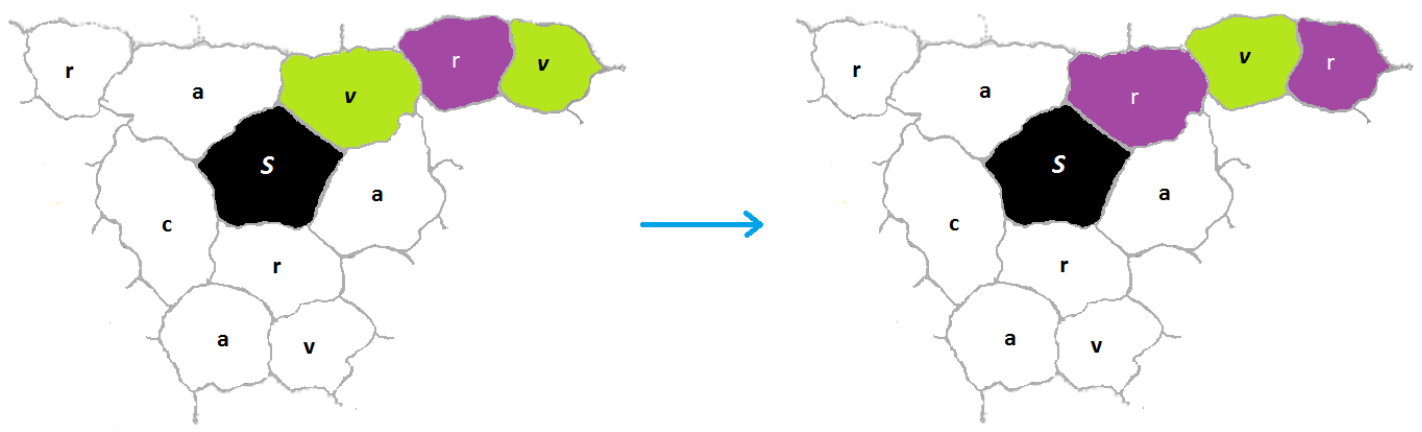

Fonte: Adaptação de (LEWARD, 2014)

Logo, se $M^{*}$ pode ser colorido com quatro cores, $M$ também pode, o que representa uma contradição com a hipótese inicial de que $M$ é pentacromático. Portanto, por contradição, concluímos que um mapa pentacromático normal mínimo com as características deste caso (2.1) não pode conter uma face com cinco vizinhos, em que dois pares deles possuem a mesma cor. 
Caso 2.2: As duas situações ocorrem:

(I) A face roxa e a face verde são conectadas através de uma Cadeia de Kempe.

(II) A face roxa e a face amarela são conectadas através de uma Cadeia de Kempe.

Chegamos agora à parte final da prova de Alfred Bray Kempe, e exatamente onde ele se equivocou e cometeu um erro. Prossigamos na análise da prova, observando a ilustração do Caso 2.2 apresentada na Figura 3.26 .

Figura 3.26: Configuração de 5 vizinhos é redutível

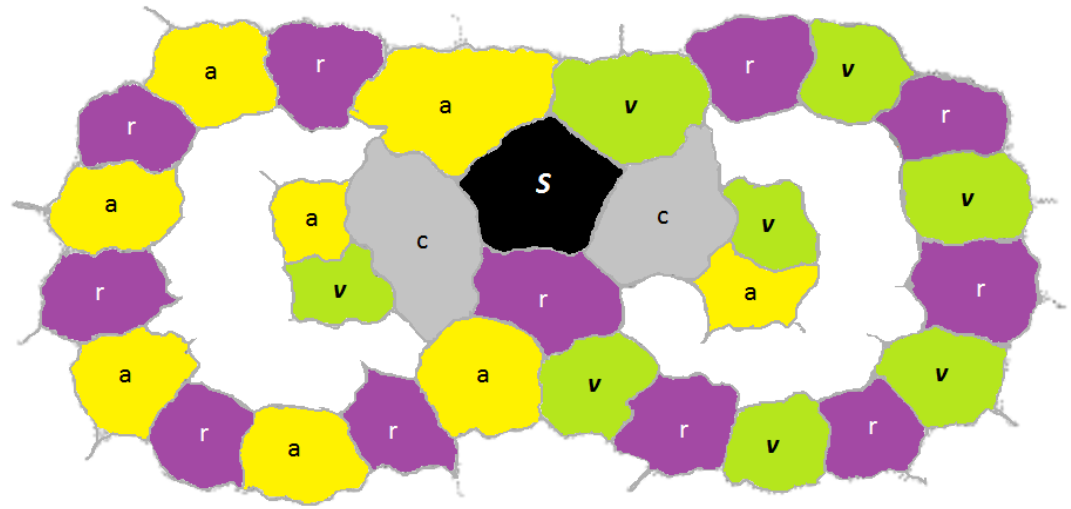

Fonte: Adaptação de (LEWARD, 2014)

Nesta última situação a se considerar, a face roxa e a face verde são conectadas através de uma Cadeia de Kempe, e também a face roxa e a face amarela são conectadas através de outra Cadeia de Kempe.

Como duas Cadeias de Kempe que não possuem cor em comum não podem se interceptar, temos que as duas faces cinzas vizinhas de $S$ não podem ser conectadas através de uma Cadeia de Kempe cinza-amarela, visto que esta seria interceptada pela cadeia verde-roxa, e também não podem ser conectadas por uma cadeia cinza-verde, porque esta seria interceptada pela cadeia roxo-amarela. Sendo assim, podemos permutar as cores da Cadeia de Kempe cinza-amarela a partir de uma das faces cinzas vizinhas de $S$, sem afetar em nada a cor da outra face cinza também vizinha de $S$, conforme ilustrado na Figura 3.27 . 
Figura 3.27: Configuração de 5 vizinhos é redutível

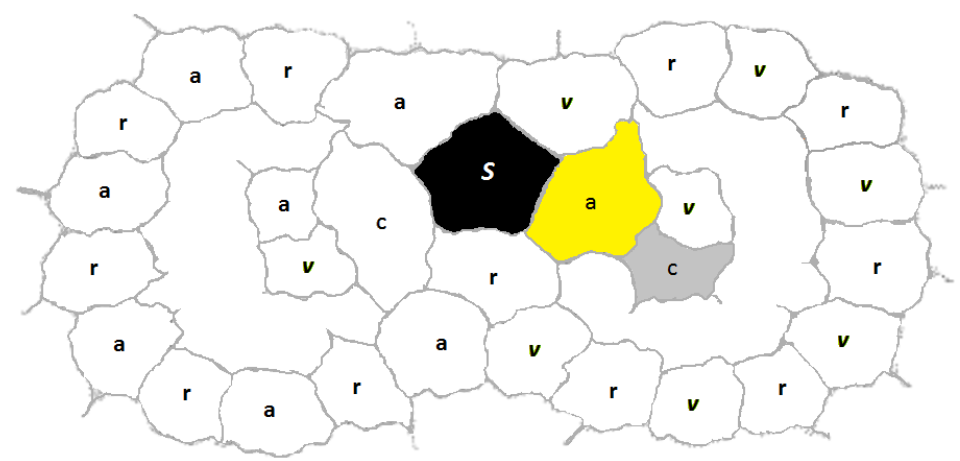

Fonte: Adaptação de (LEWARD, 2014)

E também é possível permutar as cores da Cadeia de Kempe cinza-verde a partir da outra face cinza, vizinha de $S$, sem afetar em nada a cor da primeira face cinza igualmente vizinha de $S$, conforme ilustrado na Figura 3.28 .

Figura 3.28: Configuração de 5 vizinhos é redutível

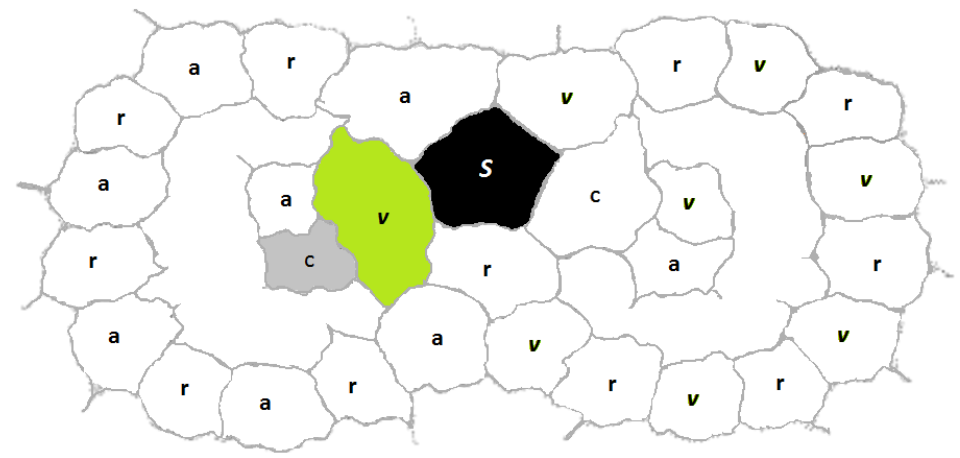

Fonte: Adaptação de (LEWARD, 2014)

Após realizarmos a permutação de cores das duas cadeias (cinza-verde e cinza-amarela) a partir das faces cinzas vizinhas da face $S$, a face $S$ passa a ter vizinhos de somente três cores distintas (amarelo, verde e roxo), como podemos ver na Figura 3.29 . 
Figura 3.29: Configuração de 5 vizinhos é redutível

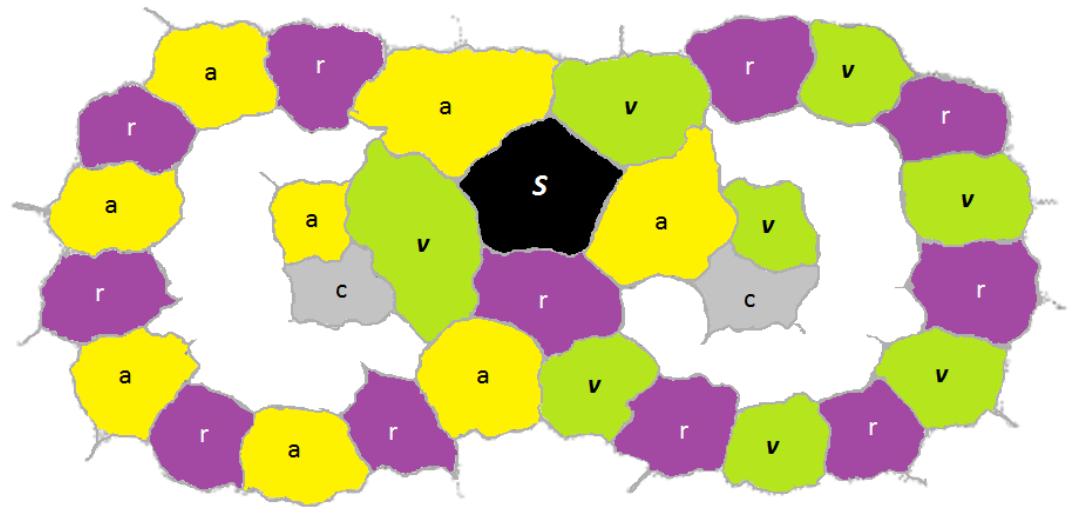

Fonte: Adaptação de (LEWARD, 2014)

Como foram usadas três cores distintas na coloração das faces vizinhas à $S$, resta ainda uma das quatro cores usadas na coloração das faces de $M^{*}$ (cinza no nosso exemplo), a qual pode ser utilizada na coloração da face $S$ (como ilustrado na Figura 3.29 .

Logo, se $M^{*}$ pode ser colorido com quatro cores, $M$ também pode, o que representa uma contradição com a hipótese inicial de que $M$ é pentacromático. Portanto, por contradição, concluímos que um mapa pentacromático normal mínimo não pode conter uma face com cinco vizinhos, em que um par de faces vizinhas possui a mesma cor, e outras três faces vizinhas possuem cores diferentes.

Por fim, após demonstrado ser impossível a existência de um mapa pentracromático normal mínimo contendo uma face com cinco vizinhos, para o Caso 1 (em que a face $S$ possui dois pares de faces vizinhas com cor igual.) e para o Caso 2 (em que a face $S$ possui um par de faces vizinhas com cor igual, e outras três faces vizinhas com cores diferentes.), finalizamos a prova do Lema 3.4 . e consequentemente a demonstração do Teorema das Quatro Cores.

Como já mencionamos várias vezes neste texto, a demonstração de Alfred Bray Kempe contém um erro, ocorrido justamente nesta última parte de sua demonstração. Analisaremos o erro de Kempe através do contraexemplo apresentado por Percy John Heawood.

\subsection{O contraexemplo de Percy John Heawood}

Percy John Heawood, após ler a prova de Alfred Bray Kempe, percebeu um grave erro em sua demonstração, e para ilustrá-lo, criou um mapa que possui uma face com cinco vizinhos, no qual, ao aplicar o processo descrito na Seção 3.3.5, fazemos com que algumas faces vizinhas sejam coloridas 
com a mesma cor, o que viola a lei inicial de que faces vizinhas só podem ser coloridas com cores distintas.

A Figura 3.30 apresenta o mapa criado e apresentado por Heawood.

Figura 3.30: Mapa criado por Heawood como contraexemplo da prova de Kempe

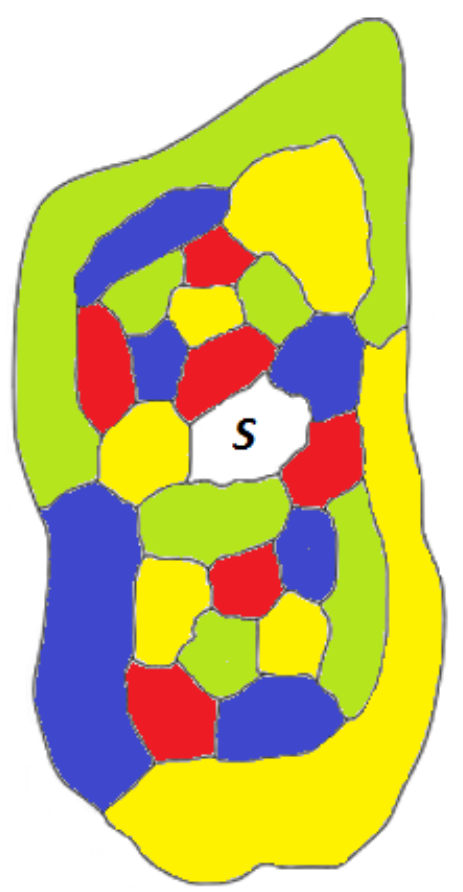

Fonte: Adaptação de (FLOOD \& RICE \& WILSON, 2011)

\subsubsection{Análise do contraexemplo de Heawood}

O mapa apresentado por Heawood possui uma face $S$ rodeada por cinco faces vizinhas, com duas delas vermelhas, uma amarela, uma verde e outra azul. Como a face azul vizinha de $S$ é a que está entre (faz fronteira com) as duas faces de mesma cor (vermelha neste caso), vizinhas de $S$, conforme a estratégia de Alfred Bray Kempe devemos verificar se a face azul está conectada através de uma Cadeia de Kempe à face amarela ou à face verde vizinhas de $S$.

Observando o mapa de Heawood, nota-se que existem as duas Cadeias de Kempe que procuramos, conforme mostrado na Figura 3.31 . 
Figura 3.31: Cadeias de Kempe no mapa de Heawood
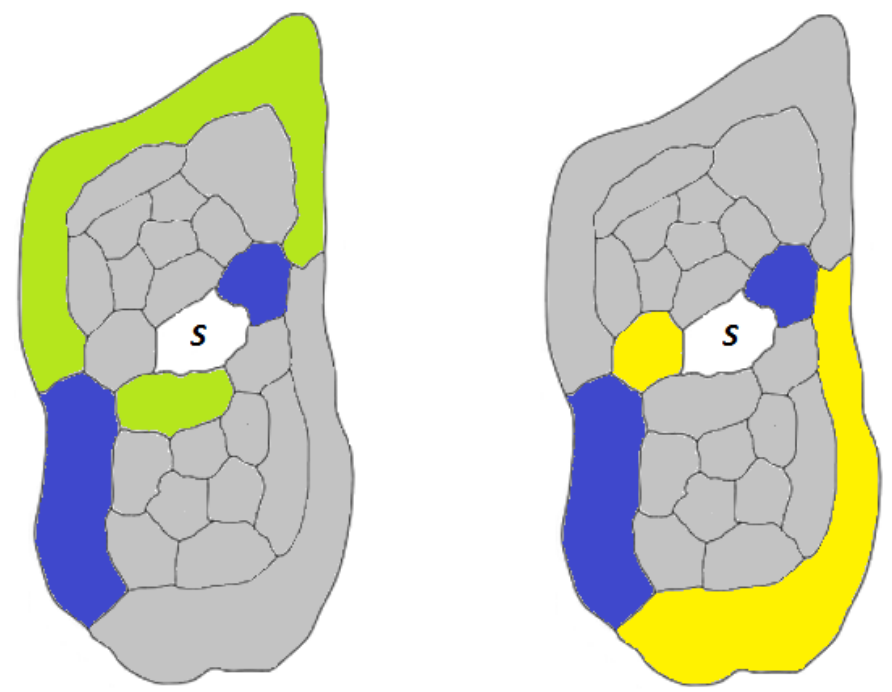

Fonte: Adaptação de (FLOOD \& RICE \& WILSON, 2011)

Como existem as duas Cadeias de Kempe que a estratégia de Kempe sugeriu investigar, segue que no mapa de Heawood não pode existir Cadeia de Kempe vermelho-amarela e vermelho-verde entre duas faces não adjacentes, vizinhas de $S$. Podemos observar na Figura 3.32 que esta afirmação de Kempe se confirma no mapa de Heawood.

Figura 3.32: Cadeias de Kempe vermelho-amarela e vermelho-verde no mapa de Heawood
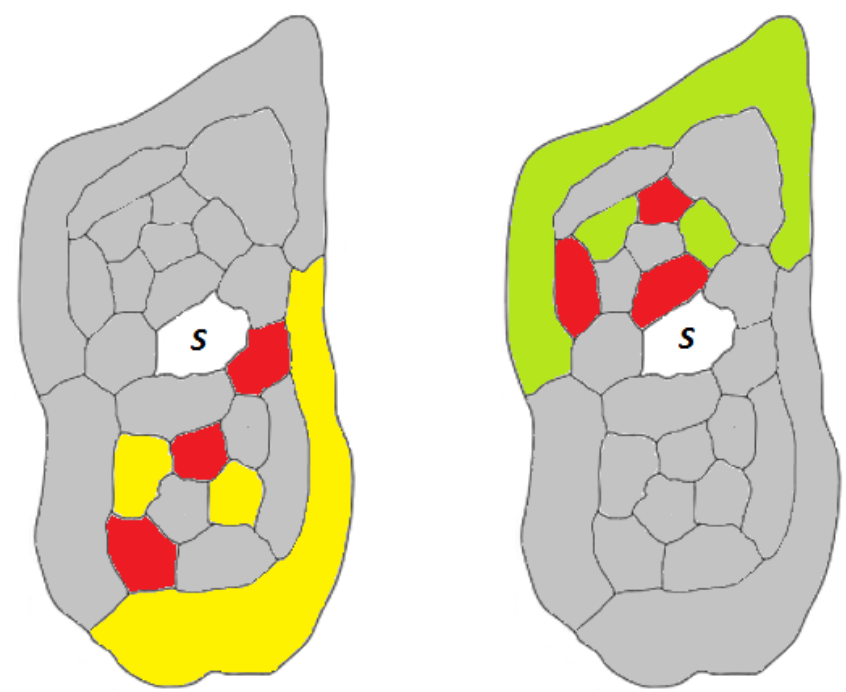

Fonte: Adaptação de (FLOOD \& RICE \& WILSON, 2011)

A última fase da demonstração de Kempe aplicada ao mapa de Heawood consiste em permutar as duas cores da Cadeia de Kempe vermelho-amarela e as duas cores da Cadeia de Kempe vermelho- 
verde destacadas na Figura 3.32 , fazendo com que a face $S$ tenha vizinhos de três cores distintas apenas, podendo desta forma utilizar uma quarta cor restante para colori-la, como podemos observar na Figura 3.33 .

Figura 3.33: Falha na estatrégia de Kempe ao aplicá-la no mapa de Heawood

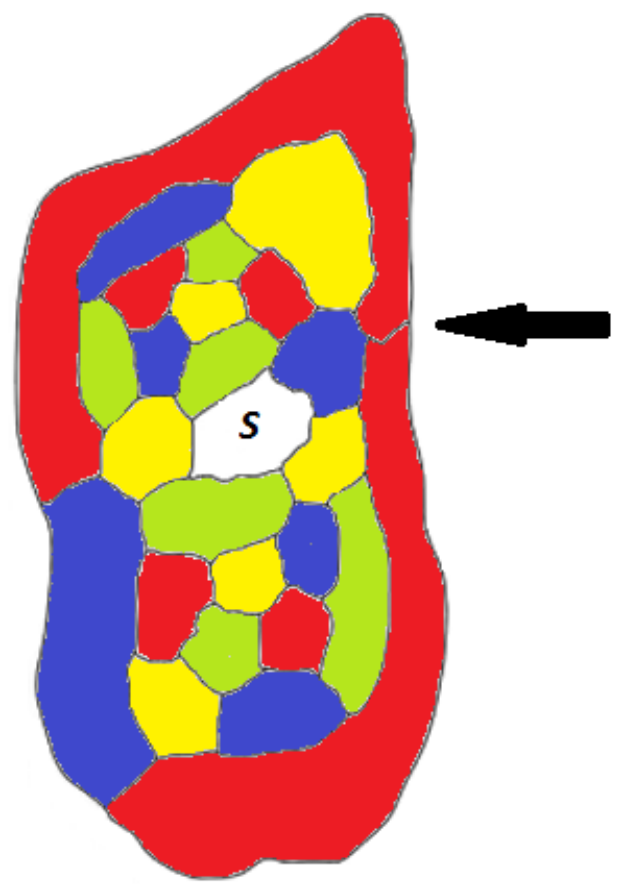

Fonte: Adaptação de (FLOOD \& RICE \& WILSON, 2011)

Veja, porém que, ao aplicarmos a permutação de cores sugerida por Kempe, temos que duas faces vizinhas passam a ter a mesma cor, o que viola a regra de coloração de mapas. Desta forma, a estratégia de Alfred Bray Kempe não funciona com o mapa de Heawood (e com outros mapas também).

É importante destarcarmos que o contraexemplo de Heawood foi uma forma de mostrar que a estratégia de demonstração de Kempe não é válida para provar o Teorema das Quatro Cores, mas não que o teorema em si não é válido. Tanto é que é possivel colorir o mapa de Heawood com apenas quatro cores, sem que faces vizinhas fiquem com a mesma cor, como podemos observar na Figura 3.34 . 
Figura 3.34: Mapa de Heawood colorido com quatro cores

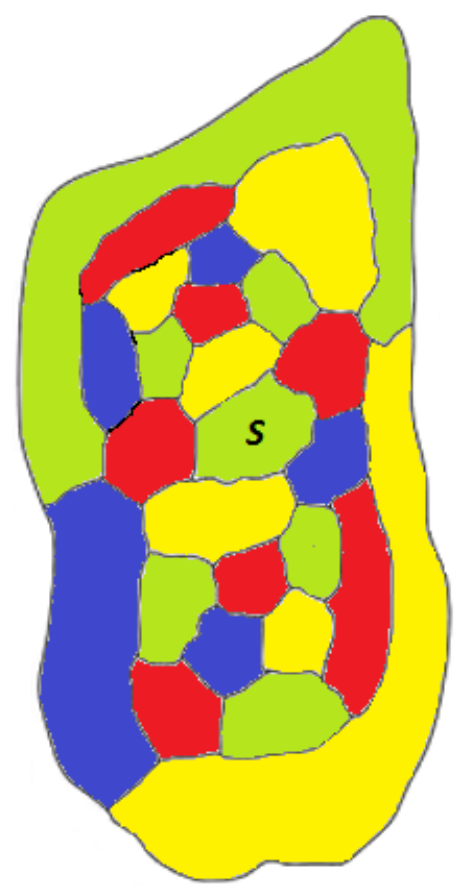

Fonte: Adaptação de (FLOOD \& RICE \& WILSON, 2011)

O erro na estratégia de Kempe aconteceu quando ele afirmou que podia fazer a permutação das cores de duas Cadeias de Kempe simultaneamente, sem que houvesse conflito de cores. Percy John Heawood criou um mapa para mostrar que nem sempre isso é possível. Essa troca de cores usada na estratégia de Kempe é possível quando realizadas em uma única cadeia, porém não é garantida quando feita em duas cadeias simultaneamente.

O mapa de Percy John Heawood foi publicado em 1890, e com isso ressurgiu a investigação e curiosidade sobre o Problema das Quatro Cores.

Apesar do erro cometido por Afred Bray Kempe em sua tentativa de demonstração do Teorema das Quatro Cores, Percy John Heawood aproveitou boa parte de sua estratégia, para demonstrar o Teorema das Cinco Cores (cinco cores são suficientes para colorir qualquer mapa).

\subsubsection{O Teorema das Cinco Cores}

Teorema 3.4.2.1 Todo mapa no plano pode ser colorido com cinco cores ou menos.

Para provar este teorema, usaremos a estratégia de supor que existe um mapa hexacromático, e a partir disto, encontrar um absurdo, invalidando assim esta hipótese inicial. 
Sabemos que, caso exista um mapa hexacromático, também existe um mapa hexacromático normal mínimo. Sabemos também, por meio do Teorema 3.3.5.1, que todo mapa possui uma face com até cinco vizinhos. Vamos provar que um mapa hexacromático normal mínimo não pode conter uma face que possui até cinco vizinhos.

Supondo que exista um mapa $M$, sendo $M$ um mapa hexacromático normal mínimo, pelo menos uma de suas faces terá dois, três, quatro ou cinco vizinhos, como ilustrado na Figura 3.5 .

Vamos analisar primeiramente o caso em que uma das faces de $M$ possui dois, três ou quatro vizinhos, e após isso, analisaremos o caso em que uma das faces de $M$ possui cinco vizinhos.

Lema 3.5 Um mapa hexacromático normal mínimo não pode conter uma face com dois, três ou quatro vizinhos.

Demonstração: Podemos remover a face que possui dois, três ou quatro vinhos, retirando sua fronteira com uma das faces vizinhas, tornando-as uma única face, obtendo assim um novo mapa $M^{*}$, que possui uma face a menos do que $M$. Obviamente, sendo $M$ um mapa normal, o novo mapa $M^{*}$ também é normal, porém, como $M$ é hexacromático normal mínimo, $M^{*}$ pode ser colorido com cinco cores (pois possui menor número de faces que o mapa hexacromático normal mínimo $M$ ).

Sendo assim, pintamos o novo mapa $M^{*}$ com cinco cores, e em seguida devolvemos a face retirada, como ilustrado nas Figuras 3.13 e 3.14 (para mapas contendo uma face com dois e três vizinhos respectivamente) e na Figura 3.35 (para mapas contendo uma face com quatro vizinhos).

Figura 3.35: Configuração de 4 vizinhos é redutível em um mapa hexacromático

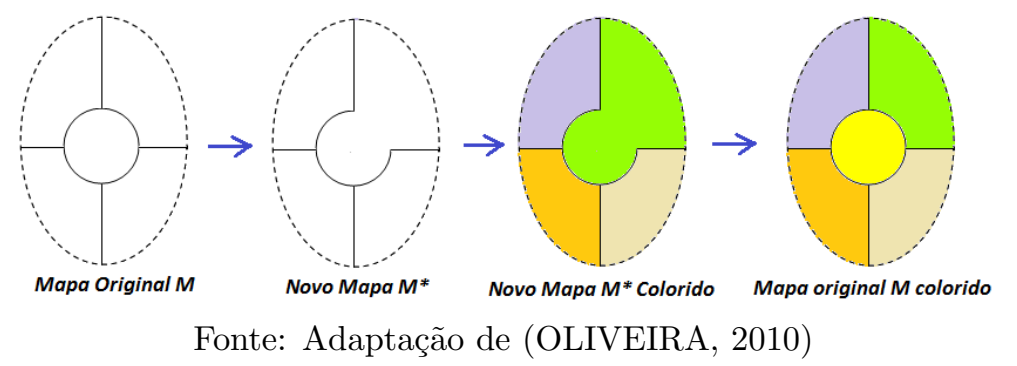

Feito isso, podemos agora escolher uma das cores restantes (diferente das cores dos vizinhos) para colorir a face restituída. Ou seja, se o mapa $M^{*}$ pode ser colorido com cinco cores, o mapa $M$ também o pode, mas por hipótese $M$ é hexacromático. Logo, por contradição, concluímos que um mapa hexacromático normal mínimo não pode conter uma face com dois, três ou quatro vizinhos. 
Lema 3.6 Um mapa hexacromático normal mínimo não pode conter uma face com cinco vizinhos.

Para demonstrar que um mapa hexacromático normal mínimo contendo uma face com cinco vizinhos não existe, dividiremos a demonstração em duas partes. Aplicaremos a mesma estratégia já usada anteriormente para demonstrar a primeira parte, em seguida aplicaremos o método das Cadeias de Kempe na demonstração da segunda parte.

Demonstração: Podemos seguir a mesma linha de raciocínio explicada anteriormente, realizando no mapa um processo de redução do número de faces (através da eliminação da face $S$ que possui cinco vizinhos), seguido da coloração do mapa com cinco cores, e finalizando com a restituição da face retirada. Desta forma teremos duas possibilidades com relação à face $S$ (que possui cinco vizinhos) recém-restituída.

Caso 1: A face $S$ possui duas faces vizinhas com a mesma cor.

Neste caso foram usadas no máximo quatro cores distintas na coloração das faces vizinhas de $S$, restando ao menos uma das cinco cores usadas na coloração das faces de $M^{*}$, a qual pode ser utilizada na coloração da face $S$ (como ilustrado na Figura 3.36.

Figura 3.36: Configuração de 5 vizinhos é redutível em um mapa hexacromático

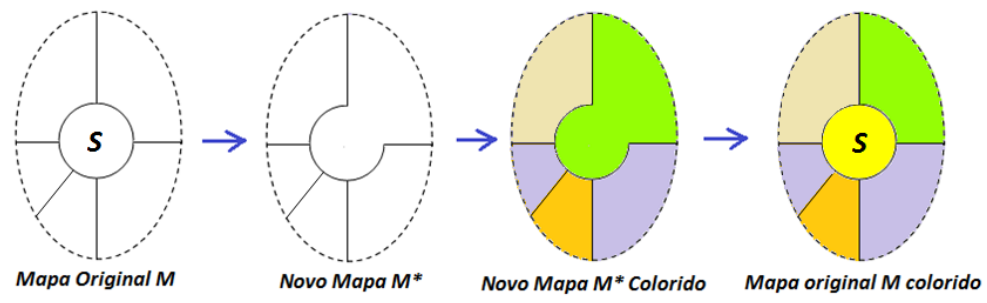

Fonte: Adaptação de (OLIVEIRA, 2010)

Logo, se $M^{*}$ pode ser colorido com cinco cores, $M$ também pode, o que representa uma contradição com a hipótese inicial de que $M$ é hexacromático. Portanto, por contradição, concluímos que um mapa hexacromático normal mínimo não pode conter uma face com cinco vizinhos, em que dois deles possuem a mesma cor.

Caso 2: Cada uma das cinco faces vizinhas de $S$ possui cor diferente das demais.

Neste caso iremos aplicar o método das Cadeias de Kempe. Sendo $S$ a face que possui cinco vizinhos, sabemos, por meio do Teorema 3.3.5.1, que pelo menos dois vizinhos de $S$ não tem fronteira em comum. Escolhamos duas destas faces vizinhas de $S$ que não possuem fronteira entre si, e 
suponhamos que uma dessas faces possui cor verde $(v)$ e a outra cor roxa $(r)$.

A partir desta hipótese teremos duas situações possíveis: ou as duas faces não adjacentes (verde e roxa), vizinhas de $S$, são conectadas através de uma Cadeia de Kempe, ou não são. Podemos ver uma ilustração dos dois possíveis casos na Figura 3.37.

Figura 3.37: Não existe / existe uma Cadeia de Kempe entre as faces verde (v) e roxa (r), vizinhas de S
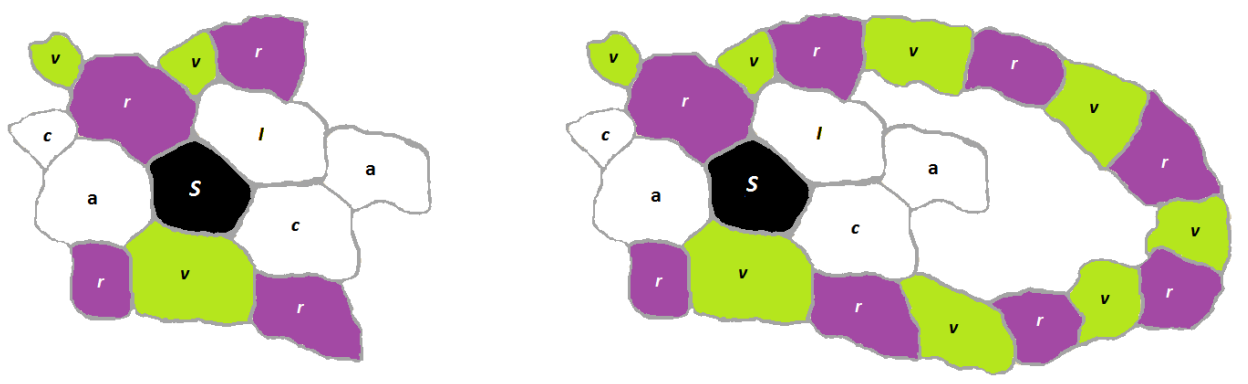

Fonte: Adaptação de (LEWARD, 2014)

Caso 2.1 : Supondo que as duas faces consideradas não são conectadas por uma Cadeia de Kempe, então podemos utilizar a seguinte estratégia para reduzir a quantidade de cores diferentes na vizinhança de $S$ : escolhemos uma das cadeias mencionadas (a que se inicia com o vizinho roxo de $S$, ou a que se inicia com o vizinho verde de $S$ ), e então permutamos as cores dela (trocando a cor das faces verdes por roxo, e a cor das faces roxas por verde), como ilustrado na Figura 3.38 .

Figura 3.38: Não existe uma Cadeia de Kempe entre as faces verde $(v)$ e roxa $(r)$, vizinhas de $S$
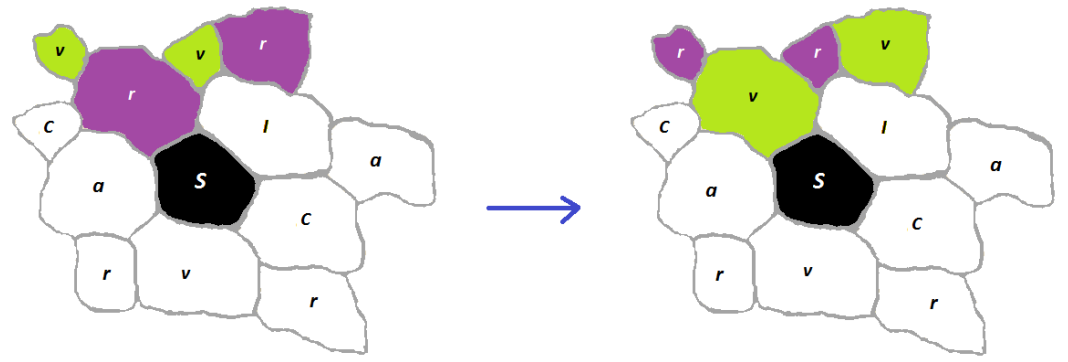

Fonte: Adaptação de (LEWARD, 2014)

Sabemos que podemos fazer a permutação das duas cores das faces de uma cadeia porque todos os vizinhos de suas faces possuem cores diferente daquelas usadas na cadeia, caso contrário, estes vizinhos também fariam parte da cadeia.

Através do processo de permutação de cores das faces de uma das cadeias, como, por exemplo, da cadeia verde-roxo iniciada pelo vizinho roxo $(r)$ de $S$ (Figura 3.38), a face $S$ passou a ter vizinhos 
de apenas quatro cores distintas, visto que agora $S$ tem duas faces vizinhas com a mesma cor (verde no nosso exemplo). Sendo assim, ainda resta uma quinta cor, com a qual podemos colorir a face $S$.

Logo, se $M^{*}$ pode ser colorido com cinco cores, $M$ também pode, o que representa uma contradição com a hipótese inicial de que $M$ é hexacromático. Portanto, por contradição, concluímos que um mapa hexacromático normal mínimo não pode conter uma face com cinco vizinhos, dos quais dois deles (não adjacentes entre si) não são conectados por uma Cadeia de Kempe.

Caso 2.2: Supondo que as duas faces consideradas são conectadas por uma Cadeia de Kempe, então, neste caso, permutar as cores de todas as faces da cadeia não seria útil na redução de cores distintas na vizinhança da face $S$, visto que o que aconteceria seria apenas a troca de posição das cores, pois a face vizinha verde de $S$ passaria a ser roxa, e a face vizinha roxa passaria a ser verde.

Porém, notemos que, se duas faces não adjacentes, porém ambas vizinhas de $S$, são conectadas por uma Cadeia de Kempe, então não pode existir outra Cadeia de Kempe entre outras duas faces não adjacentes, vizinhas de $S$ (observe o mapa da direita na Figura 3.37). Para ficar claro, selecionemos duas destas outras faces não adjacentes, vizinhas de $S$, e consideremos sendo uma delas amarela $(a)$ e a outra cinza $(c)$. Necessariamente, uma das faces selecionadas de $S$ é interna à Cadeia de Kempe (roxo-verde) existente, e a outra, externa. Isso resulta na impossibilidade delas serem ligadas por uma Cadeia de Kempe, pois haveria uma face comum às duas cadeias, caso contrário, uma cadeia cortaria a outra. Porém, não é possível existir uma face comum às duas cadeias, pois as duas cores das faces de uma das Cadeias de Kempe são distintas das duas cores da outra (hipotética) cadeia.

Desta forma, podemos escolher uma das duas cadeias iniciadas em uma das duas faces vizinhas de $S$, que não são conectadas por uma Cadeia de Kempe (em nosso exemplo, a cadeia iniciada na face amarela, ou a cadeia iniciada na face cinza), e permutarmos as cores de suas faces. No exemplo ilustrado na Figura 3.39 permutamos as cores da cadeia iniciada na face cinza. 
Figura 3.39: Existe uma Cadeia de Kempe entre as faces verde $(v)$ e roxa $(r)$, vizinhas de $S$

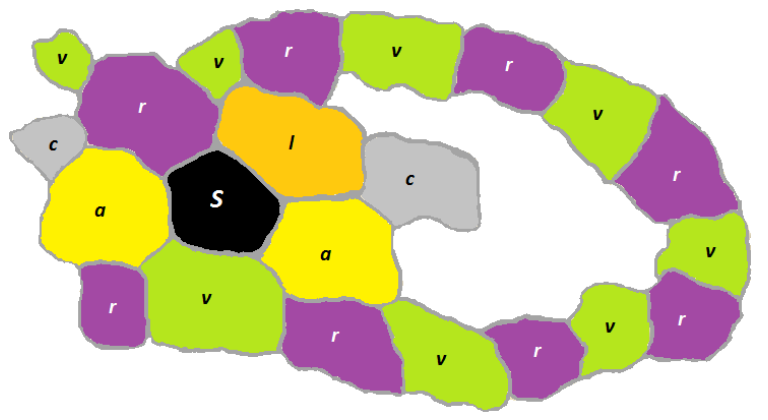

Fonte: Adaptação de (LEWARD, 2014)

Através do processo de permutação de cores das faces de uma das Cadeias de Kempe, como fizemos no exemplo anterior, a face $S$ passa a ter vizinhos de apenas quatro cores distintas, pois agora $S$ tem dois vizinhos com a mesma cor (amarela no nosso exemplo). Sendo assim, ainda resta uma quinta cor usada na coloração do mapa pentacromático $M^{*}$, com a qual podemos colorir a face $S$.

Demonstramos então, com o auxílio do método das Cadeias de Kempe, que se $M^{*}$ pode ser colorido com cinco cores, $M$ também pode, o que representa uma contradição com a hipótese inicial de que $M$ é hexacromático. Portanto, por contradição, concluímos que um mapa hexacromático normal mínimo não pode conter uma face com cinco vizinhos, dos quais dois deles são conectados por uma Cadeia de Kempe.

Por fim, após demonstrado ser impossível a existência de um mapa hexacromático normal mínimo contendo uma face com cinco vizinhos, nos dois casos de coloração possíveis (quando dois vizinhos possuem a mesma cor, e quando todos os cinco vizinhos possuem cores distintas), terminamos a prova por contradição da impossibilidade da existência de um mapa hexacromático normal mínimo contendo uma face com cinco vizinhos. Portanto, está provado o Teorema das Cinco Cores de Percy John Heawood (ou, mais corretamente, de Alfred Bray Kempe).

\subsection{Avanços nos estudos do Problema das Quatro Cores}

Após Percy John Heawood refutar a demonstração de Alfred Bray Kempe, ficou claro que a demonstração do Teorema das Quatro Cores provavelmente não seria tão simples quanto parecia. Entretanto, no decorrer dos anos, várias tentativas foram feitas neste caminho, e alguns avanços foram alcançados. 


\subsubsection{Demonstrações do teorema para um número limitado de faces}

No decorrer dos anos, algumas pessoas conseguiram demonstrar a validade do Teorema das Quatro

Cores para mapas com uma quantidade limitada de faces, como pode ser visto na Tabela 3.1 .

Tabela 3.1: Avanços na busca da demonstração do Teorema das Quatro Cores

\begin{tabular}{|l|c|c|}
\hline Ano & Autor(es) & Número de faces \\
\hline 1920 & Philip Franklin & 25 \\
1926 & C. N. Reynolds & 27 \\
1936 & Philip Franklin & 31 \\
1938 & C. E. Winn & 35 \\
1968 & Oystein Ore e Joel Stemple & 40 \\
\hline
\end{tabular}

Fonte: (SOUSA, 2001)

Estas demonstrações, embora não fossem tão importantes quanto seria a demonstração da validade do teorema para qualquer mapa, foram importantes como indicativo de que realmente o teorema era verdadeiro, e assim os matemáticos puderam seguir no caminho certo, buscando uma demonstração da validade do teorema, evitando o desperdício de tempo em buscar provar a invalidade do mesmo.

\subsubsection{O Jogo Icosiano}

Uma outra linha de pesquisa do Problema das Quatro Cores foi inspirada por um jogo chamado Jogo Icosiano, criado em 1856 por um matemático chamado William Rowan Hamilton. O objetivo de uma das versões deste jogo é, em resumo, percorrer as aretas de um determinado grafo, passando uma e somente uma única vez por cada um de seus vértices (fazer um circuito).

O grafo do Jogo Icosiano possui forma equivalente a uma projeção de um dodecaedro no plano, em que uma das faces do poliedro é representada pela face ilimitada do plano do grafo, como representado na Figura 3.40 . 
Figura 3.40: Dodecaedro e o grafo do Jogo Icosiano
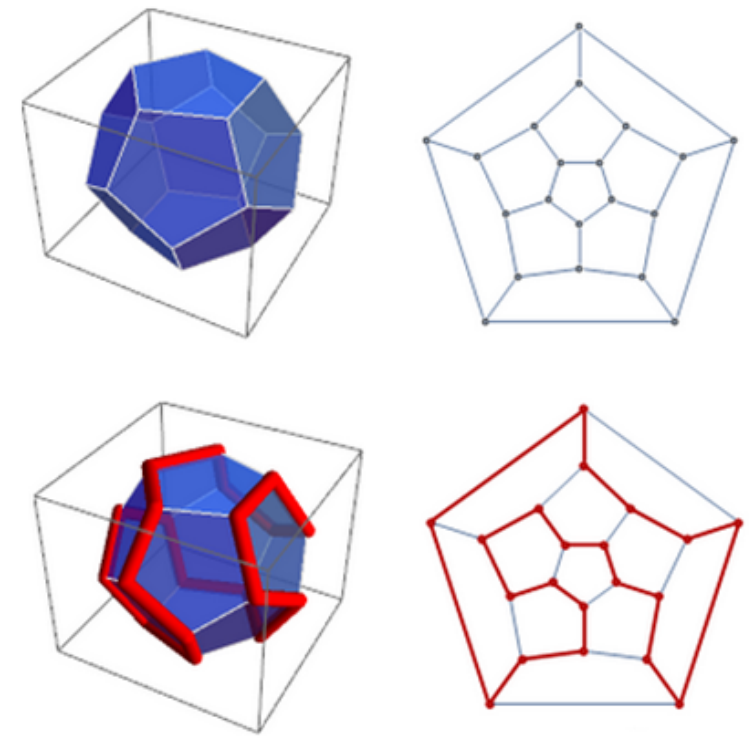

Fonte: HTTP://WWw.WOLFRAM.COM/MATHEMATICA/NEW-IN-8/GRAPH-AND-NETWORK-ANALYSIS/SOLVEthe-ICosian-Game.PT-BR.html. Acesso em: 21 nov. 2015.

Um circuito que passa por todos os vértices de um grafo é chamado circuito hamiltoniano. A importância deste tipo de circuito no estudo do Problema das Quatro Cores é apresentado pelo Lema 3.7 .

Lema 3.7 Se o grafo de um mapa (em que os vértices representam os pontos de intersecção de fronteiras, e as arestas representam as fronteiras que ligam estes pontos) permite a presença de um circuito hamiltoniano, então este mesmo mapa pode ser colorido com apenas quatro cores.

Demonstração: O circuito hamiltoniano em um grafo planar divide o plano em duas regiões, sendo uma delas interna ao circuito e a outra externa, conforme ilustrado na Figura 3.41.

Figura 3.41: Circuito Hamiltoniano

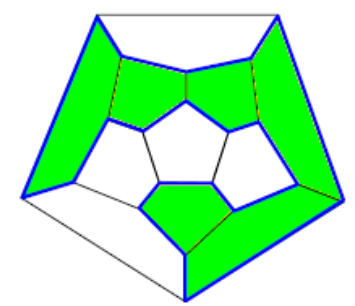

Fonte: Adaptação de (SAMPAIO, 2004)

Consideremos as faces que estão na região interna do circuito. Agora, desenhando o grafo dual $G$ deste mapa (veja a imagem esquerda da Figura 3.42), sabemos que este grafo é uma árvore, 
pois, supondo existisse um circuito, significaria haver vértices do grafo original sendo visitados duas vezes, o que não é permitido em um circuito hamiltoniano, ou seja, chegaríamos a uma contradição. Portanto, o grafo dual $G$ do mapa das faces internas ao circuito hamiltoniano é uma árvore.

Figura 3.42: Grafo dual - faces internas / Grafo dual - faces externas

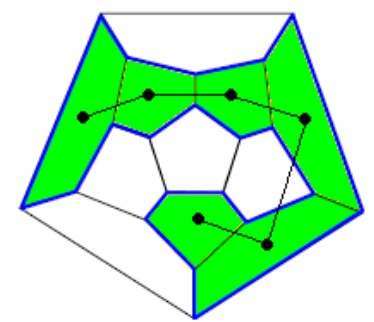

Grafo dual G - faces Internas

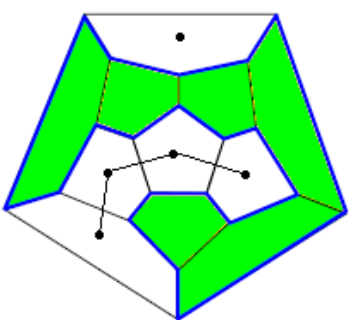

Grafo dual $G^{\prime}$ - faces externas

Fonte: Adaptação de (SAMPAIO, 2004)

Como o grafo $G$ é uma árvore, podemos colorir todos os seus vértices utilizando apenas duas cores $\left(c_{1}\right.$ e $\left.c_{2}\right)$ através da seguinte estratégia: colorindo o vértice inicial $v_{1}$ com a cor $c_{1}$, em seguida, colorindo todos os vértices $\left(v_{2}, \ldots, v_{n}\right)$ adjacentes a $v_{1}$ com a cor $c_{2}$, continuando colorindo todos os vértices adjacentes a $\left(v_{2}, \ldots, v_{n}\right)$ utilizando novamente a cor $c_{1}$, e assim sucessivamente, sempre revezando as duas cores $c_{1}$ e $c_{2}$, até que todos os vértices sejam coloridos. Como os vértices do grafo dual $G$ do mapa das faces internas ao circuito hamiltoniano podem ser coloridos com apenas duas cores, as faces internas ao circuito hamiltoniano também podem, conforme ilustrado na Figura 3.43.

Figura 3.43: Grafo dual - vértices coloridos / Mapa das faces internas coloridas

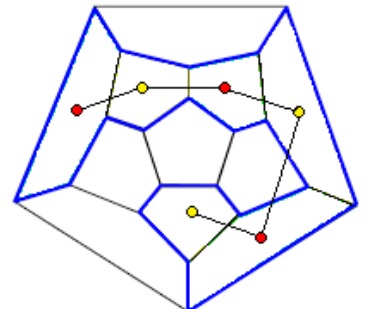

Grafo dual G - Vértices Coloridos

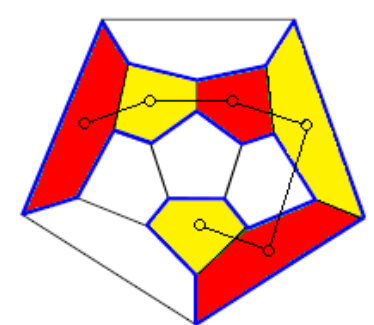

Faces Internas Coloridas

Fonte: Adaptação de (SAMPAIO, 2004)

Analogamente, o grafo dual $G^{\prime}$ do mapa das faces externas ao circuito hamiltoniano pode ser colorido com apenas duas cores $\left(c_{3}\right.$ e $\left.c_{4}\right)$. Podemos fazer isso colorindo cada componente do grafo $G^{\prime}$ aplicando a mesma estratégia utilizada anteriormente, conforme ilustrado na Figura 3.44 . 
Figura 3.44: Grafo dual - vértices coloridos / Mapa das faces externas coloridas

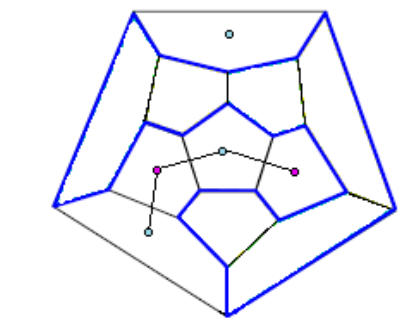

Grafo dual G - Vértices Coloridos

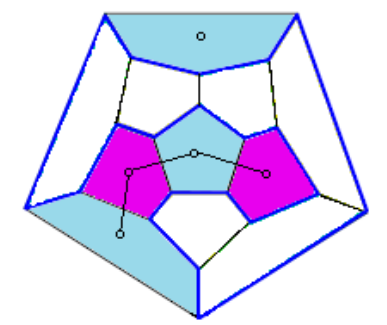

Faces Internas Coloridas

Fonte: Adaptação de (SAMPAIO, 2004)

Logo, todos os vértices do grafo dual do mapa (completo) podem ser coloridos com apenas quatro cores $\left(c_{1}, c_{2}, c_{3}\right.$ e $\left.c_{4}\right)$. Portanto, como todo grafo de mapa é planar, se um grafo de um mapa permite um circuito hamiltoniano, então este mesmo mapa pode ser colorido com apenas quatro cores, conforme ilustrado na Figura 3.45 .

Figura 3.45: Grafo contendo circuito hamiltoniano, colorido com quatro cores

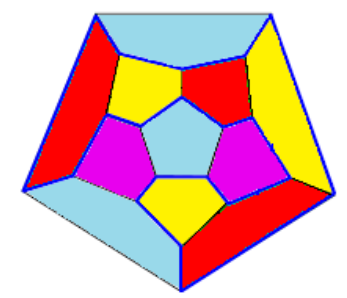

Fonte: Adaptação de (SAMPAIO, 2004)

Como foi demonstrado acima, todo mapa que contém um circuito hamiltoniano pode ser colorido com apenas quatro cores. Este resultado foi um indício de que os circuitos hamiltonianos poderiam ser a chave para a resolução do Problema das Quatro Cores.

Foi provado que bastaria demonstrar a validade do Teorema das Quatro Cores para mapas 3-regulares (em que todos os vértices possuem grau três) e 3-conexos 4 . Em busca da solução do Problema das Quatro Cores com o auxílio deste teorema, alguém conjecturou, e os matemáticos tentaram demonstrar, que todo mapa 3-regular e 3-conexo teria um circuito hamiltoniano. Caso conseguissem demonstrar esta afirmação, estaria provado o Teorema das Quatro Cores.

\footnotetext{
${ }^{4}$ São mapas nos quais, para dois vértices quaisquer $\boldsymbol{u}$ e $\boldsymbol{v}$, existem pelo menos três caminhos distintos de $\boldsymbol{u}$ até $\boldsymbol{v}$, tendo apenas o vértice inicial $\boldsymbol{u}$ e o final $\boldsymbol{v}$ em comum.
} 
Como não é raro no mundo da matemática, nos anos 30 foram publicadas algumas demonstrações (incorretas) de que em todo mapa 3-regular e 3-conexo há um circuito hamiltoniano. Porém, estas demonstrações e a possibilidade da veracidade de tal teorema foram derrubadas através de um contraexemplo publicado por William Tutte em 1946.

William Tutte apresentou um mapa 3-regular e 3-conexo, que não continha nenhum circuito hamiltoniano. Este mapa está representado na Figura 3.46.

Figura 3.46: Mapa de William Tutte
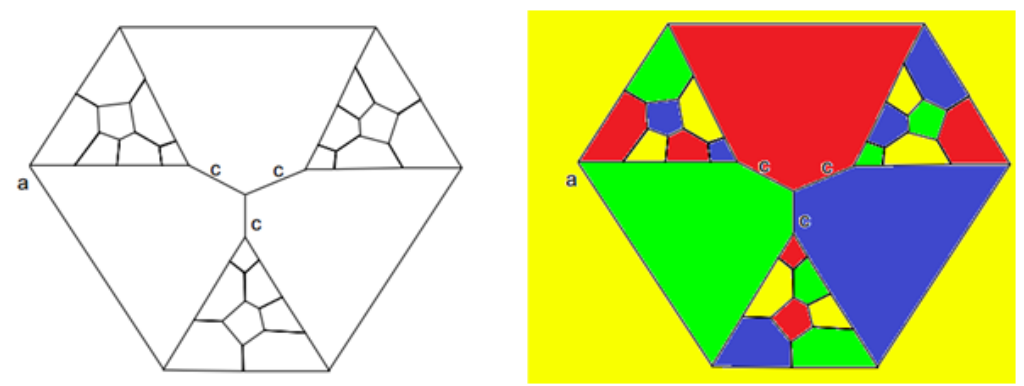

Fonte: Adaptação de (SAMPAIO, 2004)

Podemos observar na Figura 3.46 que, apesar de o mapa de Tutte não conter nenhum circuito hamiltoniano, ele pode ser colorido com quatro cores, o que nos mostra que o fato de em um mapa não existir nenhum circuito hamiltoniano não significa que ele não pode ser colorido com quatro cores.

Com a publicação do contraexemplo de Tutte, o uso do Jogo Icosiano e seus circuitos hamiltonianos deixaram de ser uma estratégia promissora na busca de uma solução para o Problema das Quatro Cores.

\subsubsection{Coloração de arestas e o Problema das Quatro Cores}

Uma outra estratégia para se estudar o Problema das Quatro Cores é através da coloração de arestas de um grafo. A estratégia é devida ao teorema de Peter Guthrie Tait enunciado a seguir.

Teorema 3.5.3.1 Um mapa plano 3-regular pode ser colorido com quatro cores se e somente se suas arestas podem ser coloridas com três cores.

Apresentaremos a demonstração utilizando a estratégia atribuída ao russo Wolinskii, que se encontra em (SAMPAIO, 2004, p. 27). 
Demonstração: Nesta demonstração usaremos os pares ordenados $(0,0),(0,1),(1,0)$ e $(1,1)$ para representar as quatro cores das faces, e os pares ordenados $(1,0),(0,1),(1,1)$ para representar as três cores das arestas.

Definimos a adição módulo 2, dos números 0 e 1 como:

$0 \oplus 0=0$,

$0 \oplus 1=1 \oplus 0=1$,

$1 \oplus 1=0$.

Definimos também a soma dos pares ordenados como a soma módulo 2 de suas coordenadas como $(w, x)+(y, z)=(w \oplus y, x \oplus z)$, em que cada uma das incógnitas $w, x, y$ e $z$ possui valor 0 ou 1. Exemplos:

$$
\begin{aligned}
& (0,0)+(0,1)=(0 \oplus 0,0 \oplus 1)=(0,1) \\
& (1,1)+(1,0)=(1 \oplus 1,1 \oplus 0)=(0,1) \\
& (1,0)+(0,1)=(1 \oplus 0,0 \oplus 1)=(1,1) .
\end{aligned}
$$

Vamos provar primeiramente que, se um mapa plano, 3-regular, pode ser colorido com quatro cores, então suas arestas podem ser coloridas com três cores.

Suponhamos primeiramente que um mapa plano 3-regular tem suas faces coloridas com quatro cores diferentes, as quais representaremos pelos pares ordenados $(0,0),(0,1),(1,0)$ e $(1,1)$. Então, para cada aresta comum a duas faces $f_{1}$ e $f_{2}$, definimos sua cor através da soma do par ordenado que representa a cor da face $f_{1}$ com o par ordenado que representa a cor da face $f_{2}$.

Supondo que as três cores das faces em torno de um vértice tenham as coordenadas: $(0,0),(1,0),(1,1)$, então as arestas em torno deste vértice ficarão com as cores representadas por:

$$
\begin{aligned}
& (0,0)+(1,0)=(1,0) \\
& (1,0)+(1,1)=(0,1) \\
& (0,0)+(1,1)=(1,1) .
\end{aligned}
$$

Logo, três arestas em torno do vértice possuem três cores diferentes, representadas pelos pares $(1,0),(0,1),(1,1)$.

Fazendo uma simples inspeção para as outras três combinações possíveis de cores, como fizemos anteriormente, verifica-se que para cada combinação o resultado são sempre três cores diferentes. Logo, esta estratégia permite definir adequadamente a cor de cada aresta. 
Portanto, está provado que se um mapa plano, 3-regular, pode ser colorido com quatro cores então, suas arestas podem ser coloridas com três cores.

Vamos provar agora que, se um mapa possui suas arestas coloridas com três cores, então as faces deste mapa podem ser coloridas com quatro cores.

Vamos supor que um mapa plano 3-regular possui suas arestas coloridas com três cores diferentes, as quais representaremos pelos pares ordenados $(0,1),(1,0)$ e $(1,1)$. Para colorir as faces deste mapa, escolhemos uma face inicial e a colorimos com a cor representada pelo par $(0,0)$. Então, para cada face vizinha da face tomada como inicial, definimos sua cor através da soma módulo 2 dos pares ordenados que representam as duas cores (face inicial e aresta comum às duas faces). Ou seja, em torno de cada vértice da face inicial teremos três cores distintas:

$(0,0) \rightarrow$ cor da face inicial

$(0,0)+(1,0)=(1,0)$

$(0,0)+(0,1)=(0,1)$.

Seguimos colorindo as demais faces utilizando o mesmo raciocínio, ou seja, a partir de uma face colorida, colorimos a face vizinha com a cor resultante da soma das coordenadas da face colorida com as coordenadas da aresta comum às duas faces. Desta forma, em torno de cada vértice as cores serão sempre o resultado da soma das coordenadas de uma das cores das faces $(0,0),(0,1),(1,0)$ e $(1,1)$ com as coordenadas de uma das cores das arestas $(0,1),(1,0)$ e $(1,1)$, o que sempre resulta em tês cores distintas em torno de cada vértice. A Figura 3.47 apresenta um exemplo.

Figura 3.47: Colorindo as faces de um mapa de arestas coloridas com três cores
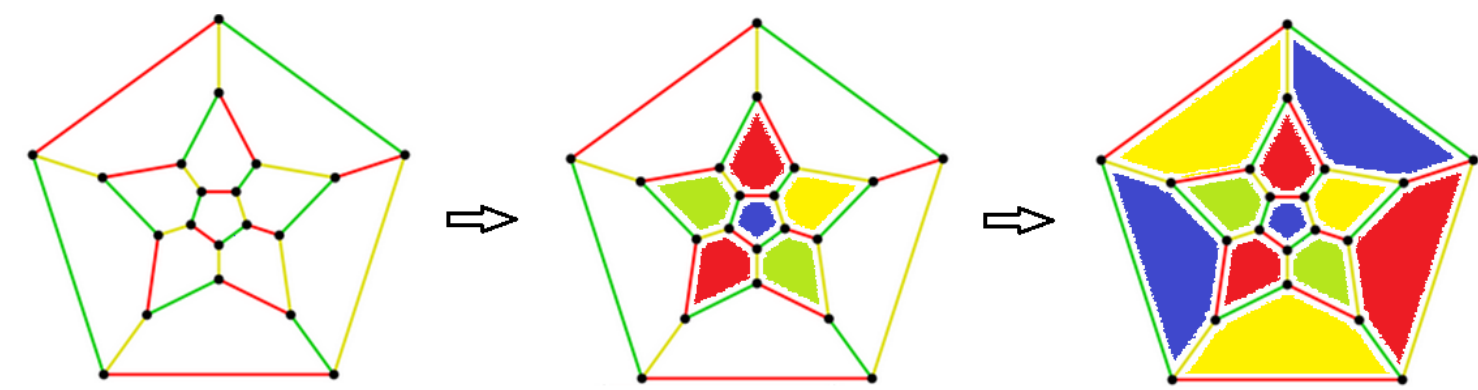

$(0,0)=a z u l$ $(0,1)=$ amarelc $(1,1)=$ vermelho

Fonte: Adaptação de HTtP://DBARbosa.me/Pt/WP-CONTEnT/UPLOAdS/SITES/3/2013/07/DodeCAHEDRON.PNG. Acesso em: 21 nov. 2015. 
Para garantir que diferentes sequências de faces escolhidas para colorir não ocasionarão conflitos de cores, observemos que a troca de sequência de faces coloridas é uma combinação de pequenas trocas de arestas a serem atravessadas (observe exemplo na Figura 3.48).

Figura 3.48: Caminhos alternativos na coloração de faces de um mapa de arestas coloridas com três cores

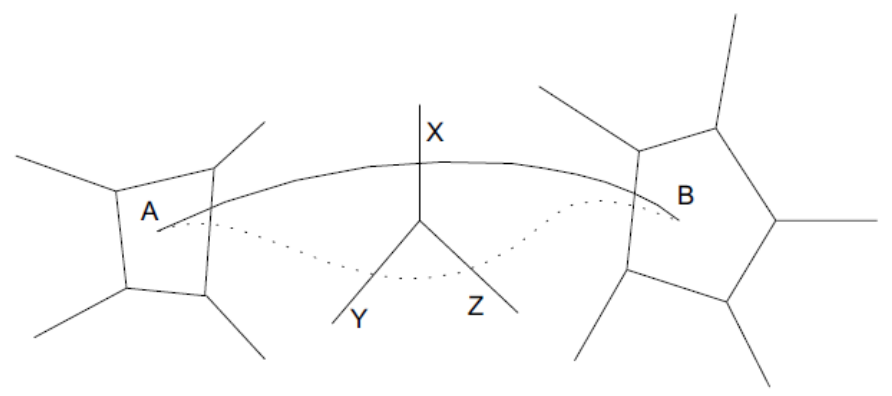

Fonte: (SAMPAIO, 2004)

Como as arestas podem ter cores representadas pelos três pares de números $(0,1),(1,0),(1,1)$, as mudanças de cores ao atraversamos a aresta $X$ é a mesma resultante ao atravesarmos as arestas $Y$ e $Z$, visto que a soma das coordenadas de dois pares de cor de arestas $(Y+Z)$ é igual ao par coordenado da terceira cor de aresta $(X)$, como mostrado abaixo:

$$
\begin{aligned}
& (0,1)+(1,0)=(1,1) \\
& (0,1)+(1,1)=(1,0) \\
& (1,0)+(1,1)=(0,1) .
\end{aligned}
$$

Logo, uma troca de caminho como representado na Figura 3.48 não ocasiona conflito de cores.

Portanto, concluímos que, um mapa plano 3-regular pode ser colorido com quatro cores se e somente se suas arestas podem ser coloridas com três cores, como queríamos demonstrar.

\subsection{A resolução do Problema das Quatro Cores}

Depois de muitos anos de trabalho por parte de diversos matemáticos, os quais criaram diversas estratégias e elaboraram diversos teoremas em busca da solução do Problema das Quatro Cores, surgiram as primeiras demonstrações, um pouco inusitadas, porém aceitas até hoje, do Teorema das Quatro Cores. 


\subsubsection{Surge a primeira demonstração (correta) do Teorema das Quatro Cores}

No ano de 1976 $\left.\right|^{5}$ o Teorema das Quatro Cores foi finalmente demonstrado (corretamente), ou seja, 124 anos depois de a questão sobre a possibilidade de coloração de qualquer mapa com apenas quatro cores ter sido levantada por Francis Guthrie.

Os elaboradores da demonstração foram o alemão Wolfgang Haken (nascido em 1928), e o americano Kenneth Appel (nascido em 1932). A prova foi anunciada no encontro de verão da American Mathematical Society e Mathematical Association of America na universidade de Toronto. Há de se destacar que a demonstração elaborada por eles foi inusitada, gerando controvérsias, de tal forma que até hoje muitos não se sentem à vontade com ela. O diferencial da demonstração feita por eles foi o uso de computadores de grande porte, que realizaram parte essencial da demonstração, trabalhando durante seis meses.

A demonstração de Appel e Haken seguiu a mesma linha de raciocínio de Alfred Bray Kempe, o qual partiu do princípio de que em todo mapa (normal) há pelo menos uma face que possui no máximo cinco vizinhos. Porém, Appel e Haken trabalharam com configurações inevitáveis mais complexas (que possuem mais regiões) do que as configurações inevitáveis apresentadas por Kempe, porém igualmente redutíveis em um mapa pentacromático.

Appel e Haken desenvolveram a demonstração do Teorema das Quatro Cores a partir de um conjunto de $1482^{6}$ configurações inevitáveis, as quais foram elaboradas através de processamento executado por computador. Seguindo a mesma estratégia de Kempe, demonstraram que todas as configurações inevitáveis eram redutíveis em um mapa pentacromático normal mínimo, alcançando assim a contradição com a possibilidade de existência de um mapa pentacromático, o que representava a demonstração do Teorema das Quatro Cores.

O computador foi usado na demonstração basicamente de duas formas. A primeira delas foi no desenvolvimento de provas de redutibilidade de conjuntos inevitáveis de configurações, e a segunda foi na construção de conjuntos inevitáveis de configurações. O processo feito após encontrado um conjunto inevitável de configurações era "testar" a redutibilidade de cada uma delas. Quando nem todas as configurações do conjunto de configurações inevitáveis eram redutíveis, faziam as modificações necessárias, como descobrindo um novo conjunto de configurações inevitáveis e novamente "testando" a redutibilidade de cada uma delas. Com este procedimento, encontraram um con-

\footnotetext{
${ }^{5}$ Com uma nova versão com os pequenos erros corrigidos publicado em 1989.

${ }^{6}$ Algumas referências dizem 1498 ou 1478 configurações inevitáveis.
} 
junto de configurações inevitáveis, em que cada uma delas era redutível, provando desta maneira o Teorema das Quatro Cores.

\subsubsection{A complexidade da demonstração de Appel e Haken}

Embora o Teorema das Quatro Cores tenha um enunciado extremamente curto e simples, a demonstração desenvolvida por Appel e Haken, além de fazer uso de computador, é muito extensa. Nela havia:

- aproximadamente 50 páginas com textos e diagramas;

- aproximadamente 2500 diagramas adicionais;

- aproximadamente 400 microfichas que apresentavam outros diagramas, além de milhares de verificações individuais dos 24 lemas principais da demonstração.

Além de todo este material, os autores ainda deixaram um aviso aos leitores de que alguns fatos haviam sido verificados com o uso de computadores processando durante 1200 horas.

\subsubsection{Uma nova demonstração mais simples}

Em 1993 $\square^{7}$ Neil Robertson, Daniel P. Sanders, Paul Seymour e Robin Thomas decidiram estudar a demonstração do Teorema das Quatro Cores desenvolvida por Appel e Haken. O objetivo deles era simplesmente se convencerem da validade de tal demonstração. Mas, eles acabaram desistindo devido ao grande esforço necessário para realizar tal verificação. Entretanto, resolveram tentar elaborar uma nova demonstração, e conseguiram tal feito de uma maneira "mais simples".

A demonstração de Neil Robertson, Daniel P. Sanders, Paul Seymour e Robin Thomas também envolvia muitos cálculos e o uso de computador, com o diferencial de que foi utilizado um computador simples, e o tempo de processamento foi de "apenas" algumas horas 8 . A estratégia usada por eles foi a mesma utilizada por Appel e Haken, porém, ao invés de cerca de 1482 configurações inevitáveis e redutíveis, eles encontraram um conjunto bem menor, contendo 633 configurações inevitáveis e redutíveis.

O interessante é que até hoje ninguém apresentou uma demonstração do Teorema das Quatro Cores em que não seja feito o uso de um computador.

\footnotetext{
${ }^{7}$ Algumas fontes dizem 1990 ou 1997.

${ }^{8}$ Há também de se levar em consideração o avanço dos computadores, que processavam mais rápido.
} 
Talvez esteja surgindo uma nova forma de se fazer matemática. Veja a interessante frase de Haken citada por (CONWAY, 2010, p. 57): "This work has changed my view of what mathematics is. I hope it will do the same for others" "9.

\footnotetext{
${ }^{9}$ Tradução: "Este trabalho fez mudar minha concepção do que é matemática. Eu espero que faça o mesmo com outros".
} 


\section{Capítulo 4}

\section{Aplicações em sala de aula}

A Teoria dos Grafos não faz parte dos Parâmetros Curriculares Nacionais de matemática e nem do Currículo do Estado de São Paulo. Por isso, dificilmente este tema é abordado pelo professor em suas aulas. Porém, seria possível e proveitoso para o aluno que este tema também fosse abordado em algum momento de sua vida escolar, como iremos defender a partir de agora.

\subsection{A Teoria dos Grafos no Ensino Básico}

Provavelmente muitos alunos que se deparam pela primeira vez com o estudo da Teoria dos Grafos somente na faculdade, se perguntam: "Por que esta interessante disciplina não poderia ter sido introduzida durante o Ensino Médio?".

Como vimos no Capítulo 2, grafos apresentam uma estrutura simples, tendo como uma de suas características mais notáveis a possibilidade de representá-los graficamente, facilitando assim o seu entendimento, e despertando a atenção e curiosidade daqueles que lidam com este tipo de estudo. Estas características dos grafos nos levam a acreditar na real possibilidade de se trabalhar a Teoria dos Grafos no Ensino Básico de maneira proveitosa e motivadora aos alunos.

Nos últimos anos, na área da educação, muito se tem falado da necessidade de haver contextualização da matemática abordada na escola, para que ela faça sentido para o aluno. Também é recorrente o questionamento por parte dos alunos sobre a aplicação da matemática na vida real. Neste sentido, como o estudo da Teoria dos Grafos apresenta uma variedade de aplicações, ele atende facilmente às exigências apresentadas pelo sistema educacional.

Diversos problemas do cotidiano podem ser modelados e resolvidos através da Teoria dos Grafos, 
fazendo uso de suas propriedades e da facilidade que sua representação gráfica traz, ou seja, os grafos são ótimas ferramentas para representar e procurar uma solução para problemas do cotidiano. Vimos no Capítulo 2 o "Problema das Pontes de Königsberg", e no Capítulo 3 o problema da coloração de mapas. Estes dois problemas podem, de alguma forma, ser trabalhados com os alunos em classe.

Veremos agora como o professor pode introduzir o ensino de grafos no Ensino Básico, e em seguida, alguns outros exemplos de problemas do cotidiano, e suas representações/resoluções com o uso de grafos.

\subsection{Apresentando a Teoria dos Grafos}

A Teoria dos Grafos pode ser apresentada aos alunos da Educação Básica através de atividades de coloração de mapas. Por exemplo, mapas da América do Sul, semelhantes ao ilustrado na Figura 3.3 . poderiam ser distribuídos aos alunos, incumbindo-lhes da tarefa de colori-los com o menor número de cores possível. Realizada esta tarefa, o professor tem a oportunidade de discutir uma forma mais simples de representar mapas: grafos.

A partir de então, o professor pode apresentar formalmente a definição de grafo, como também os vários tipos de grafos existentes, suas propriedades, inclusive falando com destaque sobre coloração de vértices, que é pertinente à atividade realizada. Em seguida, a mesma atividade de coloração de mapa pode ser repetida para outros mapas, porém, agora representando o mapa através de um grafo, e colorindo os seus vértices.

Terminadas estas atividades, já é possível ao professor apresentar aos seus alunos diversos problemas do cotidiano que também podem ser modelados e resolvidos com o auxílio dos grafos, como os problemas apresentados na seção 4.3 .

\subsection{Resolvendo problemas do cotidiano com o auxílio dos Grafos}

Problema 1: Em uma escola haverá um torneio interclasses de diversas modalidades esportivas: futebol, voleibol, basquetebol, handebol, pingue-pongue e xadrez. O torneio ocorrerá no horário de aula, e é necessário fazer o cronograma das partidas utilizando o menor número de dias possível. Porém, há alunos inscritos para participar em dois ou mais esportes, então não é possível marcar as partidas de todos os esportes para o mesmo dia. 
Veja na Tabela 4.1 a lista de alunos que estão inscritos em dois ou mais esportes.

Tabela 4.1: Alunos que participarão de mais de um esporte

\begin{tabular}{|c|c|}
\hline Esportes & Alunos \\
\hline Basquetebol & Daiana, Daniel, Kelly \\
Voleibol & Kelly, Daiana, Tiago \\
Futebol & Daniel \\
Handebol & Kelly, Raquel, Tiago \\
Pingue-pongue & Raquel, Daniel \\
Xadrez & Daniel \\
\hline
\end{tabular}

Se as partidas de um mesmo esporte ocorrerão todas no mesmo dia, qual é o número mínimo de dias de torneio necessários para que todos os alunos possam participar de todas as modalidades em que estão inscritos?

Solução: Podemos modelar o problema como um grafo, em que os vértices representam os esportes, e dois vértices são adjacentes se e somente se existe um mesmo aluno inscrito nos dois esportes que os vértices representam. Desta forma, encontramos o grafo representado na Figura 4.1.

Figura 4.1: Grafo de representação do Problema 1

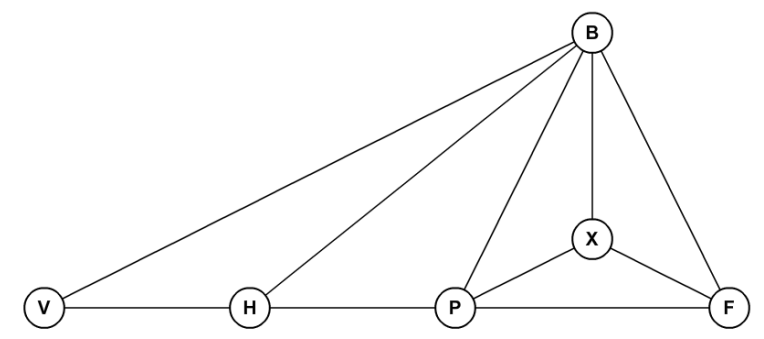

Para resolver este problema, podemos usar a coloração de vértices, em que cada cor representa um dia da semana. Sendo assim, vamos colorir os vértices com o menor número de cores possível.

Vemos que, como os vértices $B, F, P$ e $X$ são dois a dois adjacentes, são necessárias quatro cores para colori-los. Após colorir os vértices $B, F, P$ e $X$, basta colorir os vértices $V$ e $H$. Como os vértices $V$ e $H$ não são adjacentes aos vértices já coloridos $X$ e $F$, então basta reutilizar as mesmas cores de $X$ e $F$ para colorir $V$ e $H$. Portanto, quatro é o número mínimo de cores necessárias para colorir os vértices de nosso grafo, como podemos verificar na Figura 4.2 . 
Figura 4.2: Grafo de representação de solução para o Problema 1

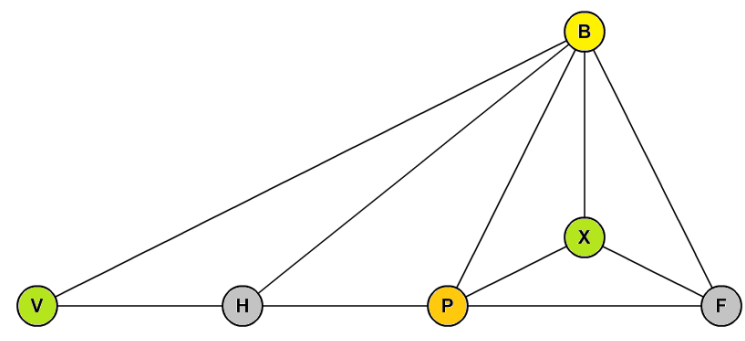

Como cada cor representa um dia, quatro é o número de dias necessários para realizar o torneio sem haver conflito de esporte para nenhum dos inscritos. Sendo assim, podemos então organizar o torneio conforme mostra a Tabela 4.2 ,

Note que poderíamos ter colorido os vértices $V$ e $H$ com outras cores diferentes das quatro cores utilizadas na coloração dos vértices $B, F, P, X$, mas como cada cor representa um dia, repetimos as cores dos vértices $F$ e $X$ na coloração dos vértices $V$ e $H$, pois buscamos usar o menor número de cores possível, como o problema exige. Também seria possível invertermos as cores dos vértices $V$ e $H$ sem causar conflito de cores.

Tabela 4.2: Um solução para as datas dos jogos

\begin{tabular}{|c|c|c|c|}
\hline Segunda-feira & Terça-feira & Quarta-feira & Quinta-feira \\
\hline $\begin{array}{c}\text { Voleibol } \\
\text { Xadrez }\end{array}$ & Basquetebol & Pingue-pongue & Futebol \\
Handebol
\end{tabular}

Objetivos e resultados esperados: Um problema como este permite ao professor, após discutir com seus alunos como poderiam encontrar uma solução, sugerir o uso de grafos. Modelando o problema como um grafo, surge o desafio de descobrir a quantidade de cores necessárias para colorir os vértices. Algum aluno ou, em segundo caso, o próprio professor poderia apontar a existência do clique de quatro vértices que traz a necessidade de se utilizar pelo menos quatro cores. Após isso, certamente os alunos poderão concluir que quatro cores são suficientes para colorir todos os vértices.

Após resolvido o Problema 1, surge a oportunidade de o professor iniciar uma discussão em classe sobre questões como: será que em outros casos quatro cores também seriam também suficientes? Haveria casos nos quais seriam necessárias mais cores? Ou talvez menos cores? Podendo, então o professor iniciar a análise de uma outra situação semelhante, como o Problema 2. 
Problema 2: Supondo que no Problema 1 o torneio de Basquete tenha sido cancelado pelo baixo número de inscritos, e que Daiana tenha resolvido participar também do torneio de xadrez. Neste novo cenário, qual é o número mínimo de dias de torneio necessários para que todos os alunos possam participar de todas as modalidades em que estão inscritos?

Veja na Tabela 4.3 a lista de alunos que estão inscritos em dois ou mais esportes.

Tabela 4.3: Alunos que participarão de mais de um esporte

\begin{tabular}{|c|c|}
\hline Esportes & Alunos \\
\hline Voleibol & Kelly, Daiana, Tiago \\
Futebol & Daniel \\
Handebol & Kelly, Raquel, Tiago \\
Pingue-pongue & Raquel, Daniel \\
Xadrez & Daniel, Daiana \\
\hline
\end{tabular}

Solução: Da mesma forma que no Problema 1, podemos modelar o nosso novo problema como um grafo, em que os vértices representam os esportes, e dois vértices são adjacentes se e somente se existe um mesmo aluno inscrito nos dois esportes que os vértices representam. Desta forma, encontramos o grafo representado na Figura 4.3 .

Figura 4.3: Grafo de representação do Problema 2

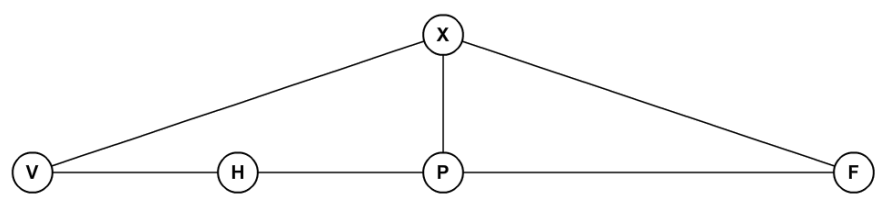

Podemos usar novamente a coloração de vértices para resolver este problema. Vamos colorir os vértices com o menor número de cores possível.

Desta vez nós não temos quatro vértices que são dois a dois adjacentes, mas note que os vértices $P, X$ e $F$ são dois a dois adjacentes, logo são necessárias três cores para colori-los. Após colori-los, basta colorir os vértices $V$ e $H$. Como $H$ não é adjacente aos vértices $X$ e $F$, podemos colori-lo com a cor de algum destes dois vértices, por exemplo, com a cor de $X$. Já o vértice $V$ é adjacente aos vértices $H$ e $X$, logo podemos usar qualquer cor diferente da cor destes dois vértices para colori-lo, por exemplo a cor de $P$. Portanto, três é o número mínimo de cores necessários para colorir os vértices de nosso grafo, como podemos verificar na Figura 4.4 . 
Figura 4.4: Grafo de representação de solução para o Problema 2

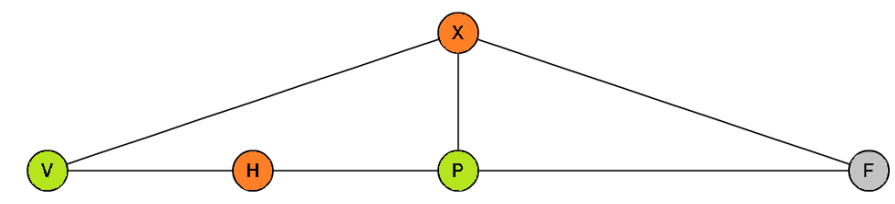

Como cada cor representa um dia, três é o número de dias necessários para realizar o torneio sem haver conflito de esporte para nenhum dos inscritos. Sendo assim, podemos então organizar o torneio conforme mostra a Tabela 4.4.

Note que novamente poderíamos ter colorido os vértices $V$ e $H$ com outras cores diferentes das três cores utilizadas na coloração dos vértices $F, P, X$, mas como cada cor representa um dia, repetimos as cores dos vértices $P$ e $X$ na coloração dos vértices $V$ e $H$, pois buscamos usar o menor número de cores possível, como o problema exige.

Tabela 4.4: Um solução para as datas dos jogos

\begin{tabular}{|c|c|c|}
\hline Segunda-feira & Terça-feira & Quarta-feira \\
\hline Voleibol & Handebol & Futebol \\
Pingue-pongue & Xadrez & \\
\hline
\end{tabular}

Objetivos e resultados esperados: Como este problema é uma variação do anterior, os alunos terão condições, sozinhos ou com o auxílio do professor, de modelar o problema como um grafo e analisá-lo. Os alunos tenderão a analisar o grafo da mesma forma que foi feito com o grafo do problema anterior, porém, neste problema não existe um clique de quatro vértices, apenas um clique de três vértices, indicando a necessidade de pelo menos três cores. Feita esta observação, novamente os alunos, sem muita dificuldade, poderão concluir que três cores são suficientes para colorir todos os vértices.

Após resolvido o Problema 2, algumas respostas foram encontradas. Já se sabe que nem sempre o número de cores necessárias para se colorir os vértices de um grafo é quatro. Pode ser menos, como aconteceu neste problema. Mas, neste ponto, ainda restará a dúvida se existe casos em que são necessárias mais do que quatro cores. Antes de responder a esta pergunta, o professor poderia discutir com os alunos a dificuldade de se testar todos os casos quando um grafo possui muitos vértices, sendo esta uma forma de esclarecer a importância das demonstrações matemáticas. A partir de então, seria possível ao professor, caso seus alunos já possuam algum conhecimento de 
demonstração por contradição e por indução, iniciar uma demonstração do Teorema das Cinco Cores. Podendo, em seguida, apresentar o Teorema das Quatro Cores, e falar sobre a complexidade de sua demonstração.

Problema 3: Atualmente ouvimos falar que o Governo do Estado de São Paulo está realizando uma "Reorganização Escolar". Vamos supor que o governador decretou que as escolas de mesmo ciclo devem ter uma distância de mais de $2.000 \mathrm{~m}$ entre elas. A Tabela 4.5 apresenta a distância entre sete escolas de um mesmo município.

Tabela 4.5: Escolas que passarão pela reorganização

\begin{tabular}{|l|c|c|c|c|c|c|c|}
\hline & Escola A & Escola B & Escola C & Escola D & Escola E & Escola F & Escola G \\
\hline Escola A & - & $1.800 \mathrm{~m}$ & $2.200 \mathrm{~m}$ & $3.500 \mathrm{~m}$ & $2.400 \mathrm{~m}$ & $3.400 \mathrm{~m}$ & $4.500 \mathrm{~m}$ \\
Escola B & $1.800 \mathrm{~m}$ & - & $2.000 \mathrm{~m}$ & $1.200 \mathrm{~m}$ & $1.000 \mathrm{~m}$ & $2.400 \mathrm{~m}$ & $3.000 \mathrm{~m}$ \\
Escola C & $2.200 \mathrm{~m}$ & $2.000 \mathrm{~m}$ & - & $500 \mathrm{~m}$ & $2.120 \mathrm{~m}$ & $3.200 \mathrm{~m}$ & $3.600 \mathrm{~m}$ \\
Escola D & $3.500 \mathrm{~m}$ & $1.200 \mathrm{~m}$ & $500 \mathrm{~m}$ & - & $1.880 \mathrm{~m}$ & $2.600 \mathrm{~m}$ & $2.800 \mathrm{~m}$ \\
Escola E & $2.400 \mathrm{~m}$ & $1.000 \mathrm{~m}$ & $2.120 \mathrm{~m}$ & $1.880 \mathrm{~m}$ & - & $1.400 \mathrm{~m}$ & $1.960 \mathrm{~m}$ \\
Escola F & $3.400 \mathrm{~m}$ & $2.400 \mathrm{~m}$ & $3.200 \mathrm{~m}$ & $2.600 \mathrm{~m}$ & $1.400 \mathrm{~m}$ & - & $2.120 \mathrm{~m}$ \\
Escola G & $4.500 \mathrm{~m}$ & $3.000 \mathrm{~m}$ & $3.600 \mathrm{~m}$ & $2.800 \mathrm{~m}$ & $1.960 \mathrm{~m}$ & $2.120 \mathrm{~m}$ & - \\
\hline
\end{tabular}

O governo deseja que você defina o ciclo (Ensino Fundamental 1, Ensino Fundamental 2, Ensino Médio) de cada uma das escolas, respeitando o critério da distância mínima, e de maneira que os três ciclos sejam atendidos, priorizando o Ensino Fundamental 1, depois o Fundamental 2 e por último o Médio. É possível? Caso seja, apresente uma solução.

Solução: Podemos representar nosso problema através de um grafo, onde os vértices representam as escolas, e onde dois vértices são adjacentes se e somente se a distância entre as escolas que eles representam é de até $2.000 \mathrm{~m}$. Este grafo está ilustrado na Figura 4.5 .

Figura 4.5: Grafo de representação do Problema 3

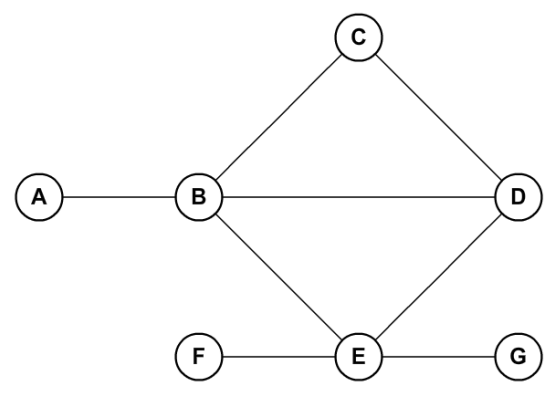

Para resolver este problema, podemos usar a coloração de vértices, em que cada cor representa 
um dos ciclos de ensino. Devemos colorir os vértices utilizando exatamente três cores, para que todos os ciclos do ensino sejam atendidos. Como a distância mínima deve ser respeitada, vértices adjacentes devem possuir cores diferentes. Um resultado da coloração dos vértices do grafo utilizando três cores é ilustrado na Figura 4.6 .

Figura 4.6: Grafo de representação de solução para o Problema 3

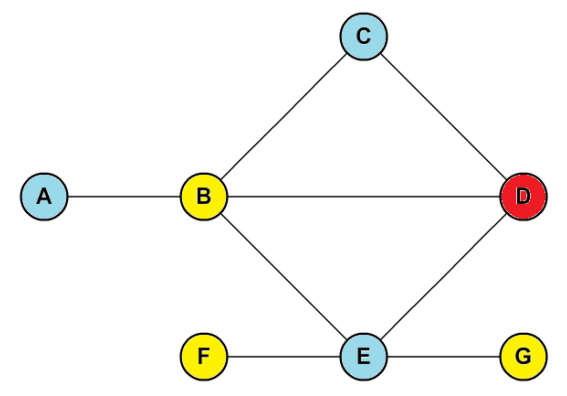

Como vemos na Figura 4.6, é possível colorir os vértices do grafo com três cores distintas. Em nosso caso, ficamos com três vértices amarelos, três azuis e um vermelho. De acordo com a prioridade estabelecida, o Ensino Médio é o de menor prioridade, então como a cor vermelha é o que menos aparece, o vértice vermelho deverá representar o Ensino Médio. Uma solução do problema é apresentado na Tabela 4.6 .

Tabela 4.6: Um solução para a Reogarnização das Escolas

\begin{tabular}{|c|c|c|}
\hline Fundamental 1 & Fundamental 2 & Médio \\
\hline Escola A & Escola B & Escola D \\
Escola C & Escola F & \\
Escola E & Escola G & \\
\hline
\end{tabular}

Objetivos e resultados esperados: Este problema, por apresentar um contexto diferente dos problemas 1 e 2, pode ser aplicado pelo professor aos seus alunos, como exercício, em que o intuito seja que eles o representem através de um grafo e, a partir do mesmo, procurem uma solução que, como visto, pode também ser encontrado pela coloração de vértices. Porém, neste caso, tendo eles que tomar cuidado, pois deve haver uma priorização de cor.

O caráter bem atual do problema, e que diz respeito aos próprios alunos, serve como forma motivacional de despertar o interesse de cada um deles. 
Problema 4: Supondo que no Problema 3 o Ensino Fundamental 1 e o Ensino Fundamental 2 fossem um único ciclo, ou seja, se existisse apenas Ensino Fundamental e Ensino Médio. Seria possível reorganizar as escolas respeitando o critério em relação à distância mínima entre elas? Caso não, no mínimo quantas escolas deveriam seriam fechadas (por não receber nenhum tipo de ensino)?

Solução: Como estamos tratando cada cor como um tipo de ensino diferente, para resolver o nosso problema basta colorirmos todos os vértices de nosso grafo representado na Figura 4.5 com apenas duas cores. Porém, percebemos que não é possível colorir todos os vértices.

Figura 4.7: Grafo de representação de solução para o Problema 4

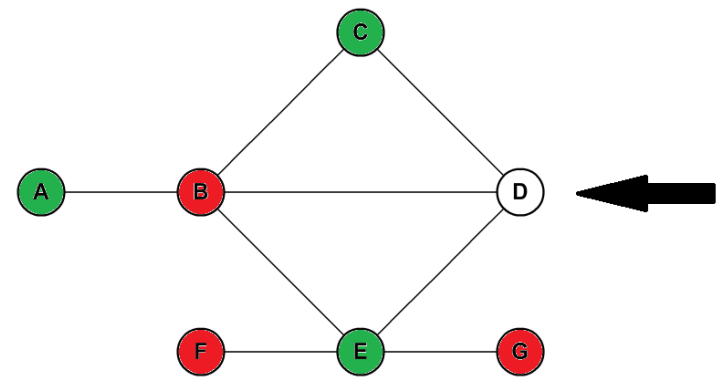

Isso acontece porque os vértices $B, E$ e $D$ são dois a dois adjacentes, o mesmo acontece com os vértices $B, C$ e $D$, ou seja, em cada um destes conjuntos de três vértices, um deles teria necessariamente que ser colorido com uma terceira cor, a qual não temos. Porém, como os vértice $B$ e $D$ são comuns aos dois conjuntos, então se sacrificarmos um deles, podemos resolver o problema, como ilustrado na Figura 4.7. E, desta forma, apenas uma escola seria fechada.

Porém, se escolhermos sacrificar um dos outros vértices $(C$ ou $E)$, teremos necessariamente que sacrificar os dois, como ilustrado na Figura 4.8 .

Figura 4.8: Grafo de representação de possível solução para o Problema 4

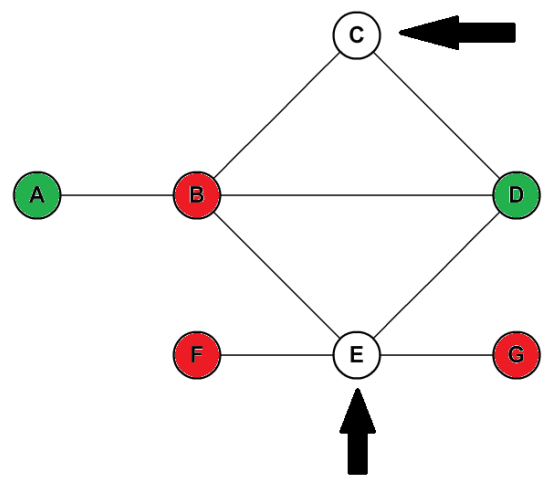


Logo, no mínimo teremos que sacrificar a coloração de um dos vértices, ou seja, no mínimo uma escola ficará sem atribuição de um tipo de ensino. Portanto, uma escola será fechada.

Objetivos e resultados esperados: Este problema é uma variação mais desafiadora do problema anterior. Ele também pode ser usado como exercício, para maior compreensão e familiarização dos alunos com grafos e suas propriedades. A situação desafiadora deste problema se deve ao fato de que nem todos os vértices podem ser coloridos.

Semelhantemente ao problema anterior, este problema também tem caráter motivacional, pois diz respeito a uma situação semelhante ao que a Secretaria da Educação do Estado de São Paulo tem cogitado fazer, afetando diretamente os próprios alunos. Portanto, os alunos deverão analisar uma forma de colorir os vértices de modo que o menor número possível de escolas sejam fechadas, visto que não existe a possibilidade de que todas elas permaneçam abertas.

Problema 5: Vamos supor que você queira conhecer algumas capitais de países sul-americanos: Santiago, Buenos Aires e Montevidéu. Você sairá de Campinas e passará uma única vez por cada uma destas cidades, terminando por voltar para Campinas. Considere os valores das viagens entre cada par de cidades (ida ou volta), apresentados na Tabela 4.7, em seguida defina a rota mais vantajosa financeiramente.

Tabela 4.7: Custo de viagem entre as cidades

\begin{tabular}{|c|c|}
\hline Rota & Custo \\
\hline Campinas $\leftrightarrow$ Santiago & $\mathrm{R} \$ 2.250,00$ \\
Campinas $\leftrightarrow$ Buenos Aires & $\mathrm{R} \$ 2.000,00$ \\
Campinas $\leftrightarrow$ Montevidéu & $\mathrm{R} \$ 1.260,00$ \\
Santiago $\leftrightarrow$ Buenos Aires & $\mathrm{R} \$ 1.570,00$ \\
Santiago $\leftrightarrow$ Montevidéu & $\mathrm{R} \$ 1.210,00$ \\
Buenos Aires $\leftrightarrow$ Montevidéu & $\mathrm{R} \$ 980,00$ \\
\hline
\end{tabular}

Solução: Podemos transformar a situação apresentada, em um grafo, onde os vértices representam as cidades, e cada aresta representa a viagem entre as cidades representadas por suas pontas. Colocaremos ao lado de cada aresta o valor do custo em reais da viagem entre as duas cidades representadas por suas pontas. Desta forma encontramos o grafo da Figura 4.9. 
Figura 4.9: Grafo de representação do Problema 5

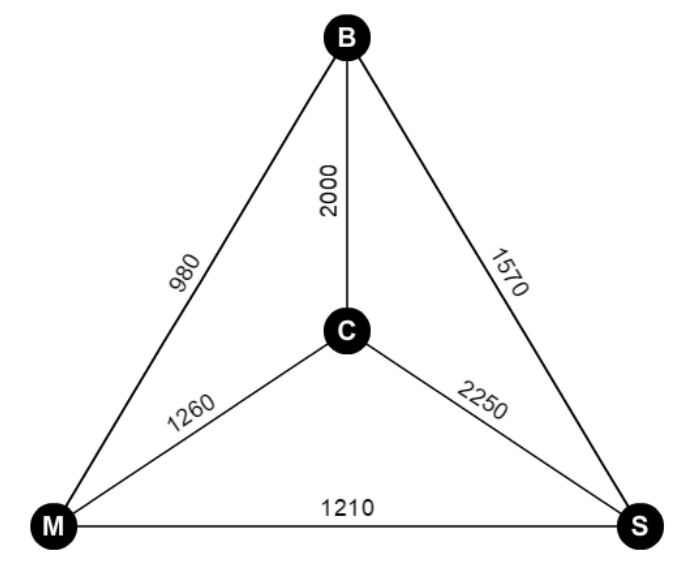

Podemos resolver este problema analisando o preço total de custo de cada circuito que percorre todos os vértices do grafo, partindo do vértice $C$, que representa Campinas, e terminado nele próprio. Para ajudar a classificar os circuitos, podemos representar todas as possíveis rotas através de um grafo em forma de árvore, conforme representado na Figura 4.10.

Figura 4.10: Árvore representando as possibilidades de rotas.

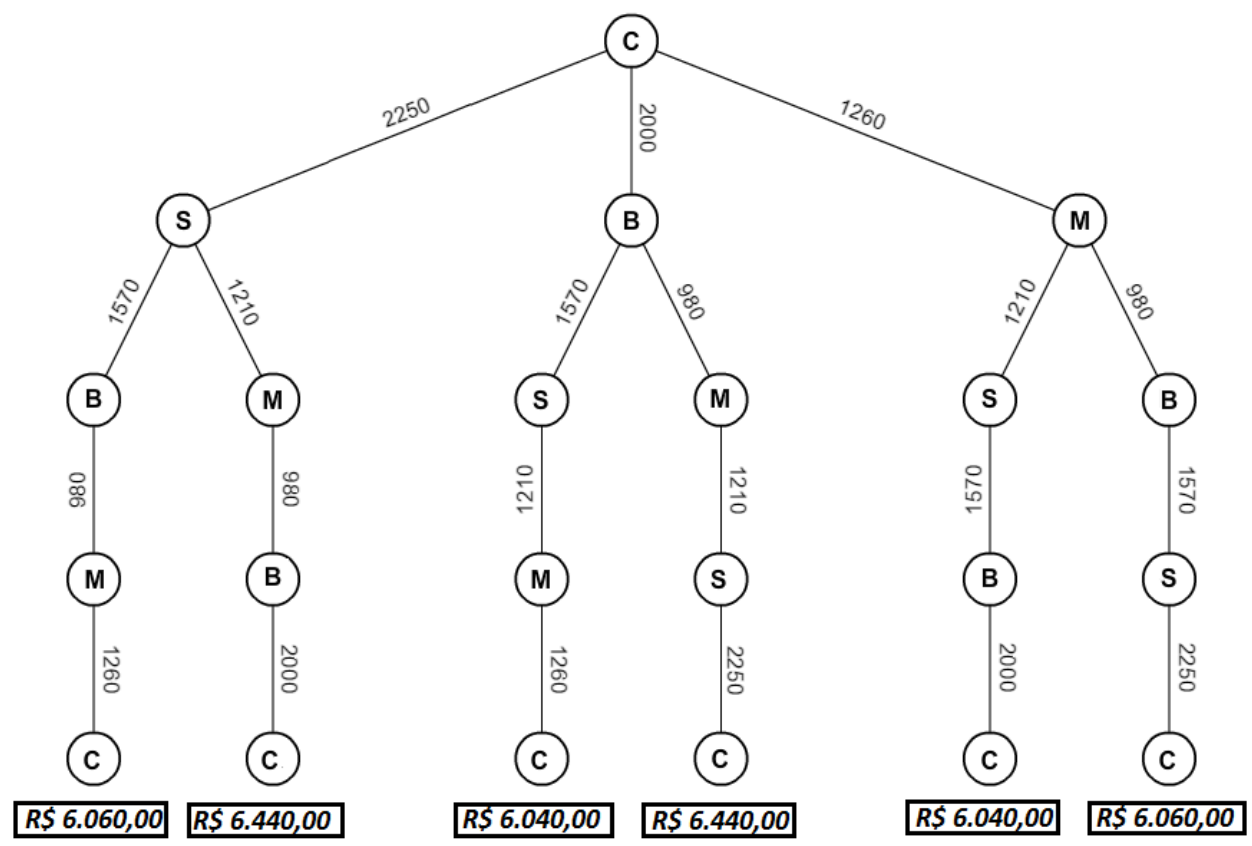

Observando todas as ramificações da árvore ilustrada na Figura 4.10, concluímos que a rota mais barata é Campinas $\rightarrow$ Buenos Aires $\rightarrow$ Santiago $\rightarrow$ Montevidéu $\rightarrow$ Campinas, que custa $\mathrm{R} \$ 6.040,00$. 
E, como já podíamos esperar, a rota contrária tem o mesmo custo.

Infelizmente o método que usamos não é tão eficiente, visto que, quando o número de vértices aumenta, o número de rotas possíveis aumenta "exponencialmente", de tal forma que para um número ainda baixo de possibilidades (de cidades a serem visitadas, no nosso caso) já levaria muito tempo para serem calculados todos os custos, até mesmo para os modernos computadores, que poderiam levar até milhões de anos em um grafo com mais de trinta vértices.

Podíamos então usar uma estratégia diferente, como saindo do ponto inicial (Campinas), escolher a cidade mais barata para iniciar a viagem. Depois, a partir desta primeira cidade, selecionar a próxima cidade mais barata ainda não visitada, e assim sucessivamente, até que todas as cidades tenham sido visitadas. Terminando de visitar todas as cidades, retornar para a cidade inicial (Campinas).

Aplicando este método em nosso exemplo, encontraríamos a rota Campinas $\rightarrow$ Montevidéu $\rightarrow$ Buenos Aires $\rightarrow$ Santiago $\rightarrow$ Campinas, que neste caso custa $\mathrm{R} \$ 6.060,00$. E, como podemos perceber pelo resultado, o problema deste método é que, embora rápido, não garante a melhor solução.

Objetivos e resultados esperados: Um problema como este permite ao professor apresentar aos seus alunos o grafo conhecido como árvore, e usá-lo para representar todas as combinações possíveis, e encontrar a solução pelo método da exaustão (testando todos os casos possíveis).

Surge novamente a oportunidade de se discutir sobre a inviabilidade de sempre buscar uma solução por exaustão, e sobre quais outros métodos alternativos de busca se poderia utilizar, para tentar encontrar a solução. O professor poderia também falar sobre o risco que existe em não encontrar a melhor solução, quando não for utilizado o método da exaustão. Podendo, então, questionar os alunos: em quais situações se poderia arriscar usar um método mais rápido, porém não tão confiável? A resolução deste problema também oferece uma oportunidade para se discutir o papel dos computadores como amigos da matemática, ou seja, auxiliares na demonstração de teoremas e busca de soluções.

Problema 6: Supondo que São Carlos possua vinte escolas, e que um grupo de alunos da escola $A$ foi encarregado de convidar todas as outras escolas da cidade para visitarem a exposição da Festa dos Estados que ocorrerá na escola $A$. Supondo que as escolas sejam representadas pelos vértices do grafo apresentado na Figura 4.11, e que cada aresta representa o caminho entre duas escolas 
representadas pelas suas pontas. Encontre um caminho partindo da escola $A$, passando por todas as outras escolas uma única e vez, e terminando a rota em sua própria escola $A$.

Figura 4.11: Grafo de representação do Problema 6

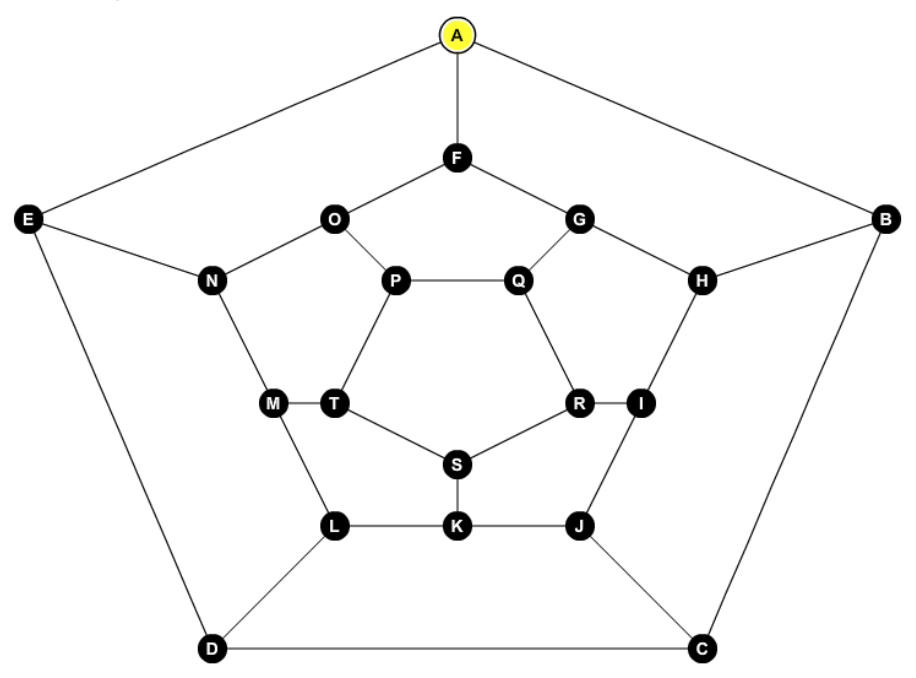

Solução: O grafo e o objetivo deste desafio é justamente o mesmo do Jogo Icosiano, ou seja, fazer um circuito percorrendo todos os vinte vértices do grafo, passando uma única vez por cada um deles, terminando o percurso no vértice de origem.

Uma solução para o problema é apresentada na Figura 4.12 .

Figura 4.12: Grafo de representação de solução para o Problema 6

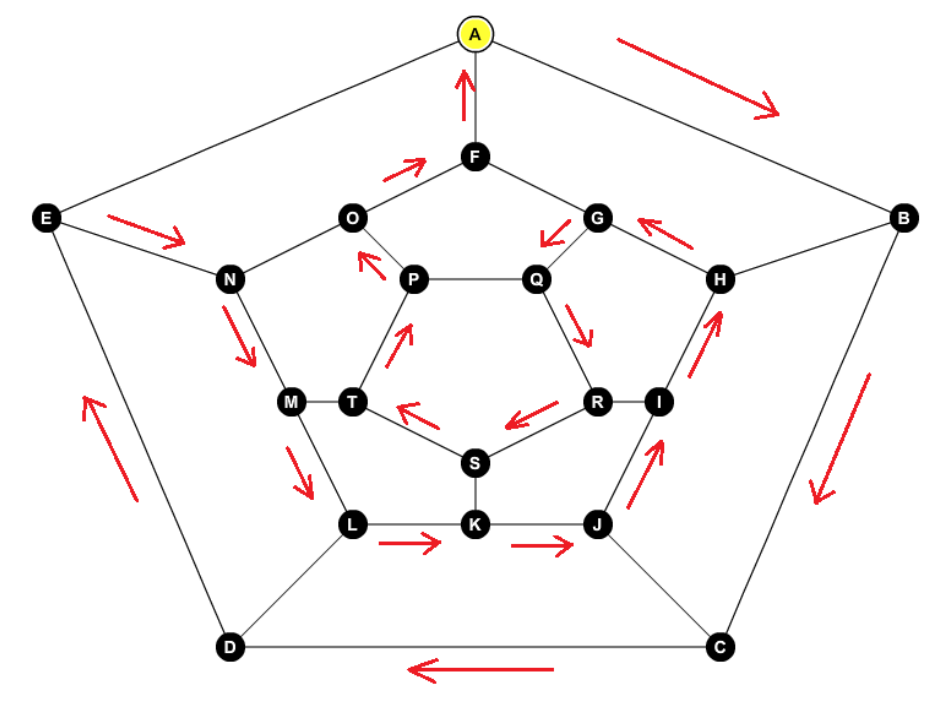

Portanto, os alunos podem percorrer as escolas na sequência: $A \rightarrow B \rightarrow C \rightarrow D \rightarrow E \rightarrow N \rightarrow$ $M \rightarrow L \rightarrow K \rightarrow J \rightarrow I \rightarrow H \rightarrow G \rightarrow Q \rightarrow R \rightarrow S \rightarrow T \rightarrow P \rightarrow O \rightarrow F \rightarrow A$, que terão passado 
por todas as escolas uma única vez, terminado o percurso em sua própria escola.

Objetivos e resultados esperados: Através deste problema, que é equivalente ao desafio do Jogo Icosiano, desponta a oportunidade para professor falar sobre o próprio Jogo Icosiano e suas características matemáticas, como sobre os circuitos hamiltonianos e sua ligação histórica com o Problema das Quatro Cores.

Após os alunos encontrarem uma solução para o problema, o professor pode aplicar uma última atividade: colorir um mapa equivalente ao grafo das escolas (em que os vértices representam os pontos de intersecção de fronteiras, e as arestas representam as fronteiras que ligam estes pontos), com quatro cores, em seguida finalizar o assunto fazendo os esclarecimentos necessários, e desafiando os alunos a pensarem um pouco sobre uma estratégia para se provar o Teorema das Quatro Cores sem o uso de computadores.

\subsection{Grafos e formas de demonstração}

Um dos maiores desafios no trabalho de um professor de matemática são as demonstrações de fórmulas, as quais praticamente todas as vezes são feitas através do que chamamos de "prova direta", que muitas vezes consiste em uma prova longa e que envolve várias etapas, dificultando para o professor apresentá-las de maneira que os alunos consigam acompanhá-las e compreendê-las. Neste sentido, o ensino de Teoria do Grafos também traz vantagens.

No Capítulo 2 vimos que o estudo da Teoria dos Grafos apresenta várias demonstrações, sendo muitas delas feitas por contradição e por indução. Estas duas formas de demonstração raramente são apresentadas aos alunos do Ensino Básico. Porém, são algumas vezes simples e intuitivas, como, por exemplo, a demonstração por contradição feita para o Teorema 2.1.7.3. Por ser simples e intuitiva, seria possível apresentá-la aos alunos, depois de abordados os conceitos básicos de grafos. Este tipo de demonstração é mais uma ferramenta a enriquecer ainda mais o conhecimento dos alunos.

Temos também a demonstração por indução finita feita para o Teorema 3.1 (Teorema de Euler), a qual não apresenta muitas dificuldades, e poderia também ser apresentada aos alunos, depois de abordado os conceitos básicos de grafos. 


\section{Capítulo 5}

\section{Considerações finais}

Ao longo deste trabalho, buscamos apresentar a Teoria dos Grafos como uma poderosa e facilitadora ferramenta para se estudar e resolver problemas do cotidiano. Para alcançarmos tal objetivo, apresentamos os conceitos básicos de Teoria dos Grafos, seguido de um estudo sobre o Teorema das Quatro Cores, além da resolução de alguns problemas do cotidiano, com o auxílio de grafos.

Destacamos o quão enriquecedor pode ser o ensino de Teoria dos Grafos na Educação Básica. Apontamos, por exemplo, que este estudo torna possível ao professor apresentar aos alunos as técnicas de demonstração por contradição e por indução finita, possibilitando, assim, que eles compreendam algumas demonstrações interessantes como, por exemplo, a do Teorema das Cinco Cores.

Concluímos que a inclusão da Teoria dos Grafos como conteúdo a ser trabalhado com os alunos da Educação Básica seria uma forma alternativa, e sem grandes obstáculos, de atender às expectativas de aplicabilidade do conhecimento adquirido na resolução de situações problema encontradas no cotidiano, além de ser uma porta de entrada para a apresentação de novos conteúdos.

Sugerimos ainda que, motivados pelo conteúdo abordado neste trabalho, os professores, alunos e demais leitores sigam estudando e pesquisando outras aplicações da Teoria dos Grafos, tanto na própria matemática como em outras áreas do conhecimento. 


\section{Referências Bibliográficas}

AGARWAL, R.; SEN, S. Creators of Mathematical and Computational Sciences. Cham Heidelberg - New York - Dordrecht - London: Springer International Publishing, 2014. 494 p.

BAlakrishnan, R.; RAnGAnATHAN, K., A Textbook of Graph Theory. 2.Ed. Nova York: Springer, 2012. 288 p.

BARTLETT, P. Introduction to Graph Theory. Canada/USA Mathcamp - Week 1, 2011, Portland: Reed College, 2011. 5 p. Disponível em: <HTTP://MATH.UCSB.EDU/ PADRAIC/MATHCAMP_2011/MATHCAMP_2011/>. ACESSO EM: 08 NOV. 2015.

CARdoso, D. M. Teoria dos Grafos e Aplicações. 2005. 99 F. (Mestrado em Matemática) - Departamento de Matemática da Universidade de Aveiro, 2005.

COnWAy, J. B., Mathematical Connections: A Capstone Course. Providence: American Mathematical Society, 2010. 241 P.

FEOFILOFF, P.; KOHAYAKAWA, Y.; WAKABAYASHI, Y., Uma Introdução Sucinta à Teoria dos Grafos. SÃO PAUlO, 2011. 61 P. DisPonível EM: <HTTP://WWW.IME.USP.BR/ PF/TEORIAdosgrafos/>. ACESSO EM: 02 NOV. 2015.

FLOOD, R.; RICE, A.; WILSON, R., Mathematics in Victorian Britain. NovA York: OXford University PRess, 2011. 405 P.

FRITSCH, R,; FRITSC. G. The Tour-Color Theorem: History, Topological FounDations, And Idea of Prof. Edmonton: Springer, 1998. 251 P.

LEWARD, O. Graph Theory - The Four Color Theorem. Uppsala: Departament of Mathematics - Uppsala University, 2014. 31 P. Disponível em: <HTtP://Uu.divaPORTAL.ORG/SMASH/GET/DIVA2:749857/FULLTEXT01.PDF>. ACESSO EM: 02 NOV. 2015. 
NISHIZEKI, T; CHIBA, N., Planar Graphs: Theory and Algorithms. NovA York: 2008. 232 P.

OliveirA, A. T. C. O. Lições Sobre o Problema das Quatro Cores. 2010. 44 F. Monografia (Curso de ComputaÇão - Licenciatura) - Instituto de Ciências Exatas, Universidade de Brasília, Brasília, 2010.

SAMPAIO, J. C. V. Quatro Cores e Matemática. Minicurso - II Bienal DA SBM, 2004, Ondina: Universidade Federal dA BAhia, 2004. 44 P. Disponível EM: <htTP://Www.Bienasbm.ufba.BR/M35.PdF>. ACesso Em: 02 nov. 2015.

SECCO, G. D. Entre Provas e Experimentos: Uma leitura Wittgensteiniana das controvérsias em torno da prova do Teorema das Quatro Cores. 2013. 191 f. Tese (Doutorado em Filosofia) - Departamento de Filosofia, Pontifícia Universidade Católica do Rio de Janeiro, 2013.

SMITHERS, D. B. Graph Theory for the Secondary School Classroom. 2005. 151 F. Tese (Mestrado em Ciências Matemáticas) - Departamento de Matemática, East Tennessee State University, 2005.

SOUSA, L. O Teorema das Quatro Cores. Viseu: Departamento de Matemática - Escola Superior de Tecnologia de Viseu, 2001. 27 P. Disponível EM: <HTtP://WWW.IPV.Pt/Millenium/Millenium24/12.PDF>. ACESSO EM: 02 NOV. 2015.

Wilson, R. J. Four Colors Suffice: How the Map Problem was Solved. Princeton: Princeton University Press, 2005. 265 P.

WILSON, R. Graphs, Colourings and the Four-colour Theorem. Nova York: Oxford University PRESS, 2004. 143 P.

ZHAng, P.; CHARtRAnd, G., Chromatic Graph Theory. Boca Raton: CRC Press, 2013. 483 P.

ZHANG, P.; CHARTRAnd, G.; BEnJAmin, A. The Fascinating World of Graph Theory. Princeton: Princeton University Press, 2015. 319 P.

ZHANG, P.; CHARTRAND, G.; LESNiAK, L. Graphs \& Digraphs. Fifth Edition. Boca Raton: CRC PREss, 2011. 586 P. 